\title{
Selective Imaging of Late Endosomes with a pH- Sensitive Diazaoxatriangulene Fluorescent Probe
}

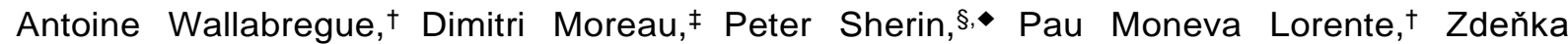
Jarolímová," Eric Bakker," Eric Vauthey, ${ }^{\S}$ Jean Gruenberg, ${ }^{\ddagger}$ and Jérôme Lacour ${ }^{*}, \dagger$

†Department of Organic Chemistry, University of Geneva, Quai Ernest Ansermet 30, 1211 Genève 4 (Switzerland)

$\ddagger$ Department of Biochemistry, University of Geneva, Quai Ernest Ansermet 30, 1211 Genève 4 (Switzerland)

$\S$ Department of Physical Chemistry, University of Geneva, Quai Ernest Ansermet 30, 1211 Genève 4 (Switzerland)

\#Department of Inorganic and Analytical Chemistry, University of Geneva, Quai Ernest Ansermet 30, 1211 Genève 4 (Switzerland)

-International Tomography Center SB RAS, Institutskaya street 3A, 630090, Novosibirsk (Russia)

Jerome.Lacour@unige.ch

Jean.Gruenberg@unige.ch

Eric.Vauthey@unige.ch

Eric.Bakker@unige.ch

\section{Table of Contents}

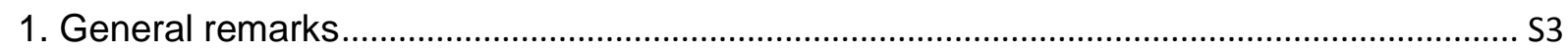

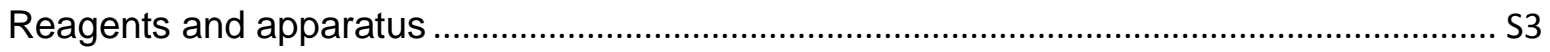

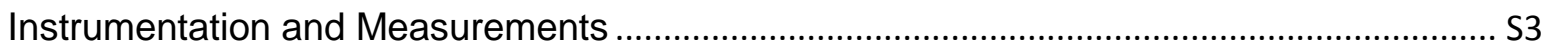

Nanosphere preparation for optical measurements ................................................................ S4

Nanosensor preparation for microscopy experiments ......................................................... S4

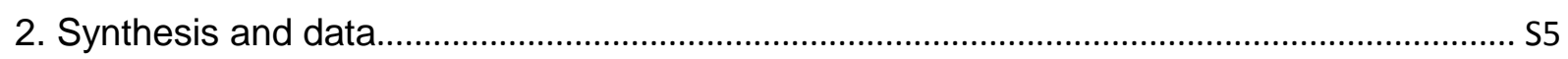

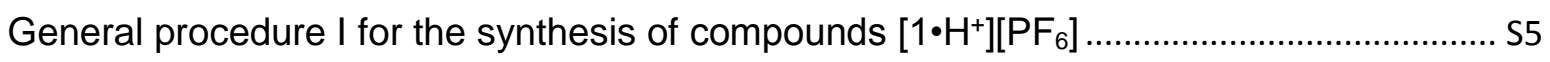

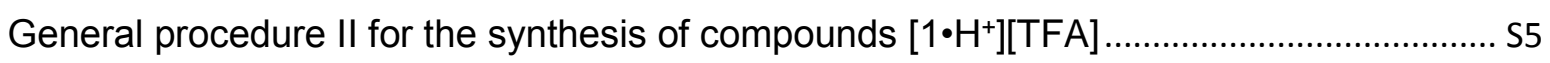

3. ${ }^{1} \mathrm{H}$ NMR, ${ }^{13} \mathrm{C} N M R,{ }^{19} \mathrm{~F}$ NMR, IR and HRMS spectra of compounds .................................. S9

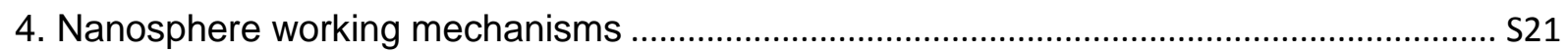

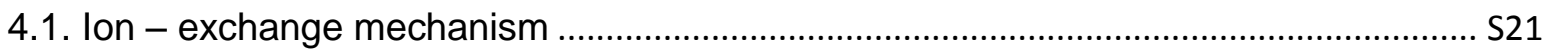

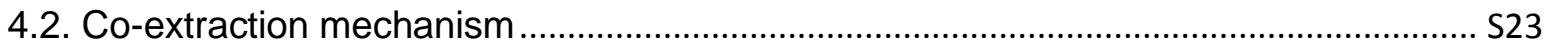

5. Absorption and emission spectra and photostability tests ................................................ S24

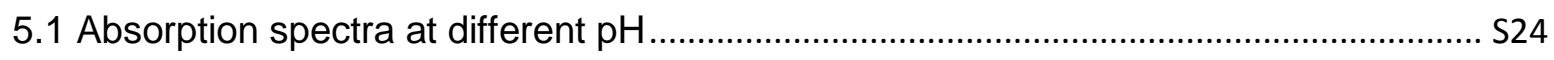


5.2. Spectral properties of triangulenes in nanospheres

5.3. Spectral and photophysical properties of triangulenes in organic solvents

5.4. Tests of photostability....

5.5. Stability of the solutions of $\left[1 \mathrm{a} \cdot \mathrm{H}^{+}\right][$TFA] with respect to aggregation/precipitation .... $\mathrm{S} 43$

5.6. Excitation spectra.. S46

5.7. Effect of paraformaldehyde S47

6. Methods for biological assays S48

References S51 


\section{General remarks}

\section{Reagents and apparatus}

Potassium chloride, sodium chloride, lithium chloride, boric acid, citric acid, sodium dihydrogenphosphate, tetrahydrofuran (THF), methanol (MeOH), bis(2-ethylexyl) sebacate (DOS), sodium tetrakis 3, 5-bis(trifluoromethyl)phenyl borate (NaTFPB), pluronic F-127, sodium dodecyl sulfate (SDS), cetyltrimethylammonium bromide (CTAB), polysorbate20 (Tween20), hydrochloric acid, sodium hydroxide, water for HPLC analysis (CHROMOSOLV Plus) and chloroform $\left(\mathrm{CHCl}_{3}\right)$ were purchased from Sigma Aldrich of analytical or spectroscopic grade and were used without further purification. Aqueous solutions were prepared by dissolving the appropriate salts in Milli-Q-purified water $(18 \mathrm{M} \Omega)$. Acetonitrile $\left(\mathrm{CH}_{3} \mathrm{CN}\right)$ of HPLC-ACS grade from Panreac and dimethylsulfoxide (DMSO) of ACS grade from Amresco were used as received. Ethanol (EtOH) from Reachem was distilled to reach the optical purity. Deuterated water from Armar was used as received.

Primary amines were distilled over Zn powder. DMF (Dimethylformamide) was dried over activated $4 \AA$ molecular sieves. Column chromatographies were performed in air with Alumine oxide, basic, Brockmann I, $60 \mathrm{~A}$ from ACROS.

\section{Instrumentation and Measurements}

NMR spectra were recorded on Brucker AMX-500 or AMX-400 or ARX-300 at room temperature. $1 \mathrm{H}$ NMR: chemical shifts are given in ppm relative to Me4Si with solvent resonances used as internal standards (7.26 ppm for $\mathrm{CDCl} 3,5.32 \mathrm{ppm}$ for $\mathrm{CD} 2 \mathrm{Cl} 2$ and $3.31 \mathrm{ppm}$ for CD3OD). Data were reported as follows: chemical shift $(\delta)$ in ppm on the $\delta$ scale, multiplicity $(s=$ singlet, brs $=$ broad singlet, $d=$ doublet, $\mathrm{t}=$ triplet, $\mathrm{dd}=$ doublet of doublet and $\mathrm{m}=$ multiplet), coupling constant $(\mathrm{Hz})$ and integration. 13C NMR: chemicals shifts were given in ppm relative to Me4Si with solvent resonances used as internal standards (77.1 ppm for $\mathrm{CDCl} 3,53.8 \mathrm{ppm}$ for $\mathrm{CD} 2 \mathrm{Cl} 2$ and $49.0 \mathrm{ppm}$ for $\mathrm{CD} 3 \mathrm{OD}$ ). IR spectra were recorded with a Perkin-Elmer 1650 FT-IR spectrometer using a diamond ATR Golden Gate sampling. Melting points (M.P.) were measured in open capillary tubes with a Buchi B-550 melting points apparatus and are uncorrected. Rf values were measured on TLC Alumina gel 60 F254 plates purchased from Merck. Electrospray mass spectra were obtained on a Finnigan SSQ 7000 spectrometer by the Department of Mass Spectroscopy of the University of Geneva. Absorption spectra were recorded with an UV-VIS spectrometer (Specord 250 plus, Analytic Jena, AG, Germany). The fluorescent spectra were measured with a fluorescence spectrometer (Fluorolog3, Horiba Jobin Yvon) with excitation at $525 \mathrm{~nm}$ and emission spectra were recorded between $550 \mathrm{~nm}$ and $800 \mathrm{~nm}$. By adjusting the slit widths, the signal at all wavelengths was kept under $10^{\wedge} 6 \mathrm{CPS}$ to ensure that it was within the linear range of the detector. The $\mathrm{pH}$ values were determined using a Metrohm $827 \mathrm{pH}$ meter (Metrohm Autolab, Utrecht, The Netherlands). Disposable poly(methyl methacrylate) or quartz cuvettes with path length of $1 \mathrm{~cm}$ were used for UV-VIS and fluorescent interrogation. Steady state 
and time-resolved fluorescence measurements were carried out with a FLSP920 system (Edinburgh Instruments). Time-correlated single photon counting (TCSPC) experiments were performed with the excitation source EPL-375 (375 nm, FWHM = 80 ps) operating at a repetition rate adjustable from 20 to $0.1 \mathrm{MHz}$. The signal was recorded at magic angle relative to the polarization of excitation pulses.

\section{Nanosphere preparation for optical measurements}

The optical properties of triangulene compounds as a function of solution acidity were characterized by absorbance and fluorescence spectroscopy. Their highly conjugated structures and hydrophobicity result in a poor solubility, aggregation and subsequent precipitation of the neutral forms of $\mathbf{1 a}, \mathbf{1 b}$ and 1c in water. A solubility enhancement in aqueous solution may be achieved by a substitution of the counterion of their protonated structures from hydrophobic $\mathrm{PF}_{6}{ }^{-}$to hydrophilic trifluoro acetate $\mathrm{CF}_{3} \mathrm{COO}^{-}$or by their incorporation into the hydrophobic core of polymeric or micellar nanospheres by a precipitation method. ${ }^{1}$ The final composition of cocktails for the nanosphere preparation is shown in Table S1. All components were dissolved in THF/MeOH to form a homogenous solution. A $0.5 \mathrm{~mL}$ aliquot of this cocktail was pipetted and injected into $4.5 \mathrm{~mL}$ of deionized water on a vortex at spinning speed of $1000 \mathrm{rpm}$. The resulting clear mixture was blown with compressed air on the surface for at least 30 minutes to remove $\mathrm{THF} / \mathrm{MeOH}$, giving a clear suspension. Nanospheres were freshly prepared before starting the experiments. No preconditioning of the nanospheres was required. All experiments were performed in $2.5 \mathrm{mM}$ universal buffer solution (UBS) containing citric acid, boric acid and sodium dihydrogenphosphate. All $\mathrm{pH}$ values of the tested solutions were adjusted with $\mathrm{HCl}$ or $2 \mathrm{M}$ $\mathrm{NaOH}$ solution.

Table S1. Cocktail compositions for the preparation of polymeric nanospheres [mg].

\begin{tabular}{ccccccccccccc}
\hline & $\mathrm{NP}_{1}$ & $\mathrm{NP}_{2}$ & $\mathrm{NP}_{3}$ & $\mathrm{NP}_{4}$ & $\mathrm{NP}_{5}$ & $\mathrm{NP}_{6}$ & $\mathrm{NP}_{7}$ & $\mathrm{NP}_{8}$ & $\mathrm{NP}$ & $\mathrm{NP}_{10}$ & $\mathrm{NP}_{11}$ & $\mathrm{NP}_{12}$ \\
\hline $\mathrm{NaTFPB}$ & 1.80 & 1.80 & - & - & 1.80 & 1.80 & - & - & 1.80 & 1.80 & - & - \\
$\mathbf{1 a}$ & 0.92 & 0.92 & 0.92 & 0.92 & - & - & - & - & - & - & - & - \\
$\mathbf{1 b}$ & - & - & - & - & 0.65 & 0.65 & 0.65 & 0.65 & - & - & - & - \\
1c & - & - & - & - & - & - & - & - & 0.59 & 0.59 & 0.59 & 0.59 \\
DOS & 5 & 5 & 5 & 5 & 5 & 5 & 5 & 5 & 5 & 5 & 5 & 5 \\
$\mathrm{~F}-127$ & 8 & - & 8 & - & 8 & - & 8 & - & 8 & - & 8 & - \\
CTAB & - & 131 & - & 131 & - & 131 & - & 131 & - & 131 & - & 131 \\
THF & 3 & 2.4 & 3 & 2.4 & 3 & 2.4 & 3 & 2.4 & 3 & 2.4 & 3 & 2.4 \\
$\mathrm{MeOH}$ & - & 0.6 & - & 0.6 & - & 0.6 & - & 0.6 & - & 0.6 & - & 0.6 \\
\hline
\end{tabular}

\section{Nanosensor preparation for microscopy experiments}

The aqueous solutions of triangulenes for microscopy experiments were prepared by addition of 13.3 $\mu \mathrm{l}$ of 1a (neutral form) in DMSO in $1.9867 \mathrm{ml}$ of Phosphate buffer saline (PBS) solution or PBS solution containing $4 \%$ paraformaldehyde (PFA) at $25^{\circ} \mathrm{C}$, affording a final concentration of $10^{-5} \mathrm{M}$. Then the solutions were agitated for 5-10 min before recording the UV spectra. 


\section{Synthesis and data}

\section{General procedure I for the synthesis of compounds $\left[1 \cdot \mathrm{H}^{+}\right]\left[\mathrm{PF}_{6}\right]$}

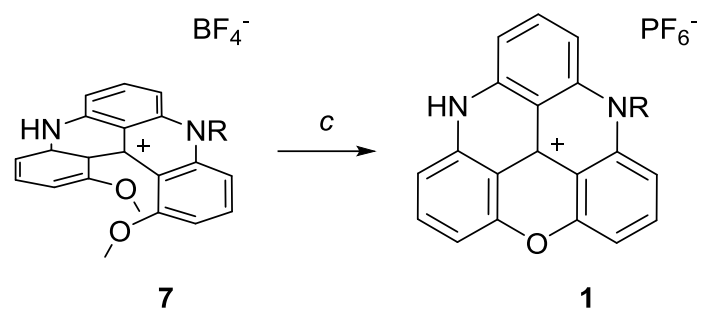

Quinacridinium salts $7 \mathrm{a}$ to $7 \mathrm{c}(5.2 \mathrm{mmol})$ were added to molten pyridinium chloride $(15 \mathrm{~g}, 130 \mathrm{mmol})$ in a sealed tube. The reaction mixture was heated at $150{ }^{\circ} \mathrm{C}$ for 4 hours. After complete consumption of the quinacridinium 7 (monitored by ESI-MS analysis), the reaction mixture was allowed to cool to 20 ${ }^{\circ} \mathrm{C}$. Then the crude solid was dissolved in $2 \mathrm{M}$ aqueous solution of $\mathrm{KPF}_{6}(\sim 20 \mathrm{ml})$ and the aqueous phase extracted three times with $\mathrm{CH}_{2} \mathrm{Cl}_{2}(500 \mathrm{~mL})$. The organic phases were combined dried over $\mathrm{Na}_{2} \mathrm{SO}_{4}$ and concentrated under reduced pressure. The compound was purified by column chromatography with silica gel and $\mathrm{CH}_{2} \mathrm{Cl}_{2} / \mathrm{MeOH}$ (98/2) as eluent affording the title dark purple compound.

\section{General procedure II for the synthesis of compounds $\left[1 \cdot \mathrm{H}^{+}\right][\mathrm{TFA}]$}

Salts $\left[1 \cdot \mathrm{H}^{+}\right]\left[\mathrm{PF}_{6}\right]$ were dissolved in $20 \mathrm{ml}$ of $\mathrm{CH}_{2} \mathrm{Cl}_{2}$ and basified with $1 \mathrm{M}$ aqueous solutions of $\mathrm{NaHCO}_{3}(\sim 20 \mathrm{ml})$. The organic phase was subsequently acidified with $1 \mathrm{M}$ aqueous solution of $\mathrm{CF}_{3} \mathrm{CO}_{2} \mathrm{H}(\sim 20 \mathrm{ml})$ and, after separation, dried over $\mathrm{Na}_{2} \mathrm{SO}_{4}$. The solvent was removed under reduced pressure affording compound $\left[\mathbf{1} \cdot \mathbf{H}^{+}\right][$TFA] as red salt.

\section{8-hexadecyl-8,12-dihydro-3a ${ }^{2} H$-benzo[ij]xantheno[1,9,8-cdef $][2,7]$ naphthyridin-3a ${ }^{2}$-ylium hexafluorophosphate $\left[1 \mathrm{a} \cdot \mathrm{H}^{+}\right]\left[\mathrm{PF}_{6}\right]$}<smiles>COCN1c2cccc3c2C2c4cccc(c4-3)Oc3cccc(c32)NC1C(F)(F)F</smiles>

Prepared following general procedure I using quinacridinium $7 \mathrm{a}(2.3 \mathrm{~g}, 5.2 \mathrm{mmol})$ and molten pyridinium chloride $(15 \mathrm{~g}, 130 \mathrm{mmol})$. The desired product was obtained as an amorphous dark orange-red solid ( $854.25 \mathrm{mg}, 1.87 \mathrm{mmol}, 36 \%$ yield).

$\mathbf{R f}=0.25$ (Basic alumina, $\left.\mathrm{CH}_{2} \mathrm{Cl}_{2} / \mathrm{MeOH}, 98: 2\right) .{ }^{1} \mathbf{H} \mathbf{~ N M R}\left(400 \mathbf{~ M H z}, \mathbf{C D}_{2} \mathrm{Cl}_{2}\right) \delta 10.38(\mathrm{~s}, 1 \mathrm{H}, \mathrm{NH}), 8.31$ (t, $J=8.6 \mathrm{~Hz}, 1 \mathrm{H}, \mathrm{CH}$ ), 8.13 (t, $J=8.5 \mathrm{~Hz}, 2 \mathrm{H}, 2 \times \mathrm{CH}$ ), 7.49 (d, $J=8.8 \mathrm{~Hz}, 2 \mathrm{H}, 2 \times \mathrm{CH}), 7.41$ (d, $J=8.7$ $\mathrm{Hz}, 2 \mathrm{H}, 2 \times \mathrm{CH}$ ), $7.38(\mathrm{~d}, J=8.2 \mathrm{~Hz}, 2 \mathrm{H}, 2 \times \mathrm{CH}), 4.52\left(\mathrm{dd}, J=9.5,7.1 \mathrm{~Hz}, 2 \mathrm{H}, \mathrm{CH}_{2}\right), 2.01(\mathrm{p}, J=8.0$ 
$\mathrm{Hz}, 2 \mathrm{H}, \mathrm{CH}_{2}$ ), 1.66 (p, J=7.4 Hz, 2H), 1.51 (t, $\left.J=7.7 \mathrm{~Hz}, 2 \mathrm{H}, \mathrm{CH}_{2}\right), 1.31$ (s, 22H), 0.92 (t, $J=6.7 \mathrm{~Hz}$, 3H, CH 3$).{ }^{13} \mathrm{C}$ NMR (101 MHz, $\mathrm{CD}_{2} \mathrm{Cl}_{2}$ ) $\delta 152.8(\mathrm{C}), 141$ (C), 139.9 (C), 139.8 (C), 139.7 (C), $139.6(\mathrm{C})$, $138.7(\mathrm{CH}), 111.6(\mathrm{CH}), 108.9(\mathrm{CH}), 108.8(\mathrm{CH}), 107.7(\mathrm{CH}), 105.7(\mathrm{CH}), 48.4\left(\mathrm{CH}_{2}\right), 31.9\left(\mathrm{CH}_{2}\right), 29.7$ $\left(\mathrm{CH}_{2}\right), 29.6\left(\mathrm{CH}_{2}\right), 29.6\left(\mathrm{CH}_{2}\right), 29.6\left(\mathrm{CH}_{2}\right), 29.5\left(\mathrm{CH}_{2}\right), 29.5\left(\mathrm{CH}_{2}\right), 29.35\left(\mathrm{CH}_{2}\right), 29.3\left(\mathrm{CH}_{2}\right), 29.3\left(\mathrm{CH}_{2}\right)$, $29.1\left(\mathrm{CH}_{2}\right), 26.7\left(\mathrm{CH}_{2}\right), 25.6\left(\mathrm{CH}_{2}\right), 22.7\left(\mathrm{CH}_{2}\right), 13.9\left(\mathrm{CH}_{3}\right) .{ }^{19} \mathbf{F} \mathbf{~ N M R}\left(282 \mathbf{~ M H z}, \mathbf{C D}_{2} \mathbf{C l}_{2}\right) \delta-69.89$ (50\%), -72.41 (50\%). IR (in $\mathrm{CH}_{2} \mathrm{Cl}_{2}, \mathrm{~cm}^{-1}$ ) v 3236, 3121, 2921, 2851, 1649, 1617, 1523, 1456, 1339, 1256, 1156, 1046, 819, 772, 629. HRMS (ESI) calculated for $\left[\mathrm{C}_{35}, \mathrm{H}_{43}, \mathrm{~N}_{2}, \mathrm{O}(\mathrm{M}+\mathrm{H})^{+}\right]$: 507.3370 Found: 507.3364

8-hexadecyl-8,12-dihydro-3a ${ }^{2} H$-benzo[ij]xantheno[1,9,8-cdef $][2,7]$ naphthyridin-3a ${ }^{2}$-ylium $\quad 2,2,2-$ trifluoroacetate $\left[1 \mathrm{a} \cdot \mathrm{H}^{+}\right][\mathrm{TFA}]$

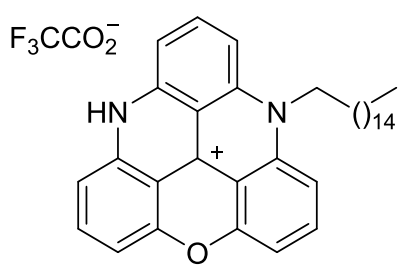

Prepared following the general procedure II using $200.8 \mathrm{mg}(0.44 \mathrm{mmol})$ of triangulene $\left[1 \mathrm{a} \cdot \mathrm{H}^{+}\right]\left[\mathrm{PF}_{6}\right]$. The product was obtained as orange-red solid (182.48 $\mathrm{mg}, 0.43 \mathrm{mmol}, 98 \%$ ).

${ }^{19} \mathrm{~F}$ NMR $\left(282 \mathrm{MHz}, \mathrm{CD}_{2} \mathrm{Cl}_{2}\right) \delta-75.79$

\section{8-phenyl-8,12-dihydro-3a ${ }^{2} H$-benzo[ij]xantheno[1,9,8-cdef][2,7]naphthyridin-3a ${ }^{2}$-ylium} hexafluorophosphate $\left[1 \mathrm{~b} \cdot \mathrm{H}^{+}\right]\left[\mathrm{PF}_{6}\right]$<smiles>FC(F)(F)Nc1cccc2oc3cccc4c3c3c(ccc(C(F)(F)F)c3n4-c3ccccc3)c12</smiles>

Prepared following general procedure I using quinacridinium $7 \mathrm{~b}(152.60 \mathrm{mg}, 0.31 \mathrm{mmol})$ and 895.58 $\mathrm{mg}(7.75 \mathrm{mmol})$ molten pyridinium chloride. The desired product was obtained as an amorphous dark orange-red solid (146.97 mg, $0.29 \mathrm{mmol}, 94 \%$ yield).

$\mathbf{R f}=0.32$ (Basic alumina, $\left.\mathrm{CH}_{2} \mathrm{Cl}_{2} / \mathrm{MeOH}, 98: 2\right) .{ }^{1} \mathbf{H}$ NMR (500 MHz, DMSO-d6) $\delta 13.53(\mathrm{~s}, 1 \mathrm{H}, \mathrm{NH})$, 8.06-7.76 (m, 6H, 6×CH), $7.60(\mathrm{~d}, J=7.2 \mathrm{~Hz}, 2 \mathrm{H}, 2 \times \mathrm{CH}), 7.36(\mathrm{~d}, J=8.4 \mathrm{~Hz}, 1 \mathrm{H}, \mathrm{CH}), 7.31$ (d, $J=$ $8.2 \mathrm{~Hz}, 1 \mathrm{H}, \mathrm{CH}$ ), 7.27 (dd, $J=8.2,5.3 \mathrm{~Hz}, 2 \mathrm{H}, 2 \times \mathrm{CH}), 6.47(\mathrm{~d}, J=8.7 \mathrm{~Hz}, 1 \mathrm{H}, \mathrm{CH}), 6.30(\mathrm{~d}, J=8.3$ $\mathrm{Hz}, 1 \mathrm{H}, \mathrm{CH}) .{ }^{13} \mathrm{C}$ NMR (126 MHz, DMSO-d6) $\delta 152.1$ (C), 151.5 (C), 141.4 (C), 141.1 (C), 140.3 (C), $140.2(\mathrm{C}), 139.4(\mathrm{C}), 138.8(\mathrm{CH}), 138.2(\mathrm{CH}), 138.2(\mathrm{CH}), 137.0(\mathrm{C}), 132.1(\mathrm{CH}), 130.7(\mathrm{CH}), 128.4$ $(\mathrm{CH}), 110.8(\mathrm{CH}), 110.3(\mathrm{CH}), 110.1(\mathrm{CH}), 108.5(\mathrm{CH}), 107.4(\mathrm{CH}), 107.3(\mathrm{CH}), 106.9(\mathrm{CH}), 106.7$ (CH), $105.4(\mathrm{CH}) .{ }^{19} \mathrm{~F}$ NMR (282 MHz, DMSO-d6) $\delta-68.19$ (50\%), -70.71(50\%). IR (in $\left.\mathrm{CH}_{2} \mathrm{Cl}_{2}, \mathrm{~cm}^{-1}\right)$ v $3327,1652,1620,1452,1341,1302,1264,1175,1106,839,770,738,694,627,555$. HRMS (ESI) calculated for $\left[\mathrm{C}_{25}, \mathrm{H}_{15}, \mathrm{~N}_{2}, \mathrm{O}(\mathrm{M}+\mathrm{H})^{+}\right]$: 359.1179 Found: 359.1176 
<smiles></smiles>

Prepared following the general procedure II using $100.5 \mathrm{mg}(0.2 \mathrm{mmol})$ of triangulene $\left[\mathbf{1} \mathbf{b} \cdot \mathbf{H}^{+}\right]\left[\mathbf{P F}_{6}\right]$. The product was obtained as orange-red solid (91.65 mg, $0.19 \mathrm{mmol}, 97 \%$ yield).

${ }^{19}$ F NMR (282 MHz, DMSO-d6) $\delta-74.50$

\section{8-propyl-8,12-dihydro-3a ${ }^{2} H$-benzo[ij]xantheno[1,9,8-cdef][2,7]naphthyridin-3a ${ }^{2}$-ylium} hexafluorophosphate $\left[1 \mathrm{c}^{\circ} \cdot \mathrm{H}^{+}\right]\left[\mathrm{PF}_{6}\right]$<smiles></smiles>

Prepared following general procedure using I quinacridinium 7c $(500.60 \mathrm{mg}, 1.09 \mathrm{mmol})$ and $3.20 \mathrm{~g}$ (27.30 mmol) pyridinium chloride. The desired product was obtained as an amorphous dark orangered solid $(410.15 \mathrm{mg}, 0.87 \mathrm{mmol}, 80 \%$ yield).

$\mathbf{R f}=0.18$ (Basic alumina, $\left.\mathrm{CH}_{2} \mathrm{Cl}_{2} / \mathrm{MeOH}, 98: 2\right) .{ }^{1} \mathbf{H} \mathbf{N M R}\left(500 \mathbf{M H z}, \mathbf{C D}_{2} \mathrm{Cl}_{2}\right) \delta 7.53(\mathrm{q}, J=8.1 \mathrm{~Hz}, 2 \mathrm{H}$, $2 \mathrm{CH}$ ), 7.38-7.30 (m, 2H, $2 \mathrm{CH}), 7.20(\mathrm{~d}, J=8.5 \mathrm{~Hz}, 1 \mathrm{H}, \mathrm{CH}), 6.68(\mathrm{dd}, J=8.0,5.3 \mathrm{~Hz}, 2 \mathrm{H}, 2 \mathrm{CH})$, $6.63(\mathrm{~d}, J=8.2 \mathrm{~Hz}, 1 \mathrm{H}, \mathrm{CH}), 6.38(\mathrm{~d}, J=7.8 \mathrm{~Hz}, 1 \mathrm{H}, \mathrm{CH}), 3.88-3.59\left(\mathrm{~m}, 2 \mathrm{H}, \mathrm{CH}_{2}\right), 2.94(\mathrm{~s}, 1 \mathrm{H}, \mathrm{NH})$, $1.78\left(\mathrm{~h}, J=7.5 \mathrm{~Hz}, 2 \mathrm{H}, \mathrm{CH}_{2}\right), 1.09$ (t, $\left.J=7.4 \mathrm{~Hz}, 3 \mathrm{H}, \mathrm{CH}_{3}\right) .{ }^{13} \mathbf{C} \mathbf{N M R}\left(126 \mathbf{~ M H z}, \mathrm{CD}_{2} \mathrm{Cl}_{2}\right) \delta 153.2(\mathrm{C})$, $151.8(\mathrm{C}), 150.5(\mathrm{C}), 148.9(\mathrm{C}), 140.4(\mathrm{C}), 140.2(\mathrm{C}), 134.2(\mathrm{CH}), 133.9(\mathrm{CH}), 132.7(\mathrm{C}), 132.7(\mathrm{CH})$, $119.3(\mathrm{CH}), 116.2(\mathrm{CH}), 112.7(\mathrm{C}), 109.1(\mathrm{C}), 107.4(\mathrm{C}), 107.3(\mathrm{CH}), 107.1(\mathrm{CH}), 103.8(\mathrm{CH}), 99.7$ $(\mathrm{CH}), 48.0\left(\mathrm{CH}_{2}\right), 18.6\left(\mathrm{CH}_{2}\right), 11.2\left(\mathrm{CH}_{3}\right) .{ }^{19} \mathrm{~F}$ NMR (282 MHz, $\left.\mathbf{C D}_{2} \mathrm{Cl}_{2}\right) \delta-70.23(50 \%),-72.75(50 \%)$. IR (in $\left.\mathrm{CH}_{2} \mathrm{Cl}_{2}, \mathrm{~cm}^{-1}\right)$ v 2925, 1610, 1525, 1457, 1384, 1351, 1250, 1154, 1042, 852, 755, 611. HRMS (ESI) calculated for $\left[\mathrm{C}_{22}, \mathrm{H}_{17}, \mathrm{~N}_{2}, \mathrm{O}(\mathrm{M}+\mathrm{H})^{+}\right]$: 325.1335 Found: 325.1336 

trifluoroacetate $\left[1 \mathrm{c} \cdot \mathrm{H}^{+}\right][T F A]$<smiles></smiles>

Prepared following the general procedure II using $150.50 \mathrm{mg}(0.32 \mathrm{mmol})$ of triangulene $\left[1 \mathrm{c}^{\circ} \mathrm{H}^{+}\right]\left[\mathrm{PF}_{6}\right]$. The product was obtained as orange-red solid (127.14 mg, $0.29 \mathrm{mmol}, 90 \%)$.

${ }^{19} \mathrm{~F}$ NMR $\left(282 \mathrm{MHz}, \mathrm{CD}_{2} \mathrm{Cl}_{2}\right) \delta-75.55$. 
3. ${ }^{1} \mathrm{H}$ NMR, ${ }^{13} \mathrm{C}$ NMR, ${ }^{19} \mathrm{~F}$ NMR, IR and HRMS spectra of compounds ${ }^{1} \mathbf{H}$ NMR $\left(500 \mathrm{MHz}, \mathrm{CD}_{2} \mathrm{Cl}_{2}\right)\left[1 \mathbf{a} \cdot \mathbf{H}^{+}\right]\left[\mathrm{PF}_{6}\right]$<smiles>CCCN1c2ccccc2C23Oc4cccc(c42)Nc2ccccc2-c2cccc1c23</smiles>

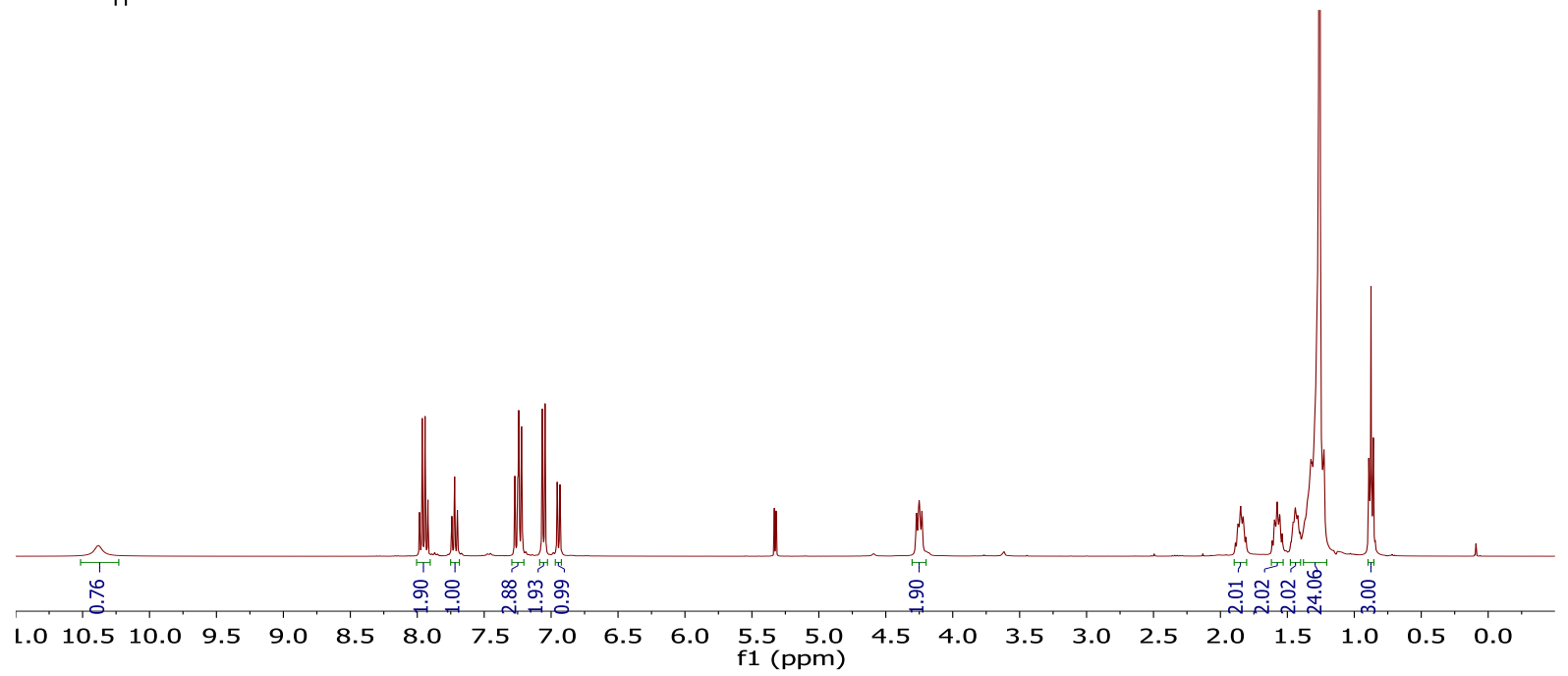

${ }^{13} \mathrm{C} \mathrm{NMR}\left(126 \mathrm{MHz}, \mathrm{CD}_{2} \mathrm{Cl}_{2}\right)\left[1 \mathrm{a} \cdot \mathrm{H}^{+}\right]\left[\mathrm{PF}_{6}\right]$

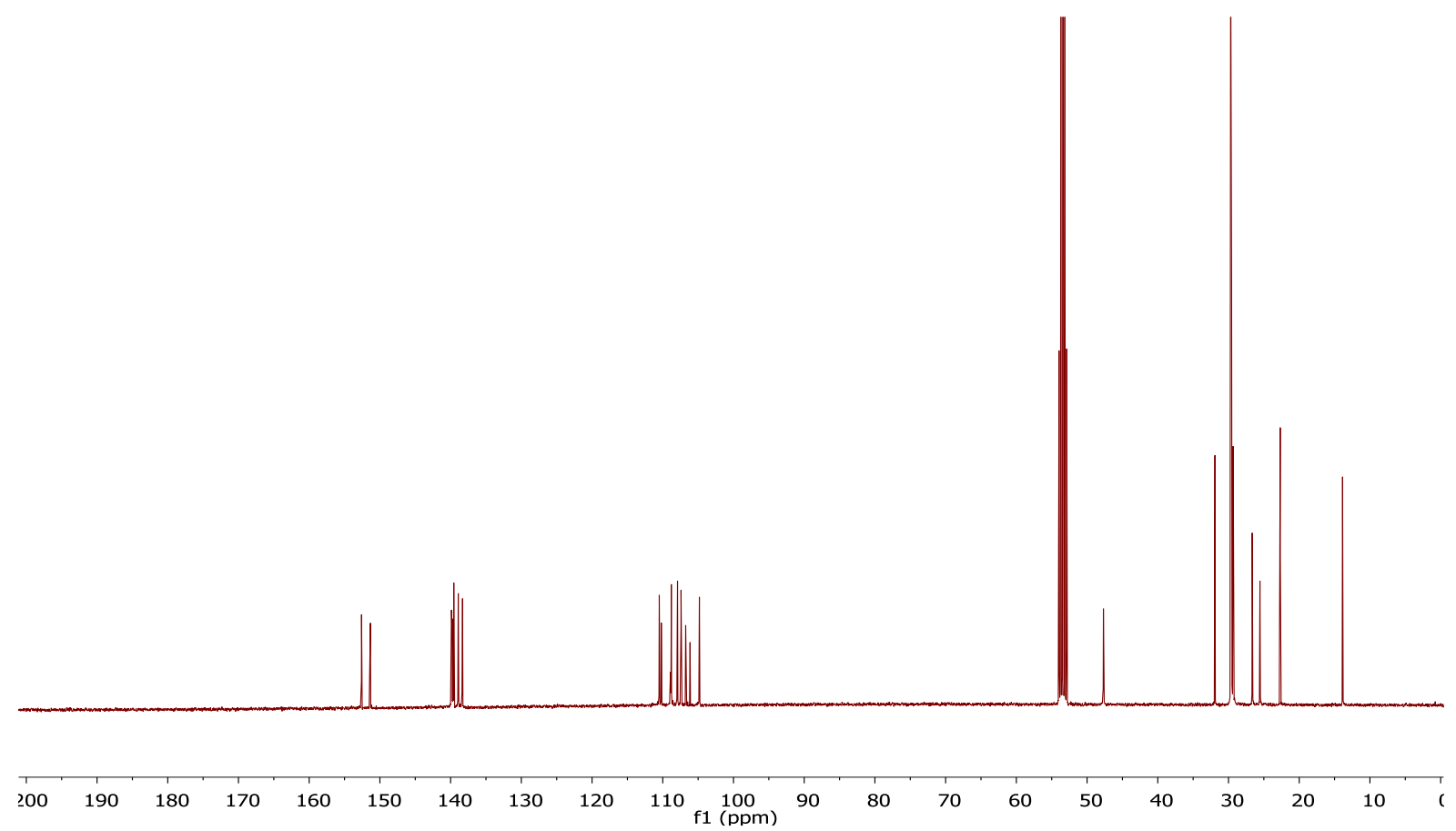


${ }^{19}$ F NMR $\left(282 \mathrm{MHz}, \mathrm{CH}_{2} \mathrm{Cl}_{2}\right)\left[1 \mathbf{a} \cdot \mathrm{H}^{+}\right]\left[\mathrm{PF}_{6}\right]$

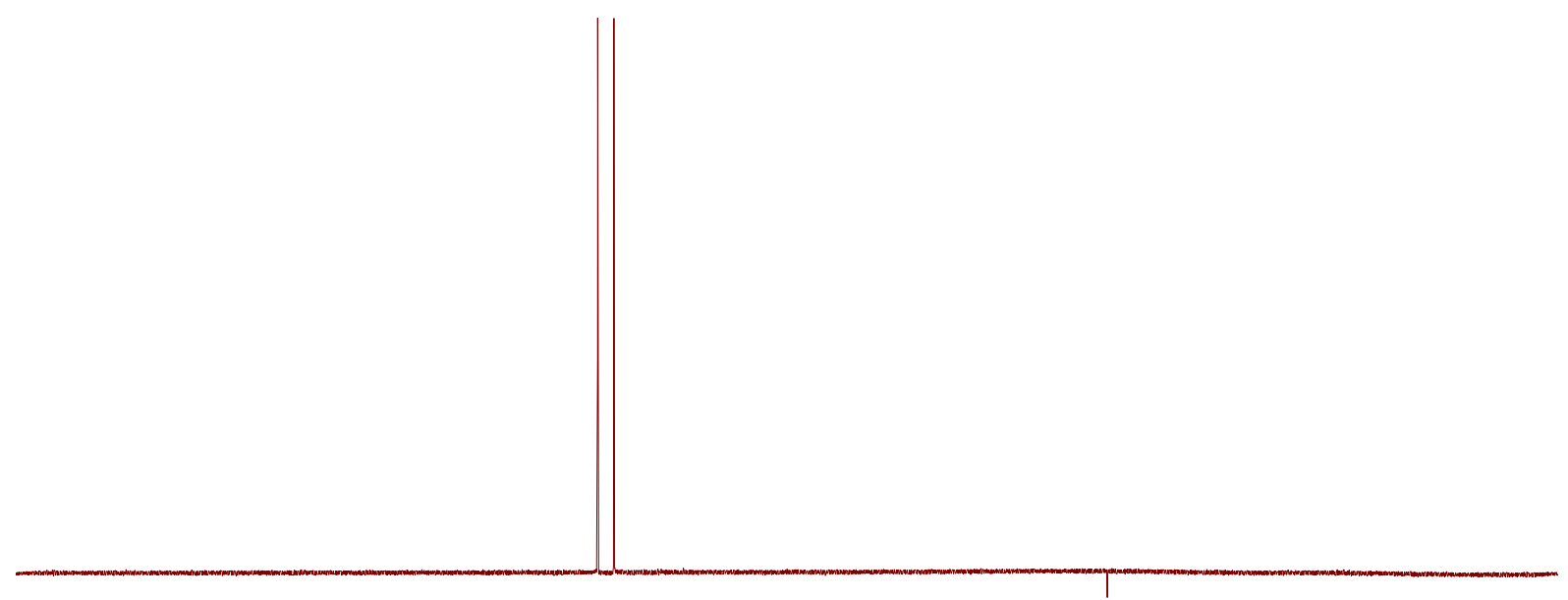

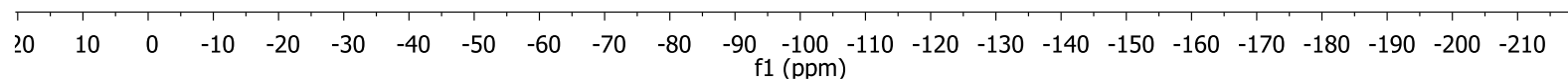

${ }^{19}$ F NMR $\left(282 \mathrm{MHz}, \mathrm{CH}_{2} \mathrm{Cl}_{2}\right)\left[1 \mathrm{a} \cdot \mathrm{H}^{+}\right][\mathrm{TFA}]$

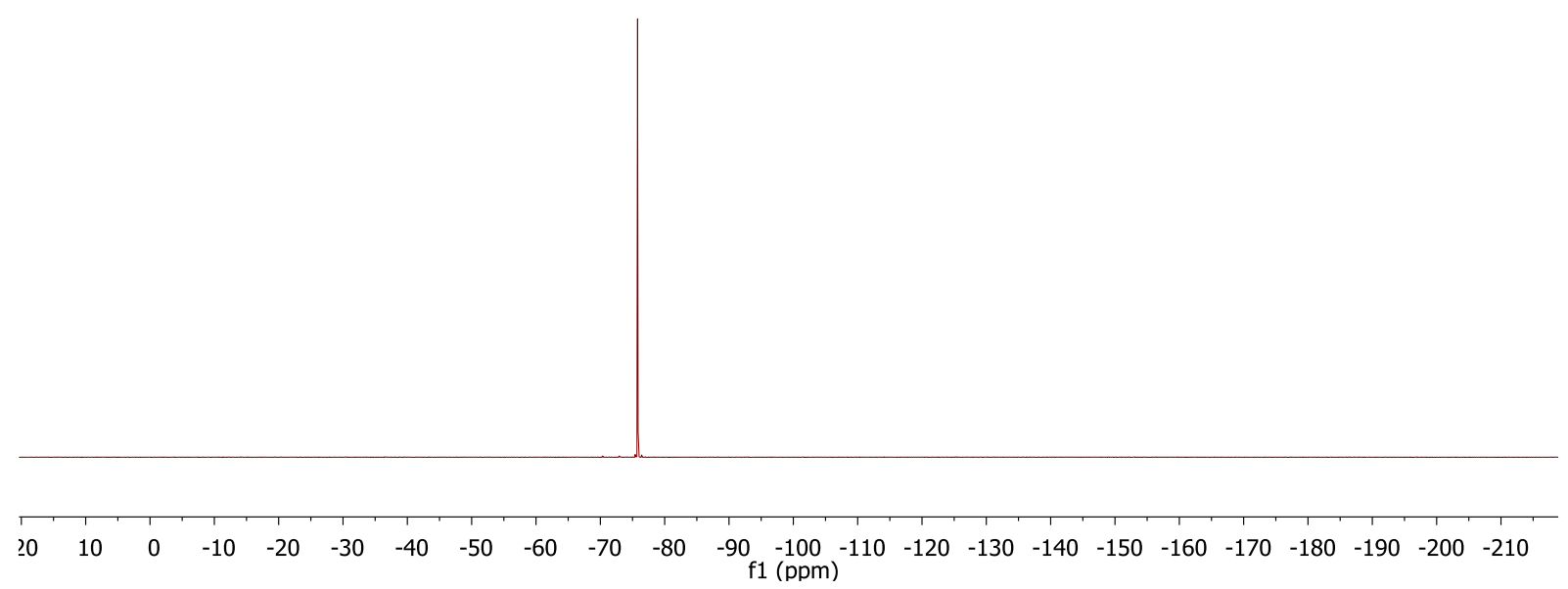




\section{$\operatorname{IR}\left[\mathbf{1} \mathrm{a} \cdot \mathrm{H}^{+}\right]\left[\mathrm{PF}_{6}\right]$}

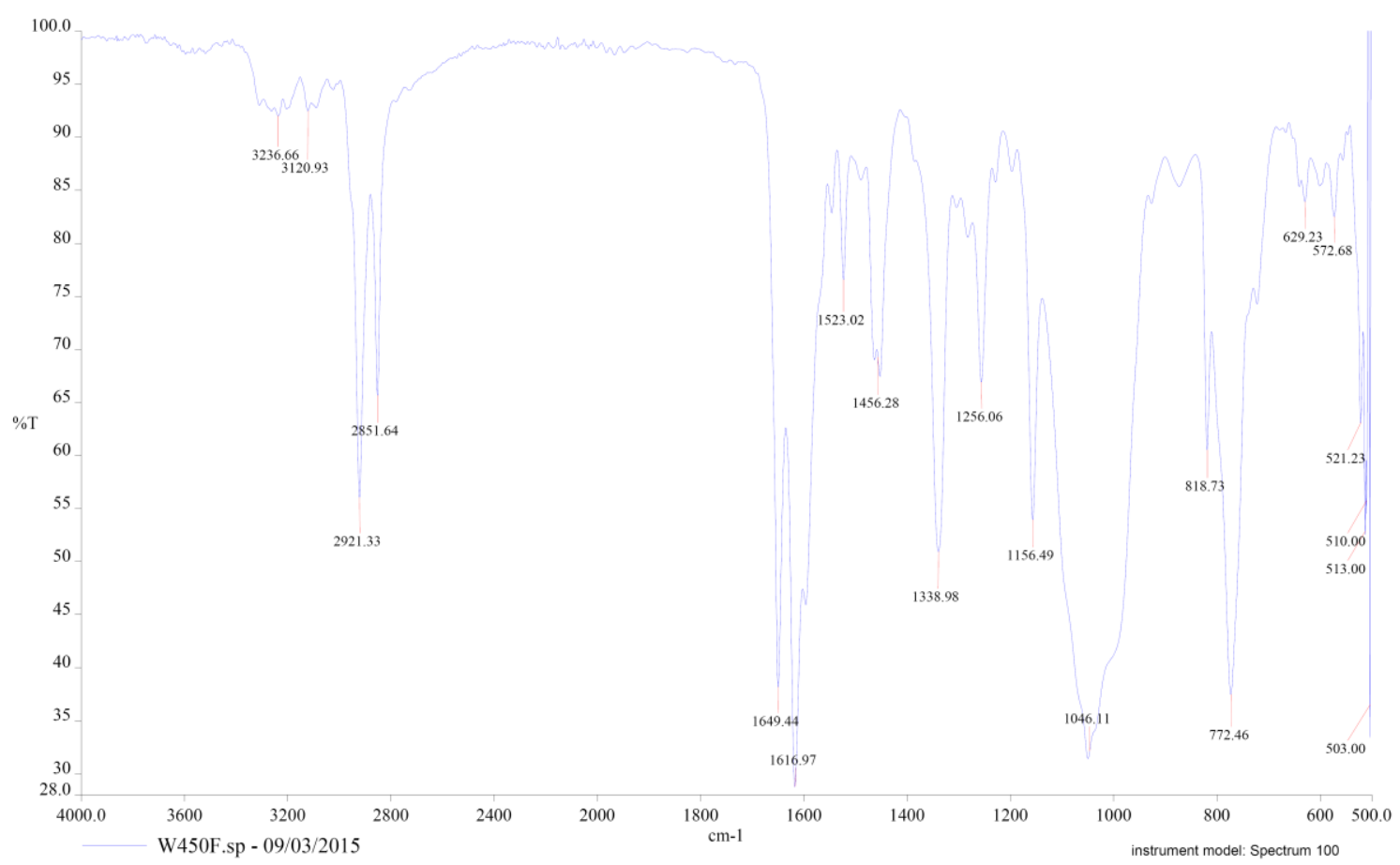




\section{UNIVERSITY OF GENEVA}

Faculty of Sciences

Sciences Mass Spectrometry

Submitter: WALLABREGUE

Date of reception: $\quad 22 / 04 / 14$

Sample name: WA450f

Date of certificate: $\quad$ 05/05/14

Sample number: $\quad 7065$

Data filename: SMS10GE-140505-ES-A001

Operator:

Eliane Sandmeier

Instrument:

QSTAR Pulsar (AB/MDS Sciex

Principal investigator: Dr. Sophie Michalet

lonisation mode: $\quad \mathrm{ESI}$ (positive mode)

\begin{tabular}{|c|c|c|c|}
\hline Expected Formula & Observed $m / z[\mathrm{M}]^{+}$ & Expected $\mathrm{m} / \mathrm{z}$ (amu) & Accuracy (ppm) \\
\hline $\mathrm{C}_{35} \mathrm{H}_{43} \mathrm{~N}_{2} \mathrm{O}$ & 507.3364 & 507.3370 & -1.2 \\
\hline
\end{tabular}

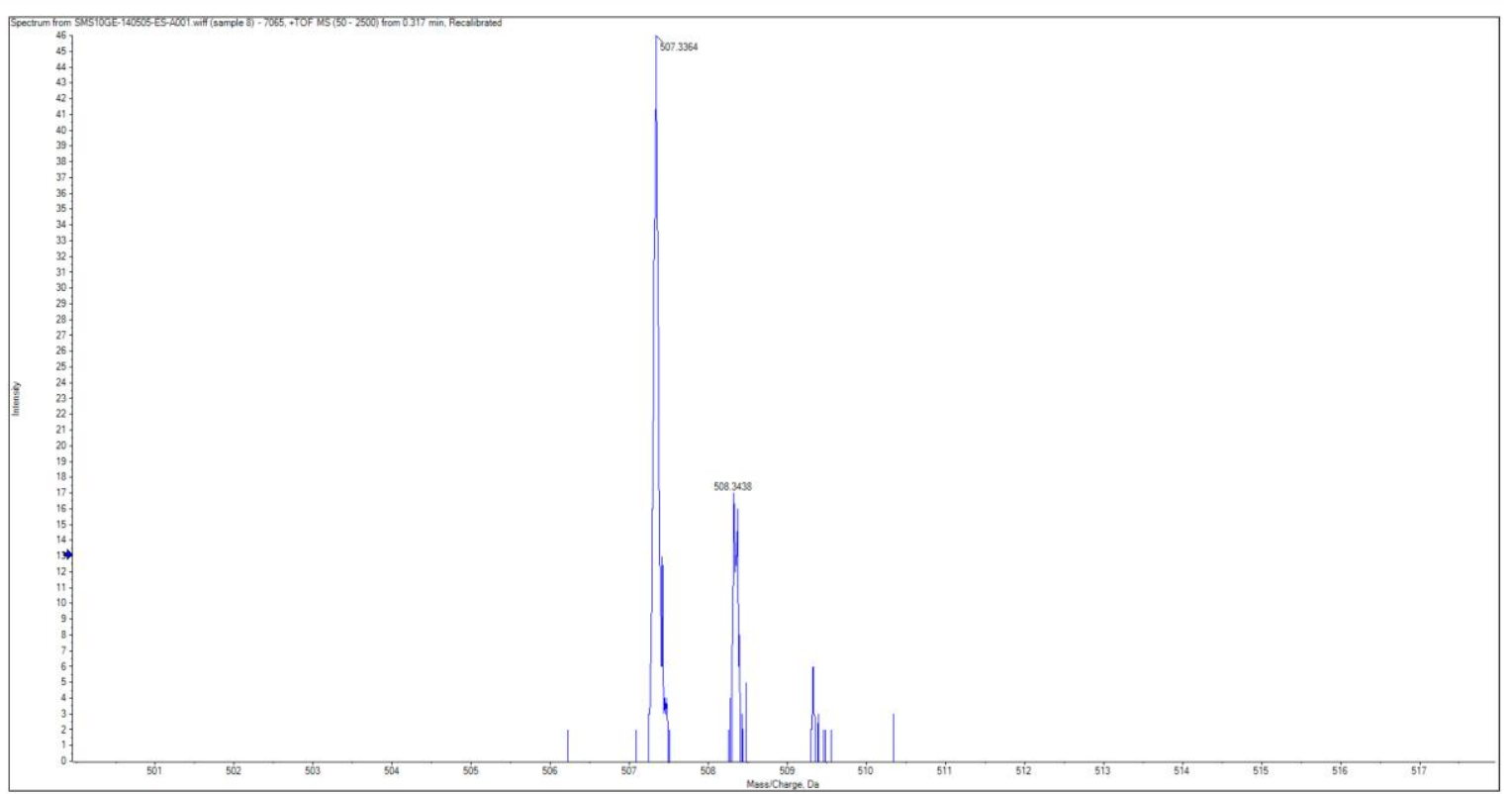


${ }^{1} \mathbf{H} \mathbf{N M R}(500 \mathrm{MHz}$, DMSO-d 6$)\left[\mathbf{1} \mathbf{b} \cdot \mathbf{H}^{+}\right]\left[\mathbf{P F}_{6}\right]$<smiles>CC(C)[In]c1cccc2c1C13Oc4cccc1c4Nc1cccc(c13)N2c1ccccc1</smiles>

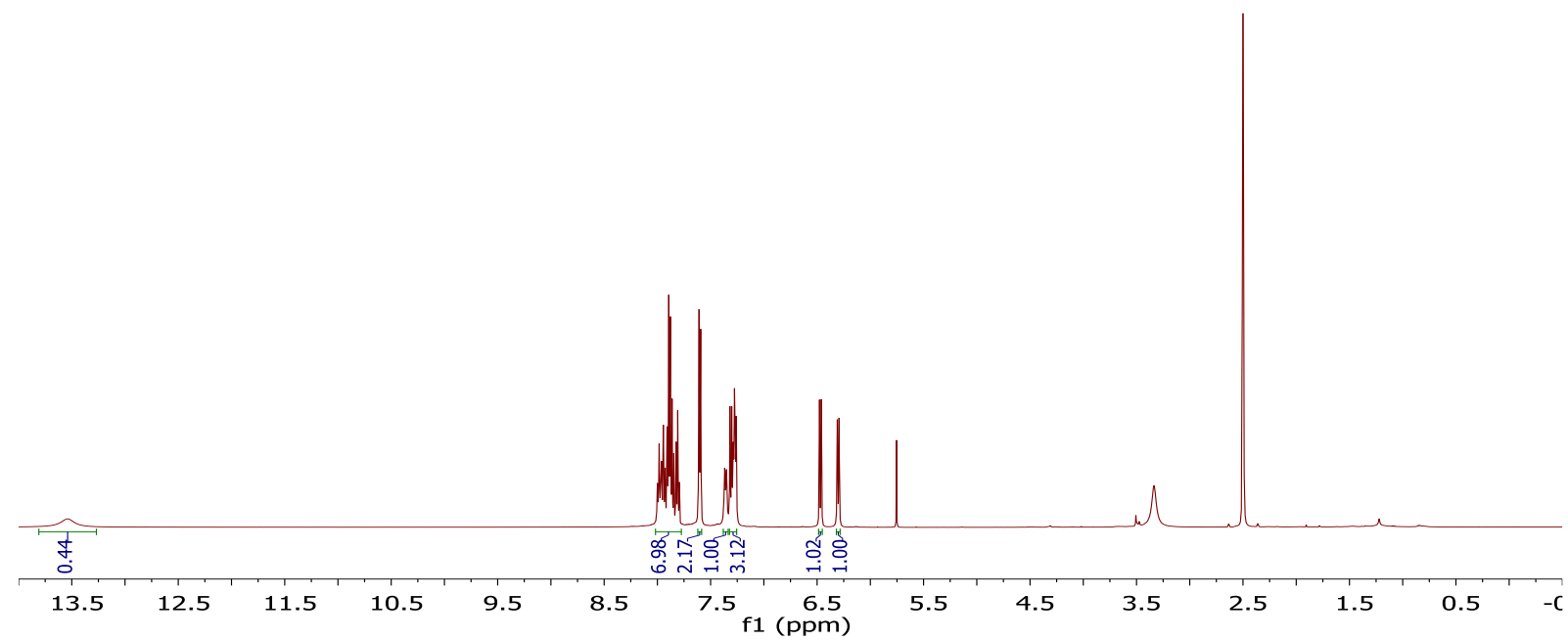

${ }^{13} \mathrm{C} \mathrm{NMR}\left(126 \mathrm{MHz}, \mathrm{DMSO}-\mathrm{d}_{6}\right)\left[\mathbf{1} \mathbf{b} \cdot \mathrm{H}^{+}\right]\left[\mathrm{PF}_{6}\right]$

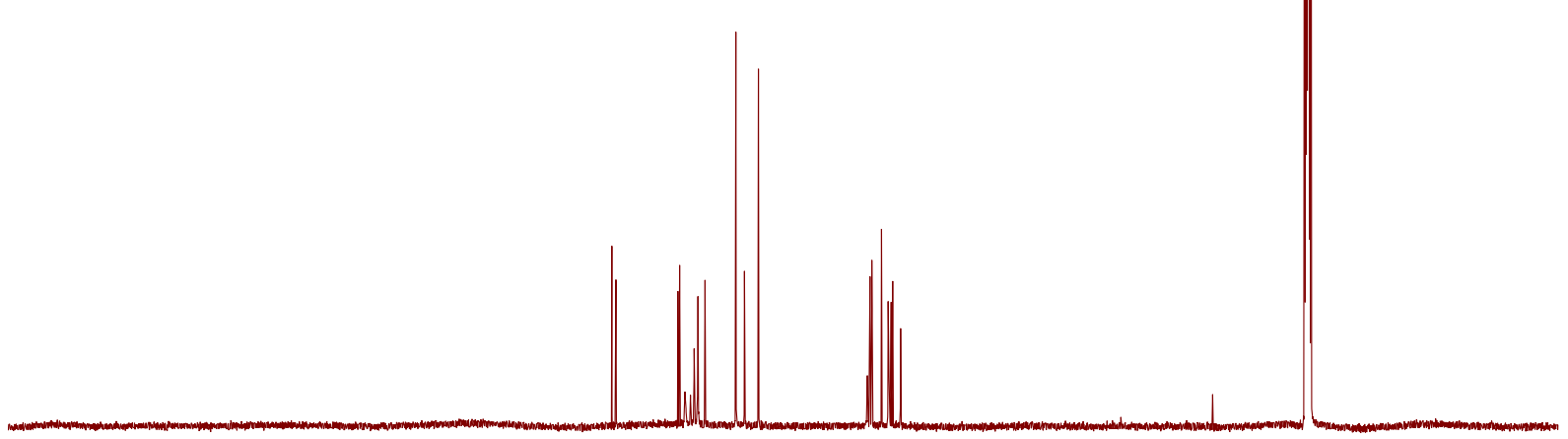

$\begin{array}{llllllllllllllllllllllllllll}240 & 230 & 220 & 210 & 200 & 190 & 180 & 170 & 160 & 150 & 140 & \begin{array}{c}130 \\ \mathrm{f} 1(\mathrm{ppm})\end{array} & 110 & 100 & 90 & 80 & 70 & 60 & 50 & 40 & 30 & 20 & 10 & \mathrm{C}\end{array}$ 
${ }^{19} \mathrm{~F}$ NMR $(282 \mathrm{MHz}, \mathrm{DMSO}-\mathrm{d} 6)\left[\mathbf{1} \mathbf{b} \cdot \mathrm{H}^{+}\right]\left[\mathrm{PF}_{6}\right]$

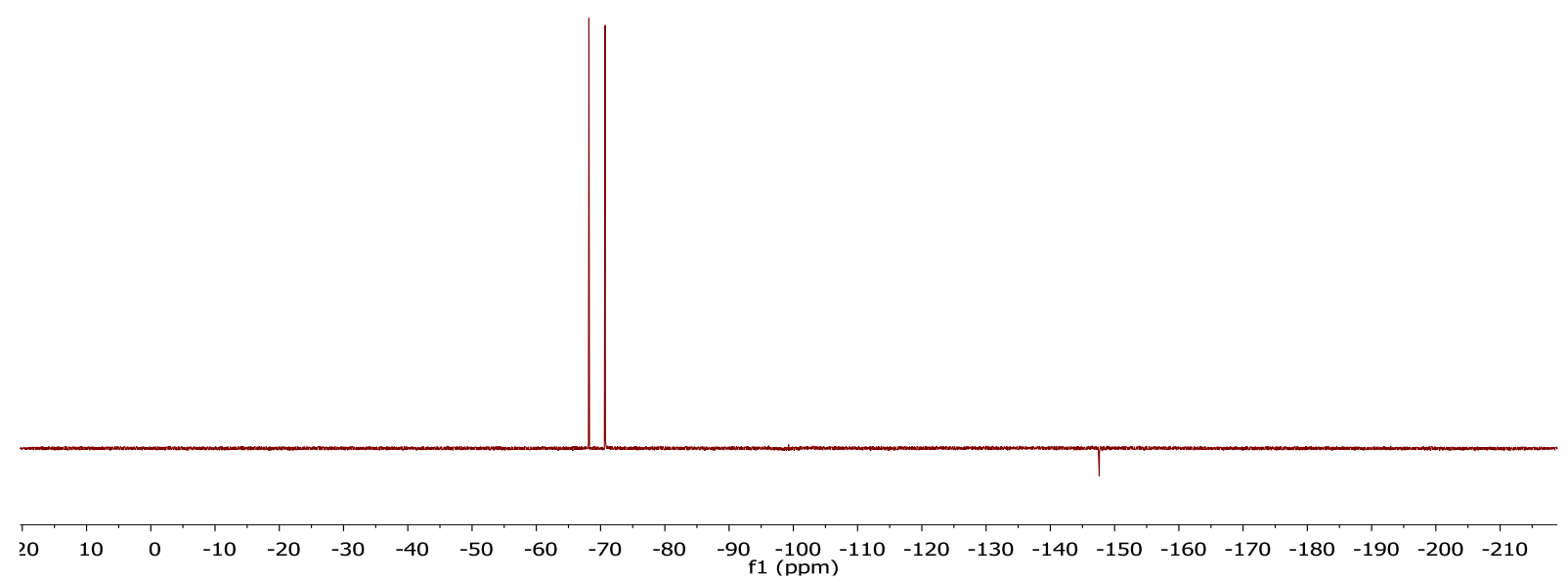

${ }^{19}$ F NMR $\left(282 \mathrm{MHz}\right.$, DMSO-d6) [1 $\left.\mathbf{b} \cdot \mathrm{H}^{+}\right][$TFA $]$

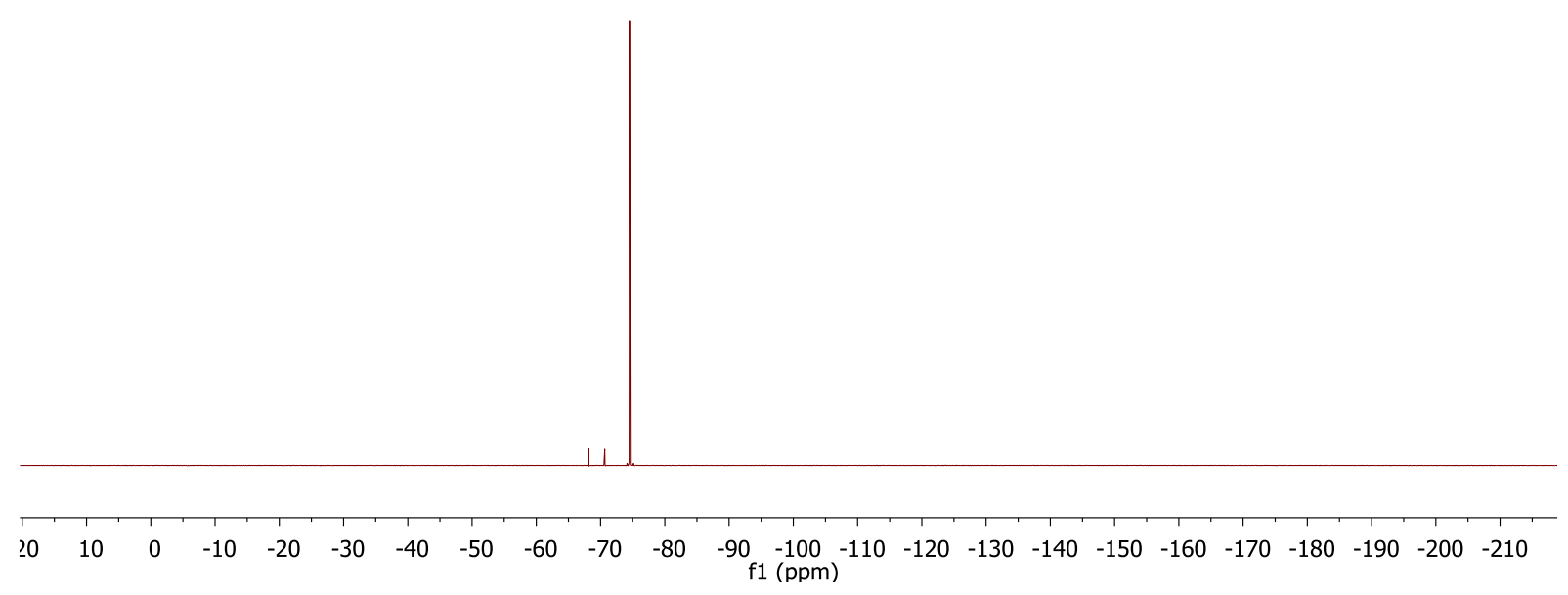




\section{$\operatorname{IR}\left[\mathbf{1 b} \cdot \mathrm{H}^{+}\right]\left[\mathrm{PF}_{6}\right]$}

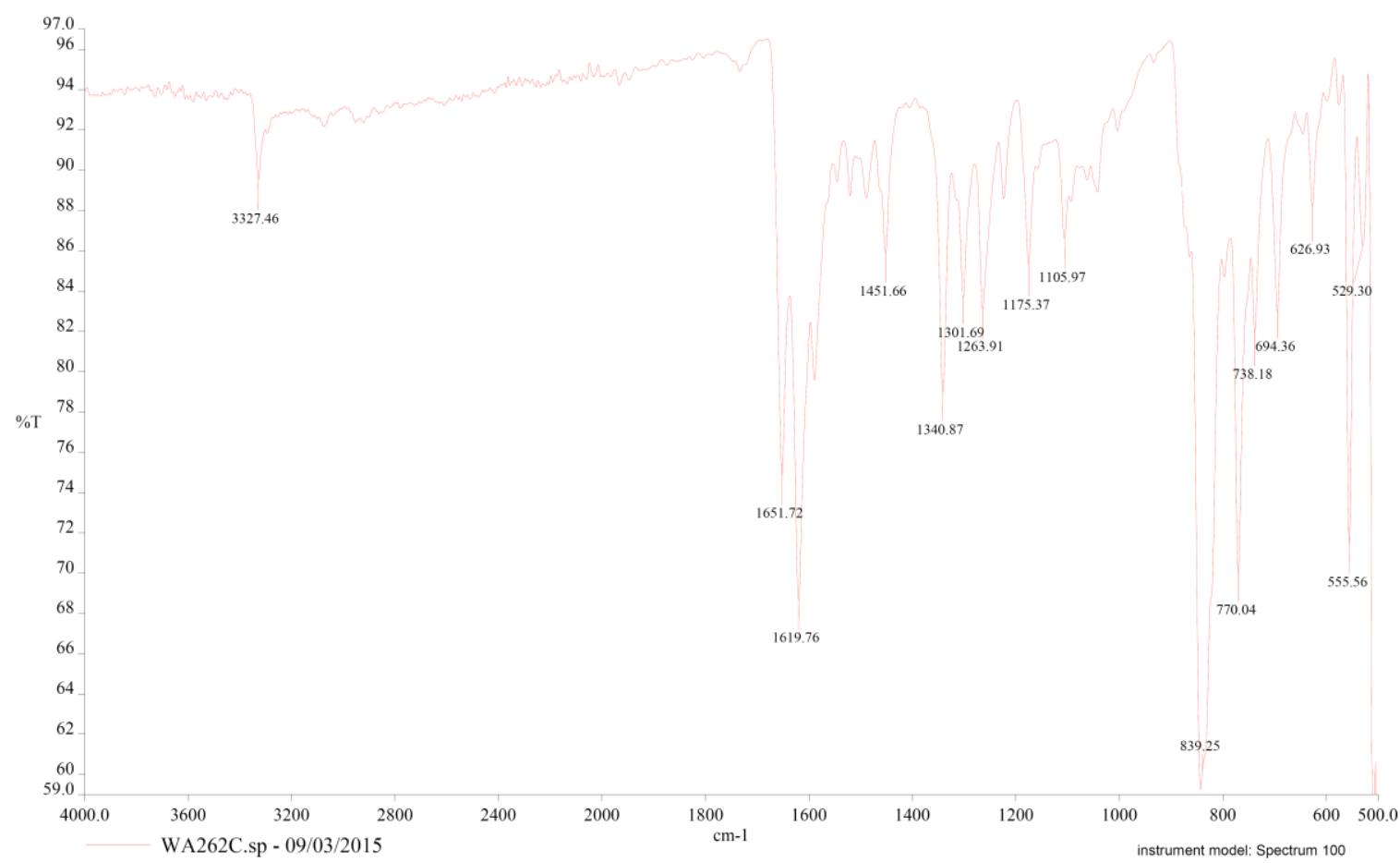




\section{UNIVERSITY OF GENEVA}

Faculty of Sciences

Sciences Mass Spectrometry

WALLABREGUE

WA262C

Sample name:

7064

Sample number:

Eliane Sandmeier

Principal investigator: Dr. Sophie Michalet
Date of reception: $22 / 04 / 14$

Date of certificate: $\quad 05 / 05 / 14$

Data filename: SMS10GE-140505-ES-A001

Instrument: QSTAR Pulsar (AB/MDS Sciex)

lonisation mode: $\quad$ ESI (positive mode)
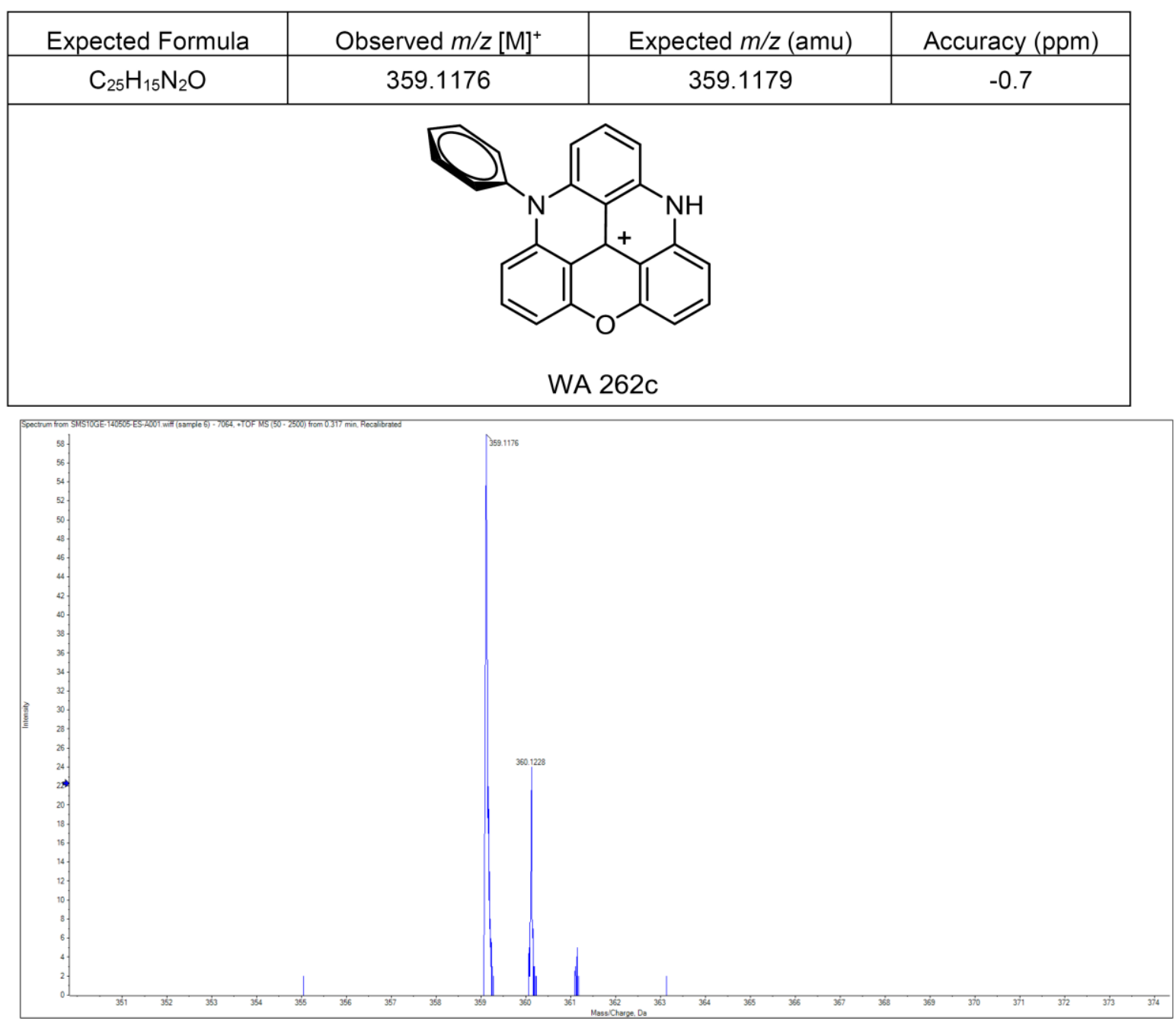
${ }^{1} \mathbf{H}$ NMR $\left(500 \mathrm{MHz}, \mathrm{CD}_{2} \mathrm{Cl}_{2}\right)\left[1 \mathbf{c}^{\circ} \mathbf{H}^{+}\right]\left[\mathrm{PF}_{6}\right]$<smiles></smiles>

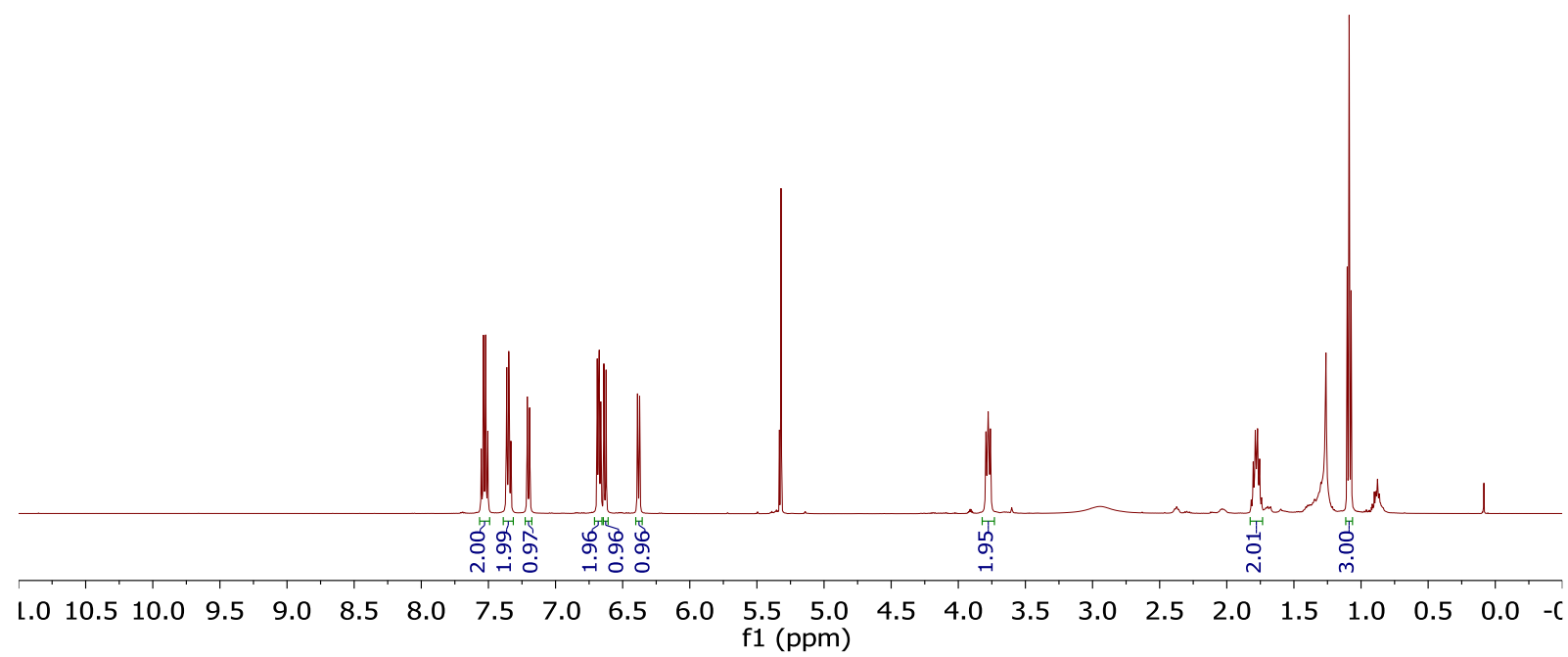

${ }^{13} \mathrm{C} \mathrm{NMR}\left(126 \mathrm{MHz}, \mathrm{CD}_{2} \mathrm{Cl}_{2}\right)\left[1 \mathrm{c}^{\circ} \mathrm{H}^{+}\right]\left[\mathrm{PF}_{6}\right]$

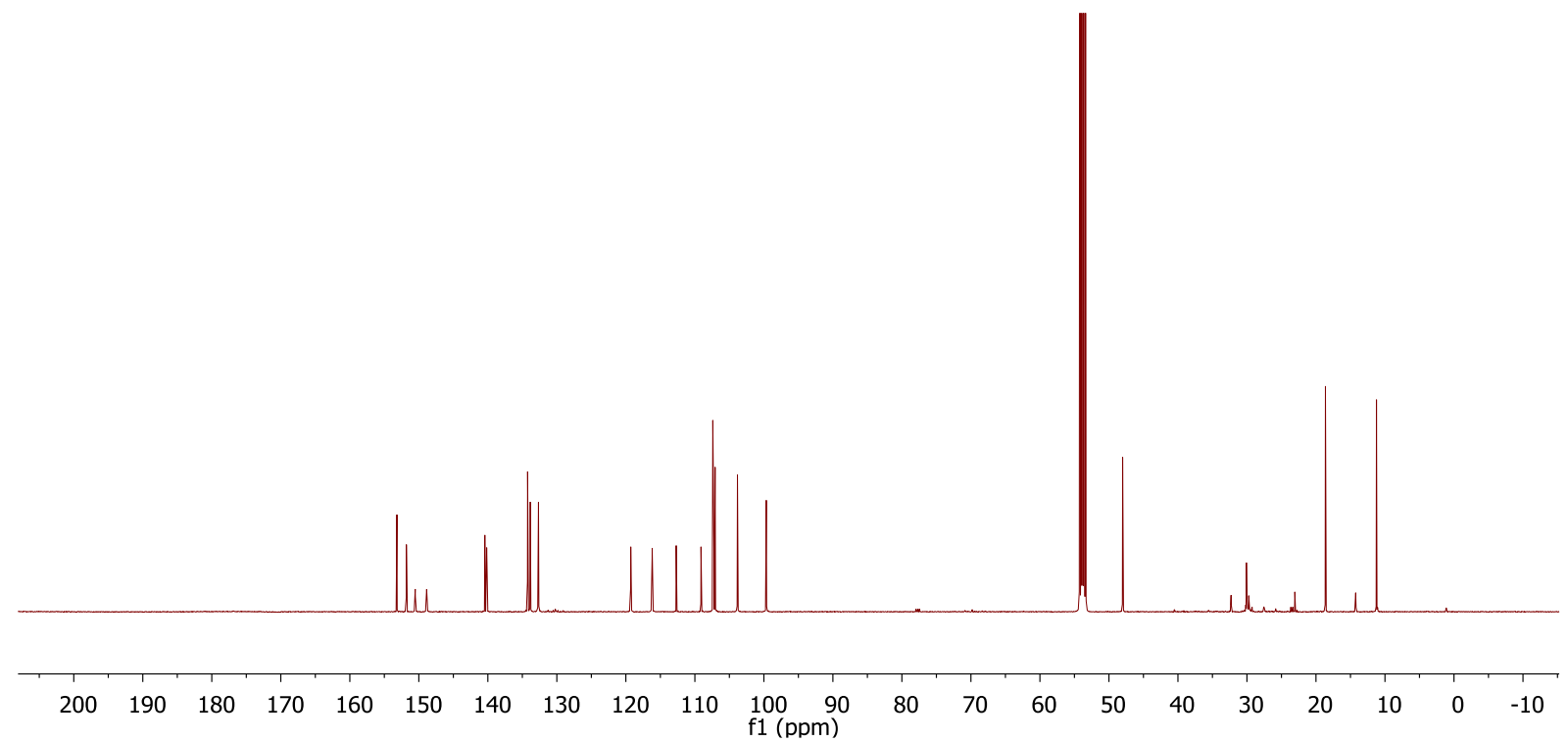


${ }^{19}$ F NMR $\left(282 \mathrm{MHz}, \mathrm{CD}_{2} \mathrm{Cl}_{2}\right)\left[1 \mathbf{c}^{\circ} \mathbf{H}^{+}\right]\left[\mathrm{PF}_{6}\right]$

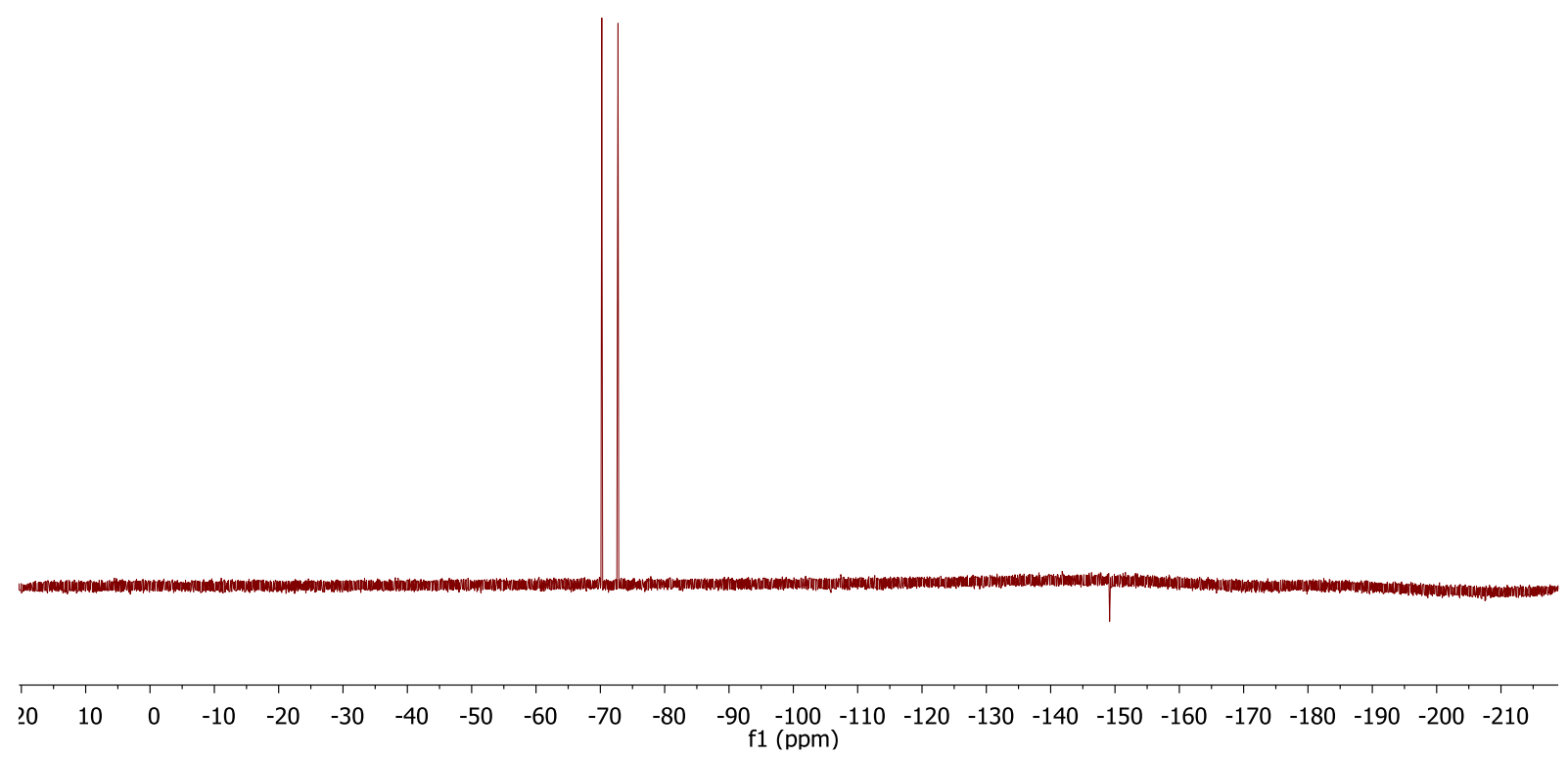

${ }^{19} \mathrm{~F} \mathrm{NMR}\left(282 \mathrm{MHz}, \mathrm{CD}_{2} \mathrm{Cl}_{2}\right)\left[1 \mathbf{c} \cdot \mathbf{H}^{+}\right][\mathrm{TFA}]$

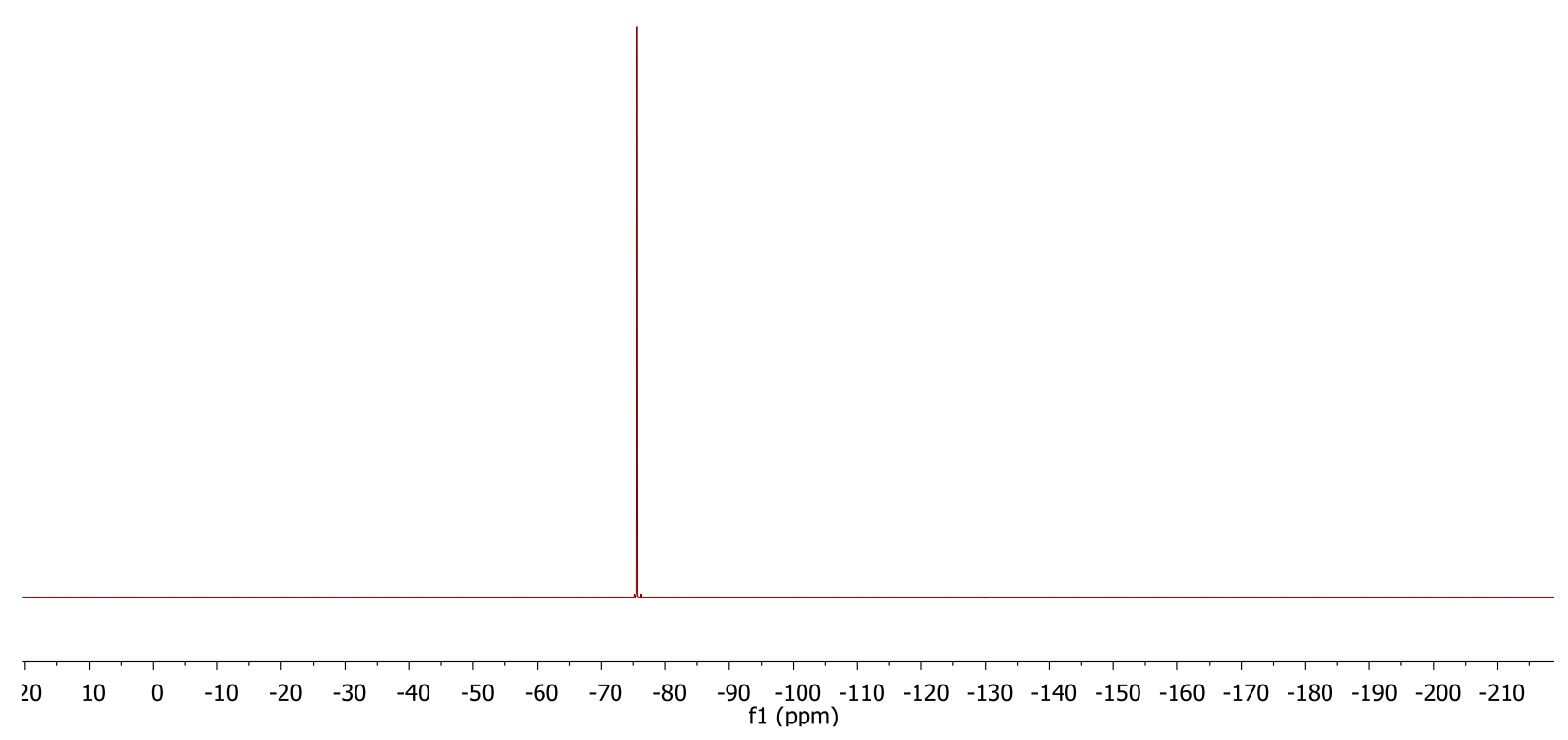


IR $\left[1 \mathbf{c} \bullet \mathrm{H}^{+}\right]\left[\mathrm{PF}_{6}\right]$

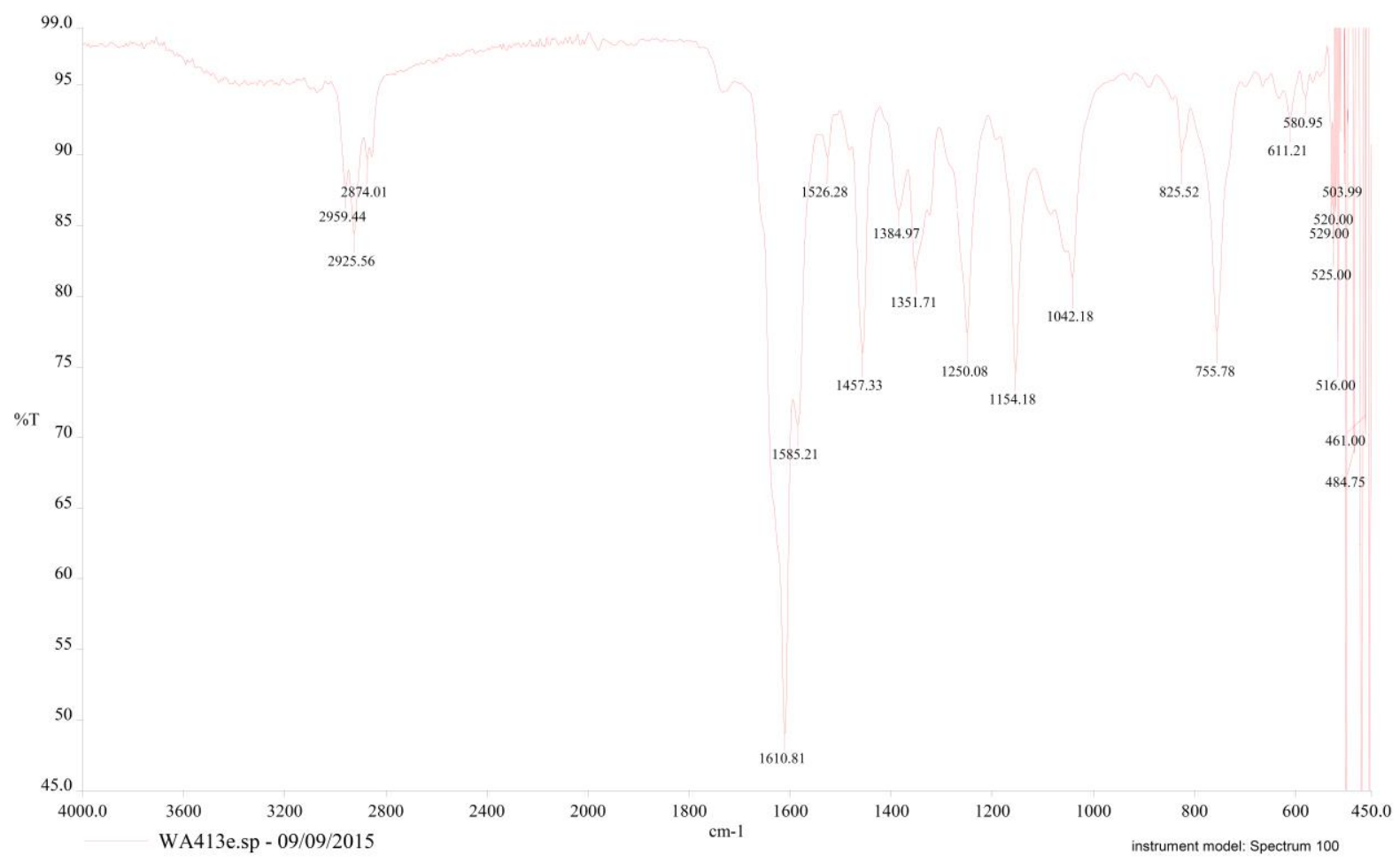

S19 


\section{UNIVERSITY OF GENEVA}

Faculty of Sciences

Sciences Mass Spectrometry

\begin{tabular}{ll|lc}
\hline Submitter: & WALLABREGUE & Date of reception: 22/04/14 \\
Sample name: & WA413e & Date of certificate: 05/05/14 \\
Sample number: & 7066 & Data filename: SMS10GE-140505-ES-A001 \\
Operator: & Eliane Sandmeier & Instrument: QSTAR Pulsar (AB/MDS Sciex: \\
Principal investigator: & Dr. Sophie Michalet & lonisation mode: & ESI (positive mode) \\
\hline
\end{tabular}

\begin{tabular}{|c|c|c|c|}
\hline Expected Formula & Observed $\mathrm{m} / \mathrm{z}[\mathrm{M}]^{+}$ & Expected $\mathrm{m} / \mathrm{z}(\mathrm{amu})$ & Accuracy (ppm) \\
\hline $\mathrm{C}_{22} \mathrm{H}_{17} \mathrm{~N}_{2} \mathrm{O}$ & 325.1336 & 325.1335 & 0.3 \\
\hline
\end{tabular}

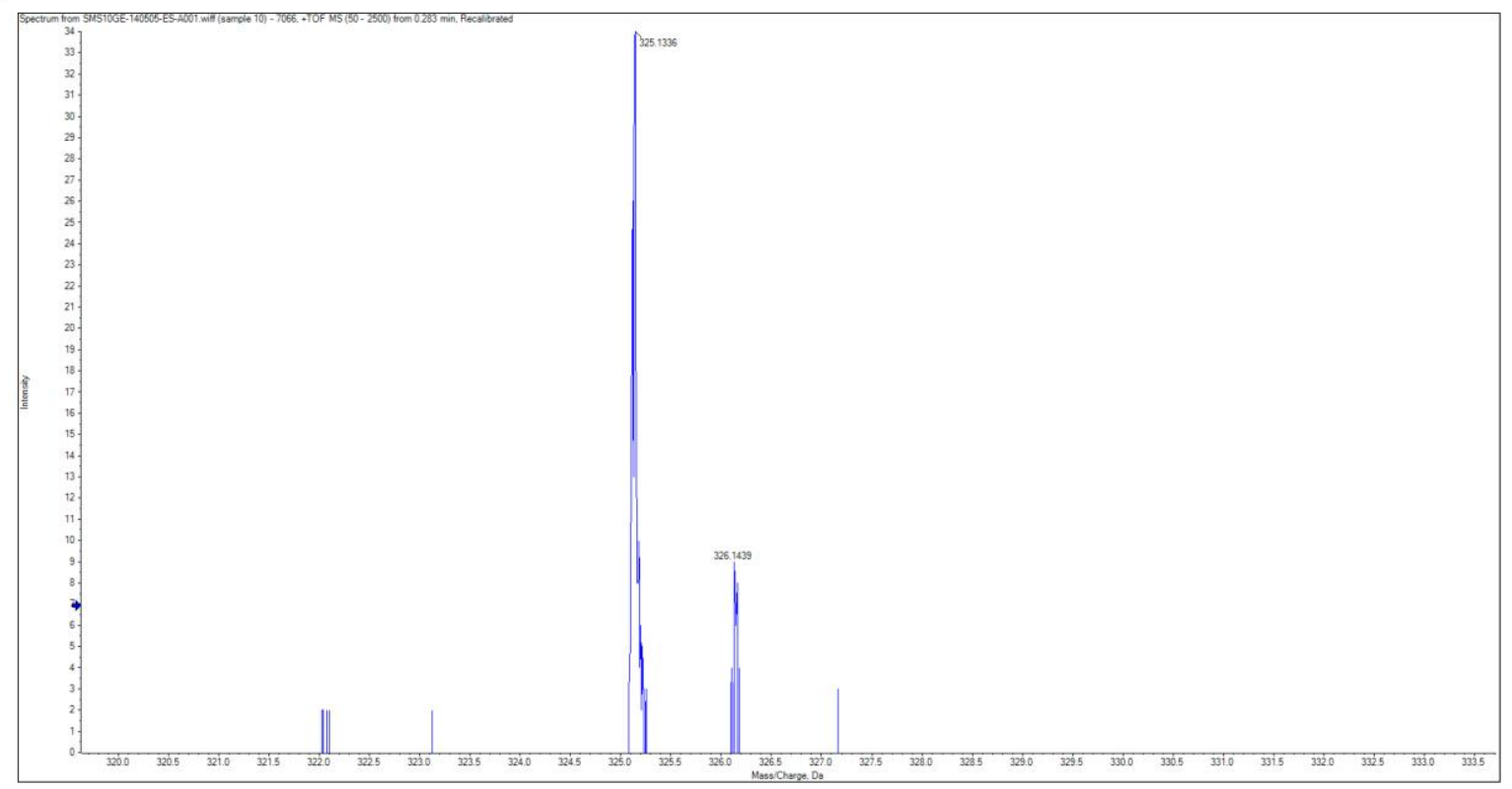




\section{Nanosphere working mechanisms}

\subsection{Ion - exchange mechanism}

The principle of the ion-exchange extraction process is shown in Scheme S1. Once the nanospheres are in contact with the ion of interest, the counter ion from the ion-exchanger is readily replaced by the target ion and forms a complex of defined stoichiometry with the ion of interest, leading to changes in the optical properties as discussed below.
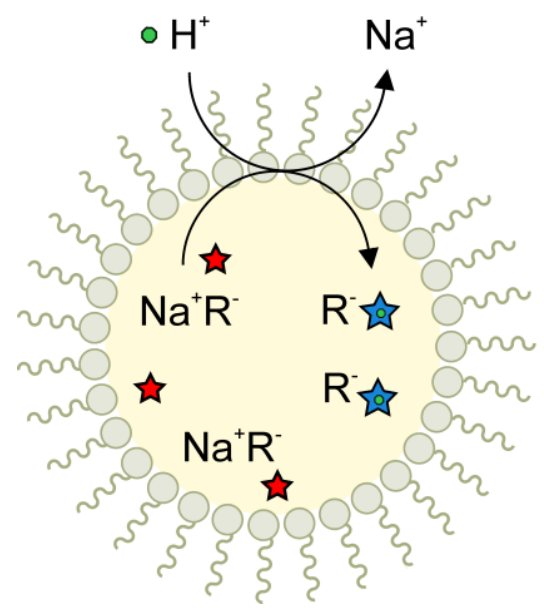

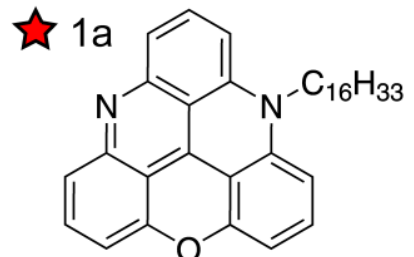

DOS

CTAB/F-127

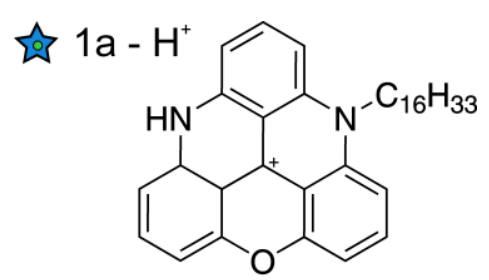

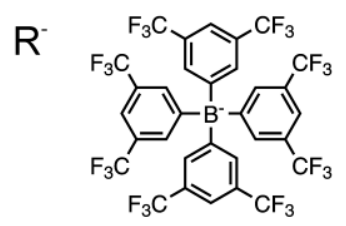

Scheme S1. Ion-selective emulsion doped with macrocyclic compounds as an ionophore, a plasticizer DOS and the hydrophobic structure of CTAB or F-127. The sensing mechanism is based on ionexchange between the target ion $\mathrm{H}^{+}$in aqueous phase and the counterion of $\mathrm{R}^{-}$in the organic phase (1) and the specific interaction between triangulene compound (1a) and the ion of interest (2).

The protonation of triangulene compounds is expressed by eq. 1 , where ns indicates the nanosphere core

$$
\text { Ind }(n s)+H^{+}(n s) \rightleftarrows I n d H^{+}(n s)
$$

and the acid dissociation constant relates to the nanosphere core phase as follows:

$$
K_{a}(n s)=\frac{[I n d]^{n s}\left[H^{+}\right]^{n s}}{\left[I n d H^{+}\right]^{n s}}
$$

The ion-exchange equilibrium between the nanosphere core and the aqueous environment (aq) is written as

$$
\operatorname{lnd}(n s)+\mathrm{H}^{+}(a q)+N a^{+}(n s) \rightleftarrows \operatorname{lnd} H^{+}(n s)+\mathrm{Na}^{+}(a q)
$$


with corresponding exchange constant:

$$
K_{e x}^{\mathrm{Na}^{+} / / n d H^{+}}=\frac{\left[\mathrm{Ind} \mathrm{H}^{+}\right]^{n s}\left[\mathrm{Na}^{+}\right]^{a q}}{[\mathrm{Ind}]^{n s}\left[\mathrm{Na}^{+}\right]^{n s}\left[\mathrm{H}^{+}\right]^{a q}}
$$

The corresponding ion-exchange equilibrium of the uncomplexed ions is expressed as:

$$
H^{+}(a q)+\mathrm{Na}^{+}(n s) \rightleftarrows H^{+}(n s)+\mathrm{Na}^{+}(\mathrm{aq})
$$

with the exchange constant.

$$
K_{e x}^{N^{+} / H^{+}}=\frac{\left[H^{+}\right]^{n s}\left[\mathrm{Na}^{+}\right]^{a q}}{\left[\mathrm{Na}^{+}\right]^{n s}\left[\mathrm{H}^{+}\right]^{a q}}
$$

The nanosphere charge balance is expressed as follows, where nTFPB- is the number of moles of ion exchanger and $\mathrm{n}_{\mathrm{IndH}}$ is number of moles of the protonated form of the ionophore:

$$
n_{\text {TFPB }}=n_{\text {IndH }}+n_{\mathrm{Na}^{+}}
$$

The mass balance for the ionophore is written by equation 8 , with $n_{\text {IndH }}$ the number of moles of the ionophore.

$$
n_{\text {Indtot }}=n_{\text {IndH }}+n_{\text {Ind }}
$$

The $\mathrm{pH}$ response of the nanospheres was evaluated in the absorption mode in the presence of $0.01 \mathrm{M}$ and $0.1 \mathrm{M} \mathrm{NaCl}$. The absorbance spectra $A$ were normalized at given equlibrium expressed as a degree of protonation of the triangulene compounds as a function of the sample $\mathrm{pH}$ fitted with ion exchange theory that allows one to obtain the overall equilibrium constant, $\mathrm{K}_{e x}^{\mathrm{Na}^{+} / I n \mathrm{HH}^{+}}{ }^{2}$ The $\mathrm{pK}_{\mathrm{a}}$ values of the compounds 1a-c were determined directly inside the nanospheres according to a methodology introduced by Xie et al. ${ }^{3}$ It allows one to determine the $\mathrm{pK}_{\mathrm{a}}$ values of hydrophobic $\mathrm{pH}$ sensitive probes from $K_{e x}^{\mathrm{Na}^{+} / I n d H^{+}}$and $K_{e x}^{\mathrm{Na}^{+} / \mathrm{H}^{+}}$:

$$
K_{a}(n s)=\frac{K_{e x}^{N^{+} / H^{+}}}{K_{e x}^{N a^{+} / I n d H^{+}}}=\frac{\left[H^{+}\right]^{n s}\left[\mathrm{Na}^{+}\right]^{a q}}{\left[\mathrm{Na}^{+}\right]^{n s}\left[H^{+}\right]^{a q}} \frac{[I n d]^{n s}\left[\mathrm{Na}^{+}\right]^{n s}\left[H^{+}\right]^{a q}}{\left[I n d H^{+}\right]^{n s}\left[\mathrm{Na}^{+}\right]^{a q}}=\frac{[I n d]^{n s}\left[H^{+}\right]^{n s}}{\left[I n d H^{+}\right]^{n s}}
$$

The latter value (eq 6) can be obtained from spectroscopic experiments on the same type of nanospheres, but incorporating a solvatochromic dye instead of the probe of interest and using either hydrogen ions or sodium ions for competitive ion-exchange with the solvatochromic dye..$^{3-4}$ The ratio of the two exchange constants for this experiment cancels out the contribution of the solvatochromic dye, thereby resulting in the desired value for $\mathrm{K}_{e x}^{\mathrm{Na}^{+} / \mathrm{H}^{+}}$. 


\subsection{Co-extraction mechanism}

To evaluate the influence of the counterion on the $\mathrm{pK}_{\mathrm{a}}$ values, the nanospheres without ion-exchange properties were prepared. The principle of the co-extraction process is shown in Scheme S2. Once the nanospheres are in contact with the ion of interest, hydrogen ions are exctracted from the aqueous phase into the nanospheres accompanied by co-extraction of a counter-ion in order to maintain neutrality. ${ }^{2}$ The coextraction equilibrium $K_{\text {coex }}$ of sample counterions occurs according to the following reaction :

$$
I n d(n s)+H^{+}(a q)+C l(a q) \rightleftarrows I n d H^{+}(n s)+C l(n s)
$$

with corresponding co-extraction constant:

$$
K_{\text {coex }}^{H^{+} C l}=\frac{\left[I n d H^{+}\right]^{n s}[\mathrm{Cl}]^{n s}}{[I n d]^{n s}\left[H^{+}\right]^{a q}[\mathrm{Cl}]^{a q}}
$$

The charge balance is expressed in the following equation, where $\mathrm{n}_{\text {IndHns }}$ is the number of moles of the protonated form of the ionophore and $\mathrm{n}_{\mathrm{cl}}$ is number of moles of co-extracted anions.

$$
n_{I n d H^{+}}(n s)=n_{C l}(n s)
$$

The mass balance for the ionophore is expressed with $n_{\text {IndH }}$ the number of moles of the ionophore:

$$
n_{\text {Indtot }}=n_{\text {IndH }}+n_{\text {Ind }}
$$

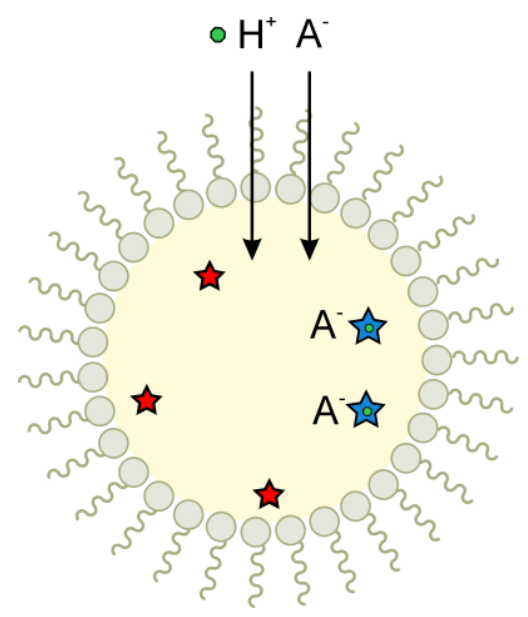

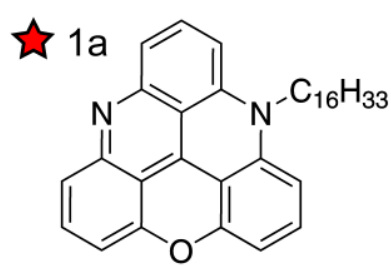

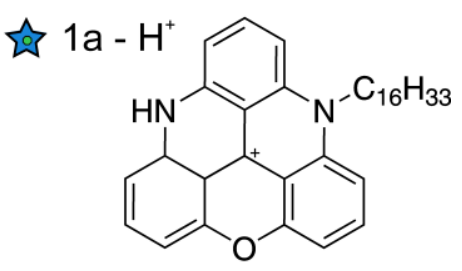

\section{DOS}

CTAB/F-127

Scheme S2. Emulsion doped with triangulene compounds as an ionophore, a plasticizer DOS and the hydrophobic structure of CTAB or F-127. The coextraction mechanism is based on the extraction of the target ion into the organic phase accompanied by coextraction of the anions. 


\section{Absorption and emission spectra and photostability tests}

\subsection{Absorption spectra at different pH}

To evaluate the influence of the polymeric matrix on the optical properties, sodium dodecyl sulfate (SDS), cetyltrimethylammonium bromide (CTAB), Tween20 and pluronic F-127 were used as anionic, cationic and non-ionic surfactants. The presence of anionic SDS results in significant changes in the absorption spectra of dyes. Non-ionic Tween20 has no influence on the spectral properties of triangulene compounds but dyes precipitate within $1 \mathrm{~h}$ after sample preparation in the presence of $0.03 \%$ DMSO (by volume). Cationic CTAB and non-ionic pluronic F-127 do not induce any visible changes in the absorption spectra and prevents the dye precipitation during long time period (See Figure S1). The stabilization of triangulenes 1 in was achieved at CTAB concentrations higher (> 2 $\mathrm{mM})$ than the critical micellar concentration $\mathrm{cmc}_{\mathrm{C}} \mathrm{AB}(0.8 \mathrm{mM})$.

The degree of protonation 1- $\alpha$ was calculated according to the following equations 14 and 15 , where $A$ is the absorbance at $575 \mathrm{~nm}$ for the system based on F-127 and $512 \mathrm{~nm}$ for the CTAB system at given equilibrium, $A_{\text {deprotonated }}$ is $A$ in the fully deprotonated state and $A_{\text {protonated }}$ is the absorbance in the fully protonated state.

$$
\begin{aligned}
& 1-\alpha=\frac{A_{\text {protonated }}-A}{A_{\text {protonated }}-A_{\text {deprotonated }}} \\
& 1-\alpha=\frac{A-A_{\text {deprotonated }}}{A_{\text {protonated }}-A_{\text {deprotonated }}}
\end{aligned}
$$




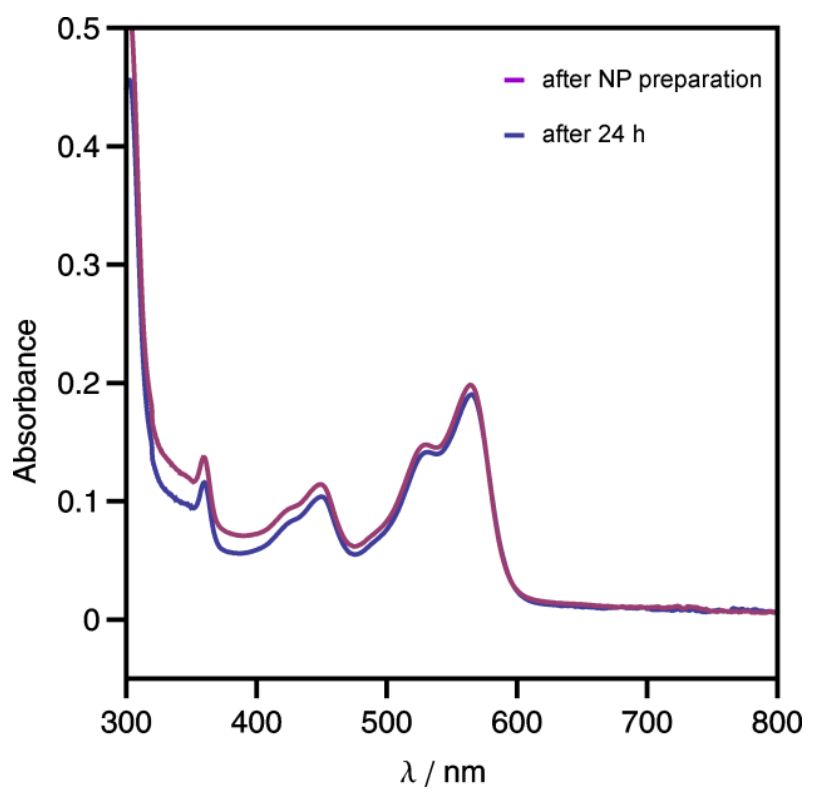

Figure S1. Stability of the nanospheres encapsulating triangulene dye $\mathbf{1 b}$ incorporated in the nonionic surfactant pluronic F-127 (NP5) measured immediately after preparation (purple trace) and after $24 \mathrm{~h}$ (blue trace). The concentration of $1 \mathrm{~b}$ is $2.3 \times 10^{-5} \mathrm{M}$. 

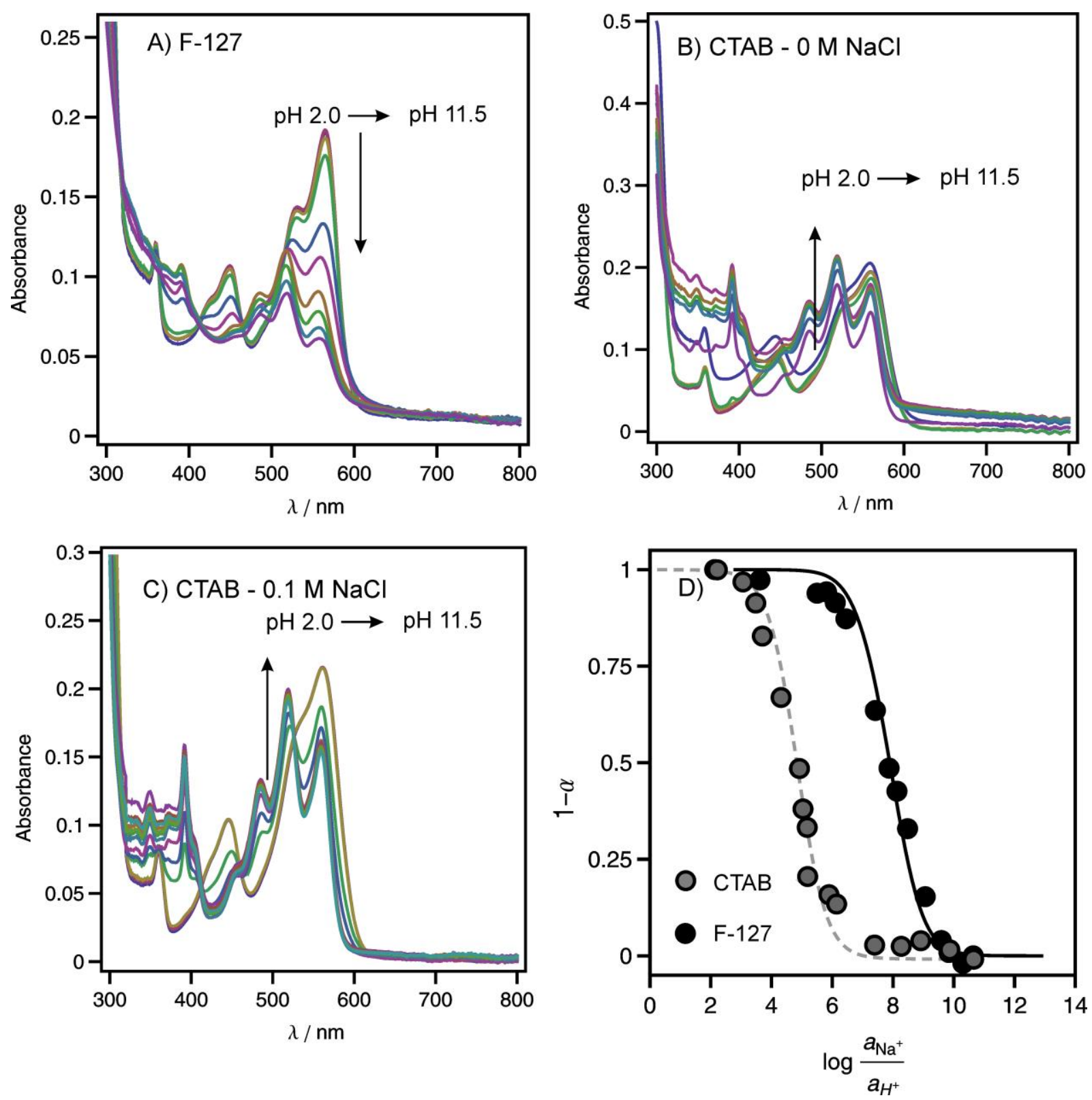

Figure S2. Electronic absorption spectra $(\mathrm{A}, \mathrm{B}, \mathrm{C})$ collected at different $\mathrm{pH}$ for $\mathbf{1 a}$ incorporated into two different varieties of ion-selective nanospheres, one containing F-127 (NP1) and the other one CTAB (NP2) in the absence and presence of $\mathrm{NaCl}$. The absence of $\mathrm{NaCl}$ in $\mathrm{CTAB}$ micelles results in light scattering that significantly influences the measurements. Comparison of absorbance mode response (D) toward different activity of $\mathrm{H}^{+}$for $\mathrm{F}-127$ and CTAB. The solid black and dashed light gray sigmoidal curves were simulated from classical ion exchange theory mentioned above. The concentration of $1 \mathrm{a}$ in the cuvette is $2.2 \times 10^{-5} \mathrm{M}$. 

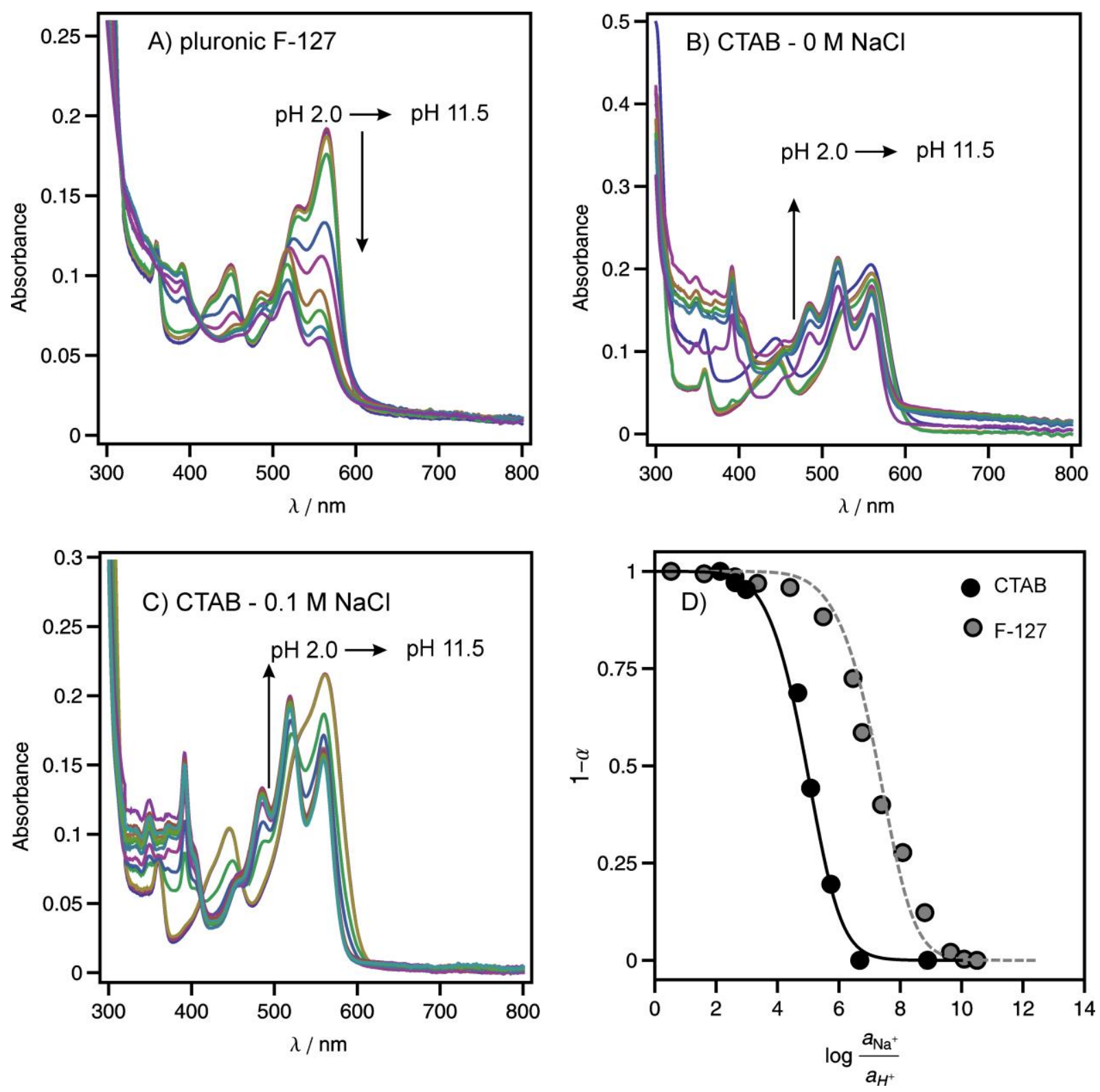

Figure S3. Electronic absorption spectra $(\mathrm{A}, \mathrm{B}, \mathrm{C})$ collected at different $\mathrm{pH}$ for $\mathbf{1 b}$ incorporated into two different varieties of ion-selective nanospheres, one containing F-127 (NP5) and the other one CTAB (NP6) in the absence and presence of $\mathrm{NaCl}$. The absence of $\mathrm{NaCl}$ in $\mathrm{CTAB}$ micelles results in light scattering that significantly influences the measurements. Comparison of absorbance mode response (D) toward different activity of $\mathrm{H}^{+}$for $\mathrm{F}-127$ and CTAB. The solid black and dashed light gray sigmoidal curves were simulated from classical ion exchange theory mentioned above. The concentration of $\mathbf{1 b}$ in the cuvette is $2.3 \times 10^{-5} \mathrm{M}$. 

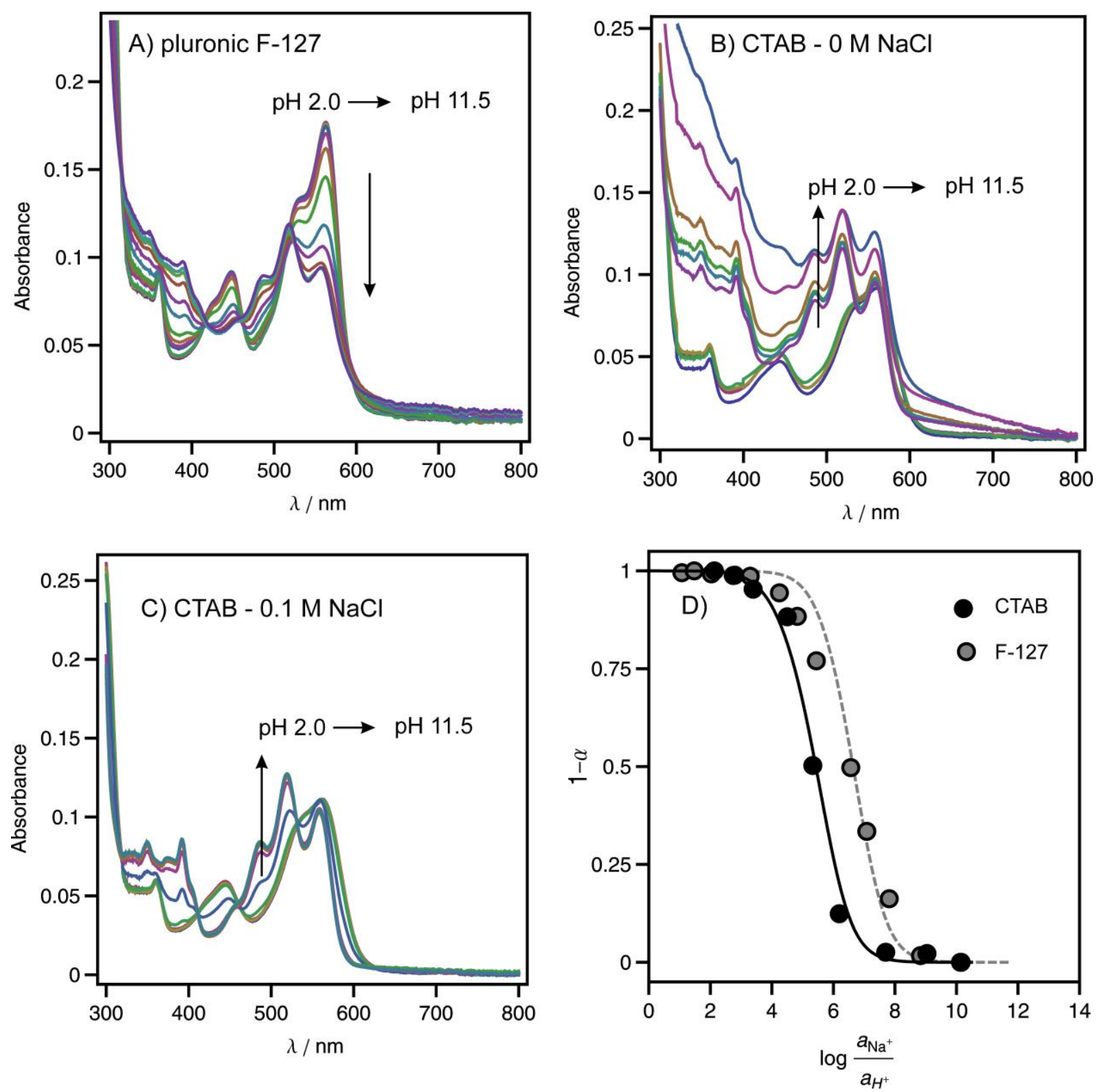

Figure S4. Electronic absorption spectra $(\mathrm{A}, \mathrm{B}, \mathrm{C})$ collected at different $\mathrm{pH}$ for $\mathbf{1 c}$ incorporated into two different varieties of ion-selective nanospheres, one containing F-127 (NP9) and the other one CTAB (NP10) in the absence and presence of $\mathrm{NaCl}$. The absence of $\mathrm{NaCl}$ in $\mathrm{CTAB}$ micelles results in light scattering that significantly influences the measurements. Comparison of absorbance mode response (D) toward different activity of $\mathrm{H}^{+}$for $\mathrm{F}-127$ and CTAB. The solid black and dashed light gray sigmoidal curves were simulated from classical ion exchange theory mentioned above. The concentration of $\mathbf{1 c}$ in the cuvette is $2.2 \times 10^{-5} \mathrm{M}$. 


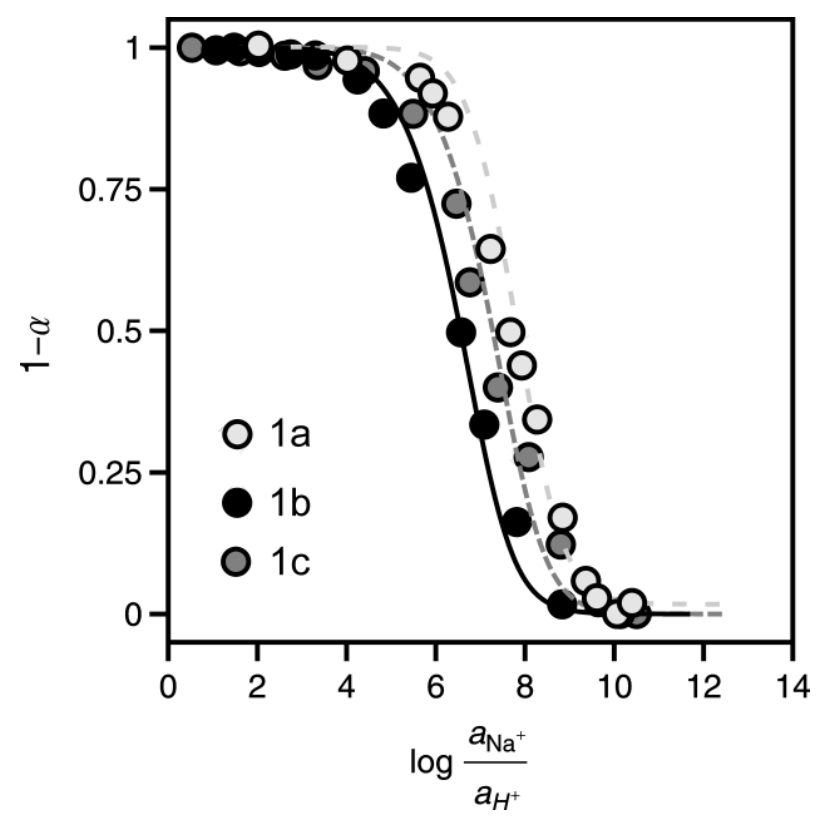

Figure S5. Comparison of $\mathrm{pH}$ response of $\mathbf{1 a}, \mathbf{1 b}, \mathbf{1} \mathbf{c}$ in the pluronic $\mathrm{F}-127$ system (NP 1, 5, 9) at a fixed electrolyte concentration of $0.1 \mathrm{M} \mathrm{NaCl}$.

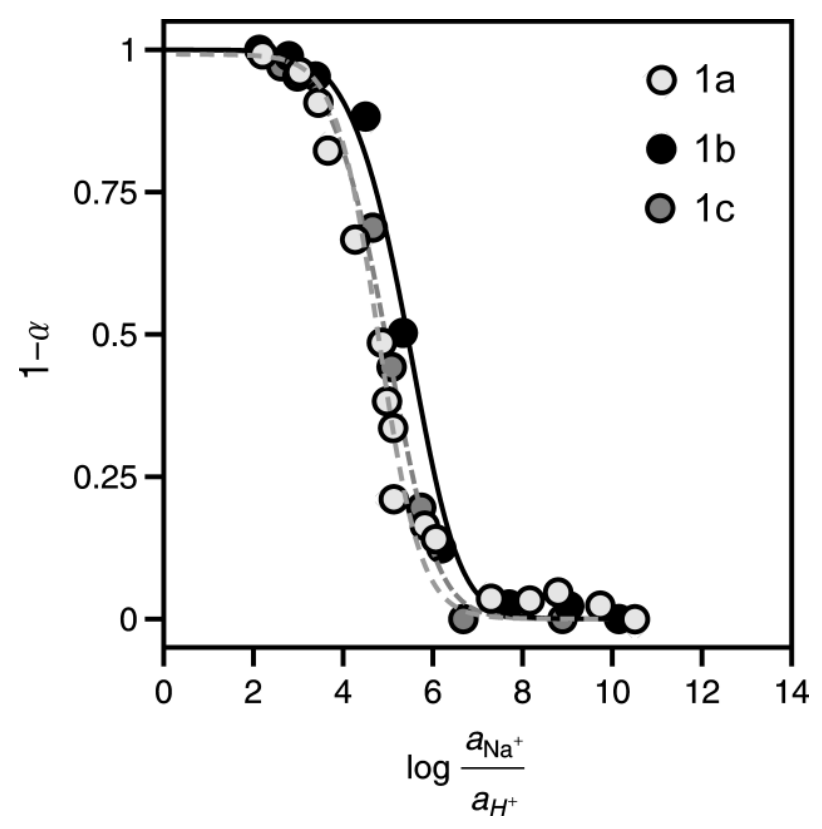

Figure S6. 1a, 1b, 1c in $C T A B$ system $\mathrm{pH}$ titration of the nanospheres encapsulating triangulene compounds with different side chains, NaTFPB in the CTAB matrix in aqueous solution of $0.1 \mathrm{M} \mathrm{NaCl}$ (NP 2, 6, 10). 
The pKa values of $\mathbf{1 a}, \mathbf{1 b}$ and $\mathbf{1 c}$ experimentally obtained and determined are listed in Table S2. The pKa values were calculated according to eq 9, the exchange constant $K_{e x}^{\mathrm{Na}^{+} / H^{+}}$was determined by Xie et al. as 7.9. ${ }^{3}$ As can be seen in the Table S2, the nanosphere composition has a strong impact on the characteristics of the $\mathrm{pH}$ nanospheres. It is important to distinguish between the pKa in the organic phase and the corresponding apparent one that is obtained as an inflection point of the protonation of triangulene compounds as a function of the $\mathrm{pH}$. The apparent $\mathrm{pKa}$ depends on the nanosphere composition and on the nature and the concentration of the ions in the sample solution. Indeed, the pKa values inside the nanospheres are approximately 1 unit higher in comparison to the corresponding apparent pKa values. The environment of the nanosphere induces the differences between pKa values, and two different matrices (F127, CTAB) give opposite trends. This is likely due to molecular interactions within the nanospheres. The reduced values of $\mathrm{pKa}$ in the case of pluronic $\mathrm{F}$ 127 are attributed to the relatively high polarity of the spheres, in agreement with earlier results. ${ }^{4}$

Table S2. pKa values of triangulene compounds directly determined in the nanospheres based on F127 and CTAB for ion-exchange and co-extraction systems.

\begin{tabular}{|c|c|c|c|c|c|c|c|}
\hline & \multicolumn{5}{|c|}{ lon-exchange } & \multicolumn{2}{|c|}{ Co-extraction } \\
\hline & $\log K_{e x}{ }^{\mathrm{Na}+, \mathrm{IndH}+}$ & $\mathrm{pK}_{\mathrm{a}}$ & $\log K_{e x}{ }^{N a+, I n d H_{+}}$ & $\mathrm{pKa}$ & $\log K_{c e}{ }^{H+C l-}$ & $\log K_{C e}{ }^{H+C l O 4-}$ & $\log K_{c e}{ }^{H+C l}$ \\
\hline & F127 & F127 & CTAB & CTAB & F127 & F127 & CTAB \\
\hline $1 a$ & -8.6 & 9.5 & -6.4 & 7.3 & -10.1 & -10.5 & -8.6 \\
\hline $1 b$ & -8.4 & 9.3 & -6.9 & 7.8 & -9.0 & -12.2 & -9.8 \\
\hline $1 c$ & -8.0 & 8.9 & -7.6 & 8.4 & -10.9 & -11.6 & -9.3 \\
\hline
\end{tabular}

To evaluate the influence of interfering cations, a competitive extraction experiment was performed. The nanosphere suspension containing $0.1 \mathrm{M}$ of different the cations sodium, potassium and lithium were titrated with $2 \mathrm{M} \mathrm{NaOH}$. The selectivity of the nanospheres corresponds to the equilibrium constant (eq 4) of the exchange reaction of the primary $\left(\mathrm{H}^{+}\right)$and interfering $\left(\mathrm{Na}^{+}, \mathrm{Li}^{+}, \mathrm{K}^{+}\right)$ion between the organic phase and the aqueous phase. As shown in Figure S7-S9, the ion-exchange equilibrium is reasonably independent on the nature of the exchanging cation, which suggests a rather polar solvent environment of the nanosphere cores. 

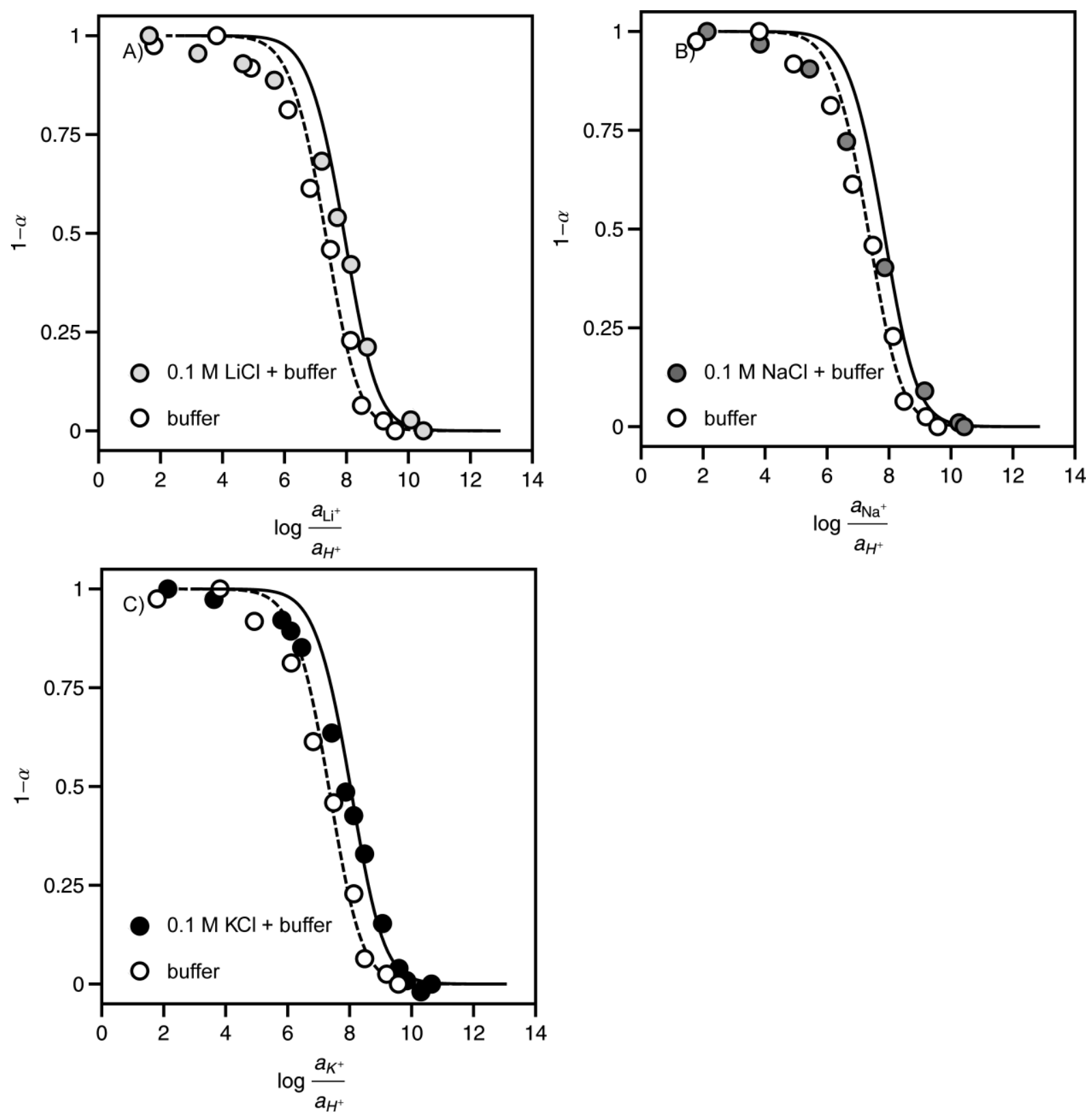

Figure S7. Observed typical s-shape curve of normalized absorbance response of F-127 based (NP1) nanospheres encapsulating triangulene compound $\mathbf{1 a}$ to the hydrogen ions in the presence of $0.1 \mathrm{M}$ $\mathrm{LiCl}(\mathrm{A}), 0.1 \mathrm{M} \mathrm{NaCl}(\mathrm{B})$ and $0.1 \mathrm{M} \mathrm{KCl}(\mathrm{C})$ in the buffer solution of $2.5 \mathrm{mM}$ citric acid, boric acid and sodium phosphate monobasic. 

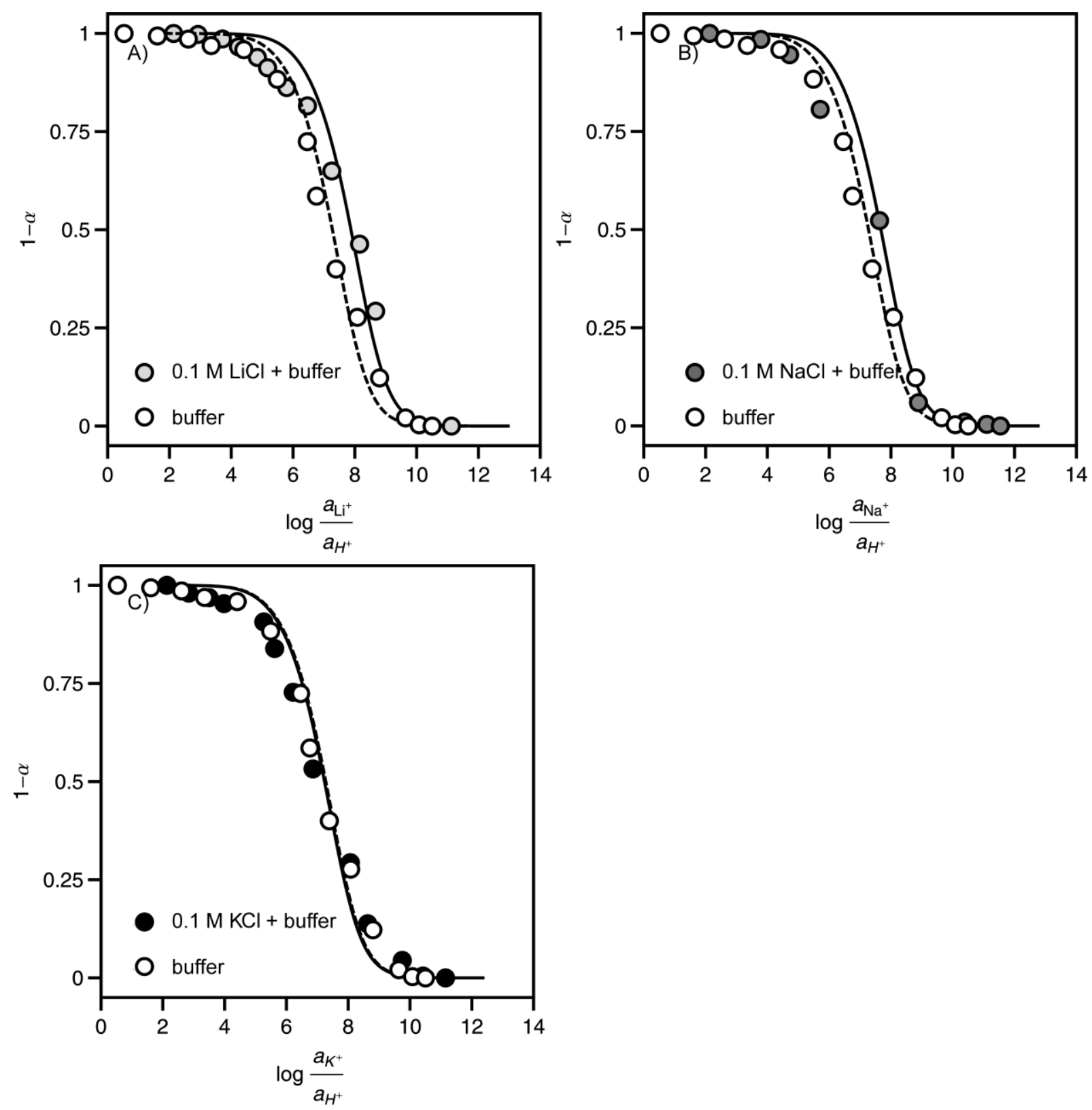

Figure S8. Observed typical S-shape curve of normalized absorbance response of F-127 based nanospheres (NP5) encapsulating triangulene compound $\mathbf{1 b}$ to the hydrogen ions in the presence of $0.1 \mathrm{M} \mathrm{LiCl}(\mathrm{A}), 0.1 \mathrm{M} \mathrm{NaCl}(\mathrm{B})$ and $0.1 \mathrm{M} \mathrm{KCl}(\mathrm{C})$ in the buffer solution of $2.5 \mathrm{mM}$ citric acid, boric acid and sodium phosphate monobasic. 

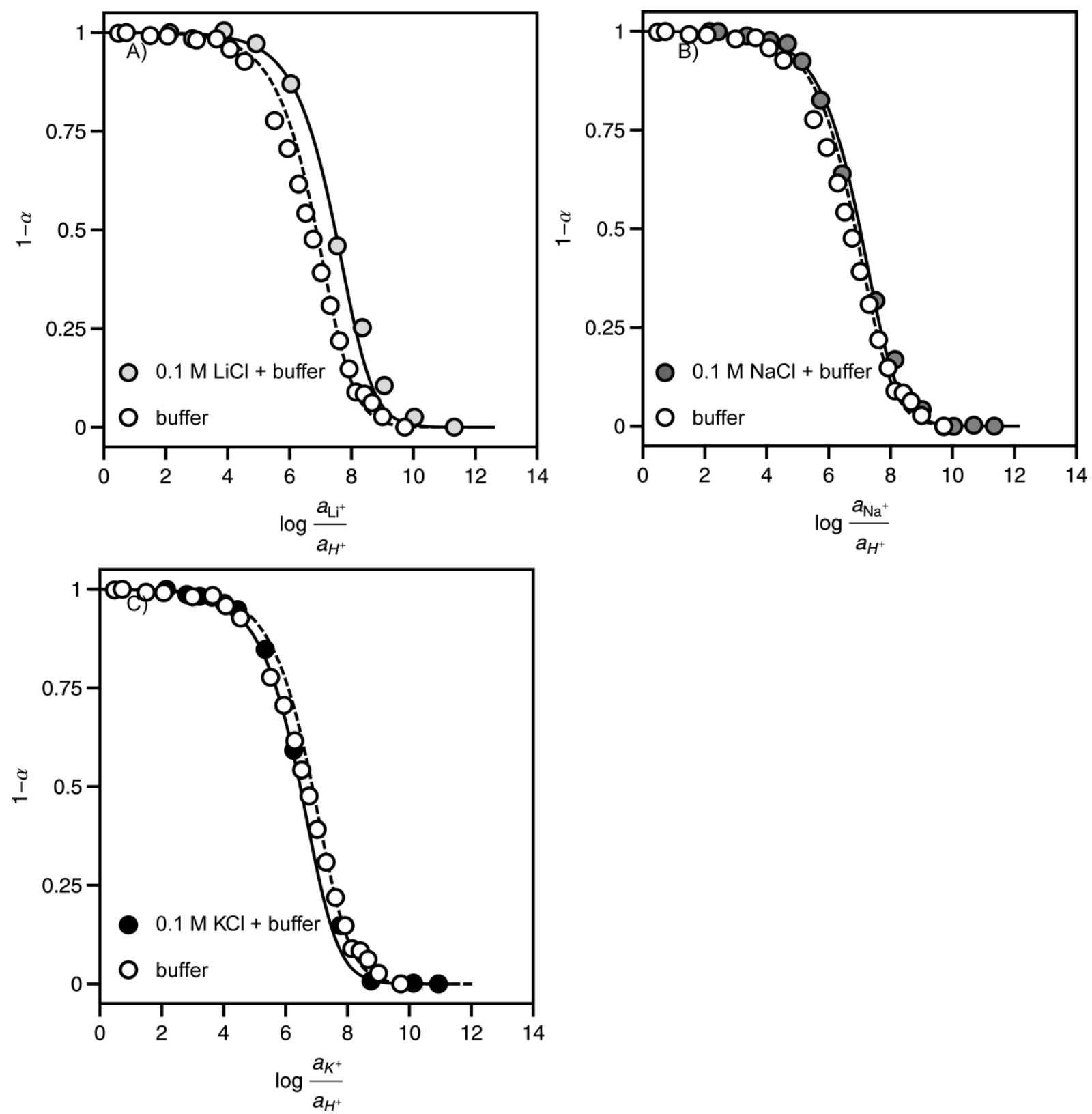

Figure S9. Observed typical s-shape curve of normalized absorbance response of F-127 based nanospheres (NP9) encapsulating triangulene compound 1c to the hydrogen ions in the presence of $0.1 \mathrm{M} \mathrm{LiCl}(\mathrm{A}), 0.1 \mathrm{M} \mathrm{NaCl}(\mathrm{B})$ and $0.1 \mathrm{M} \mathrm{KCl}(\mathrm{C})$ in the buffer solution of $2.5 \mathrm{mM}$ citric acid, boric acid and sodium phosphate monobasic.

To evaluate the influence of the counterion on the coextraction equilibrium, nanospheres without ionexchanger were prepared and evaluated in the presence of $0.01 \mathrm{M}$ and $0.1 \mathrm{M}$ chloride and perchlorate background. According to theory (eq. 11), the extent of co-extraction of $\mathrm{HCl} / \mathrm{HClO}_{4}$ may increase with lower $\mathrm{pH}$ or a higher activity and lipophilicity of the sample anion. As shown in Figure S10, the electrolyte co-extraction results a shift in the equilibrium that indeed depends on the lipophilicity of the anion according to the Hofmeister selectivity sequence of $\mathrm{ClO}_{4}^{-}>\mathrm{SCN}^{-}>\mathrm{NO}_{3}{ }^{-}>\mathrm{Cl}^{-}>\mathrm{HPO}_{4}{ }^{2-}{ }^{2}$ The resulting co-extraction constants are shown in Table S2. The $K_{\text {coex }}$ for the perchlorate anion in the presence of CTAB micelles is not shown due to precipitation as evidenced by light scattering. The values vary significantly more for the different compounds $1 \mathrm{a}$ to $1 \mathrm{c}$ than suggested based on the pKa 
values obtained from ion-exchange nanospheres. This strongly suggests that ion pair formation between the extracted anion and the protonated dye is relatively strong and structure dependent.
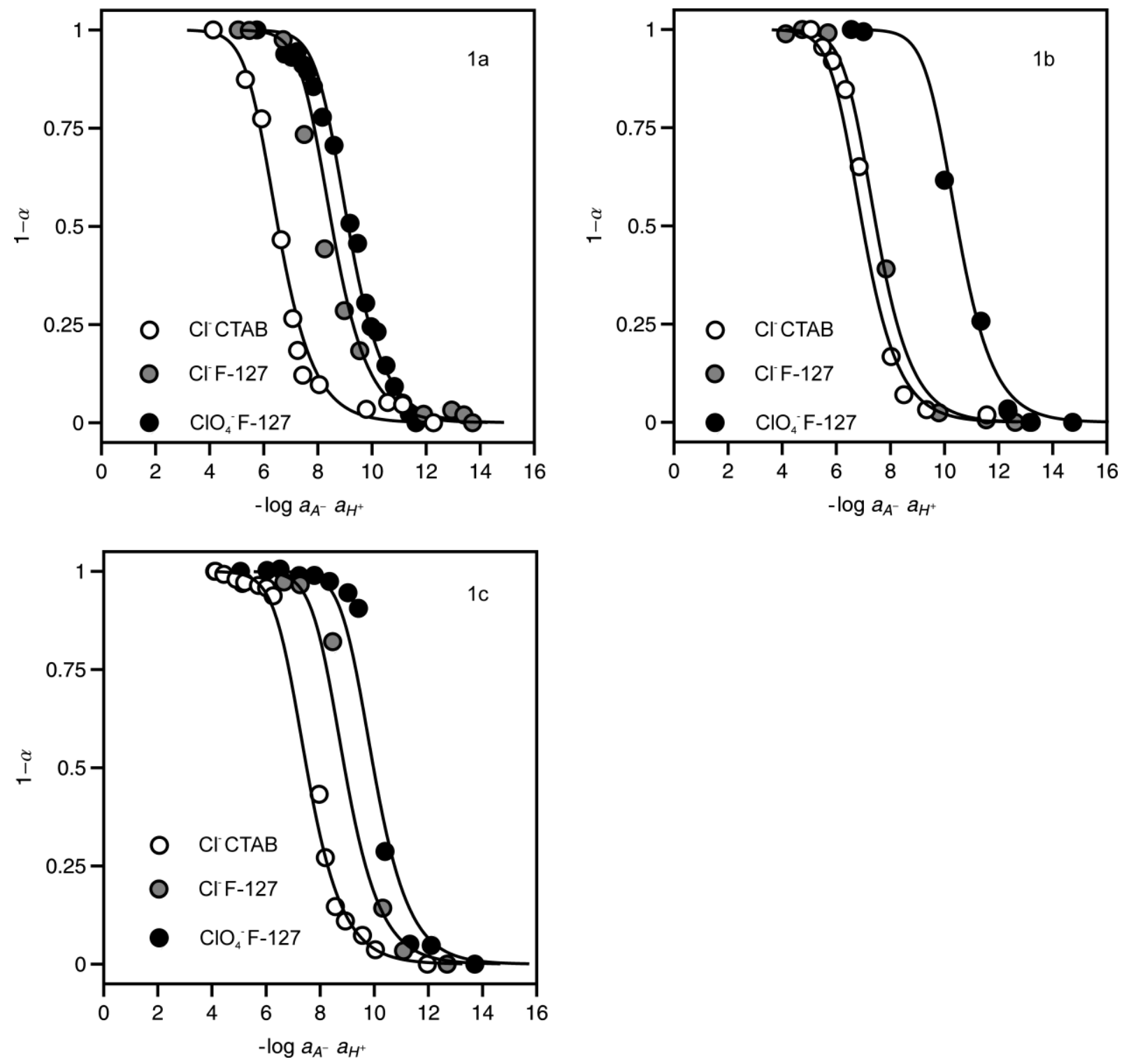

Figure S10. Observed s-shape curve for the normalized absorbance response of nanospheres containing triangulene compounds to hydrogen ions in the presence of different anions for evaluating co-extraction equilibria (NP $3,4,7,8,11,12$ ). The selectivity follows the Hofmeister sequence, as expected. 


\subsection{Spectral properties of triangulenes in nanospheres}
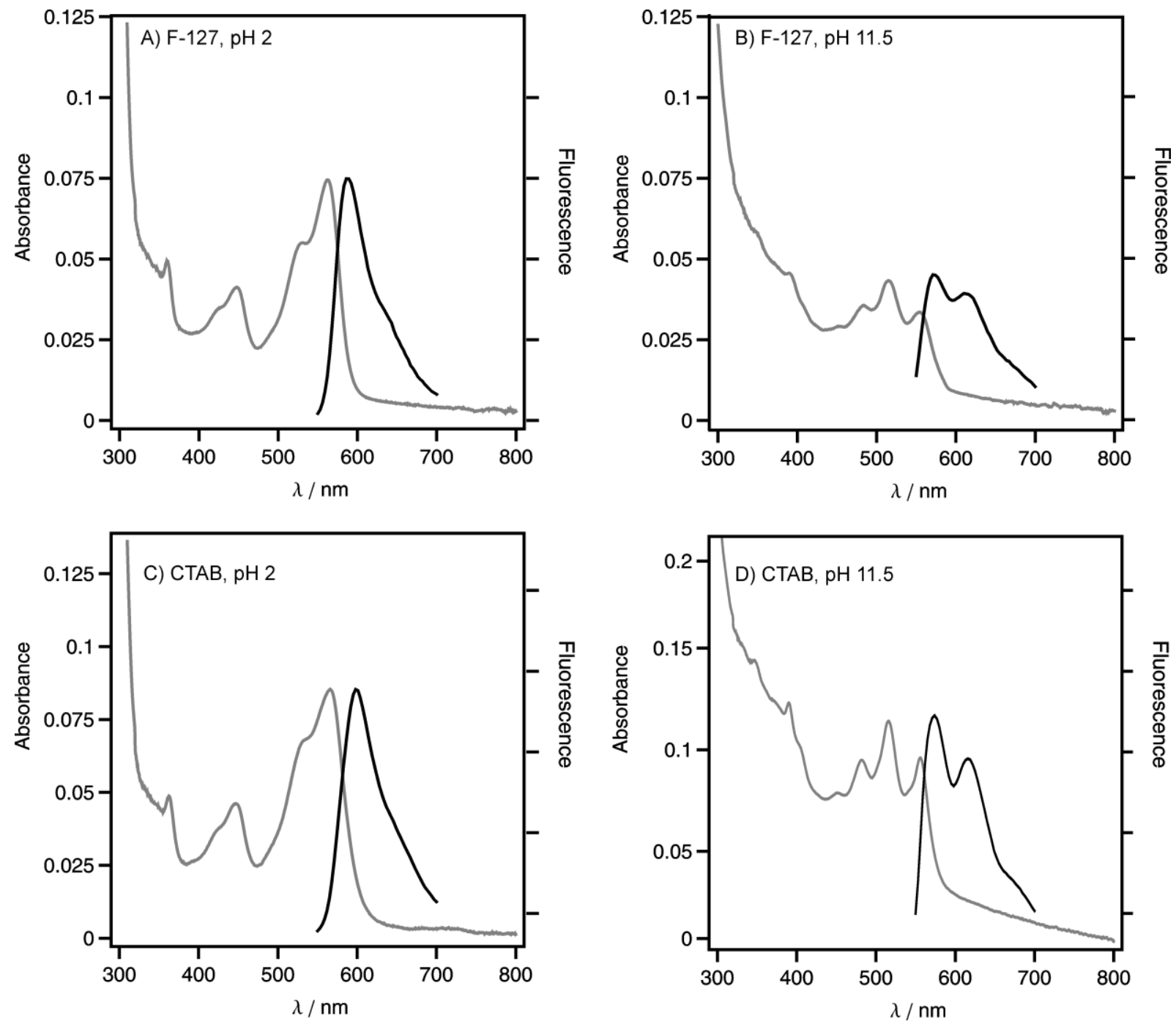

Figure S11. Absorption and emission spectra of 1a in F-127 (A, B) and CTAB (C, D) system recorded at different $\mathrm{pH}$. The concentration of the dye in the cuvette is $2.2 \times 10^{-5} \mathrm{M}(\mathrm{C}, \mathrm{D})$. 

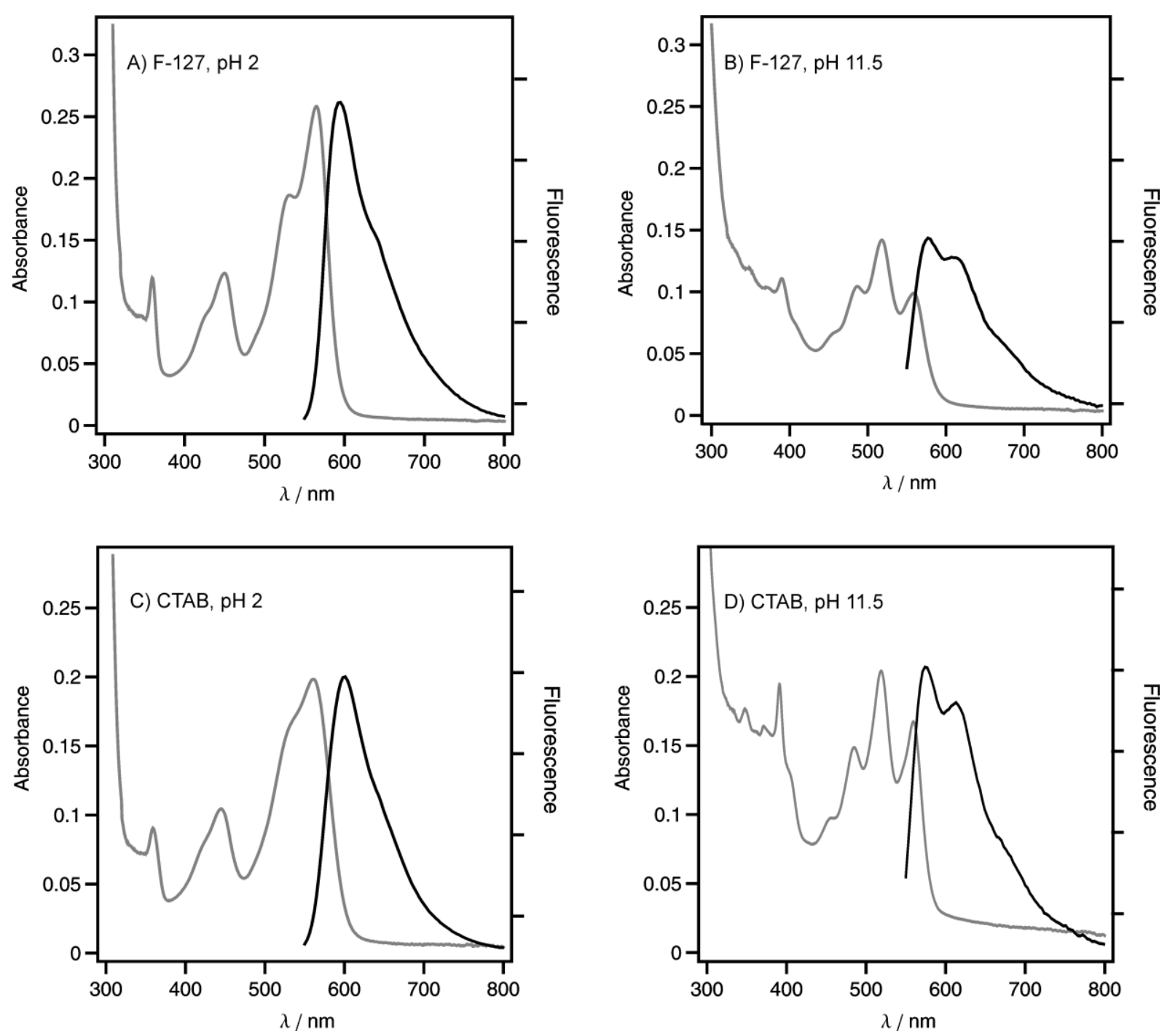

Figure S12. Absorption and emission spectra of $1 \mathrm{~b}$ in F-127 (A, B) and CTAB (C, D) system recorded at different $\mathrm{pH}$. The concentration of the dye in the cuvette is $2.3 \times 10^{-5} \mathrm{M}$. 

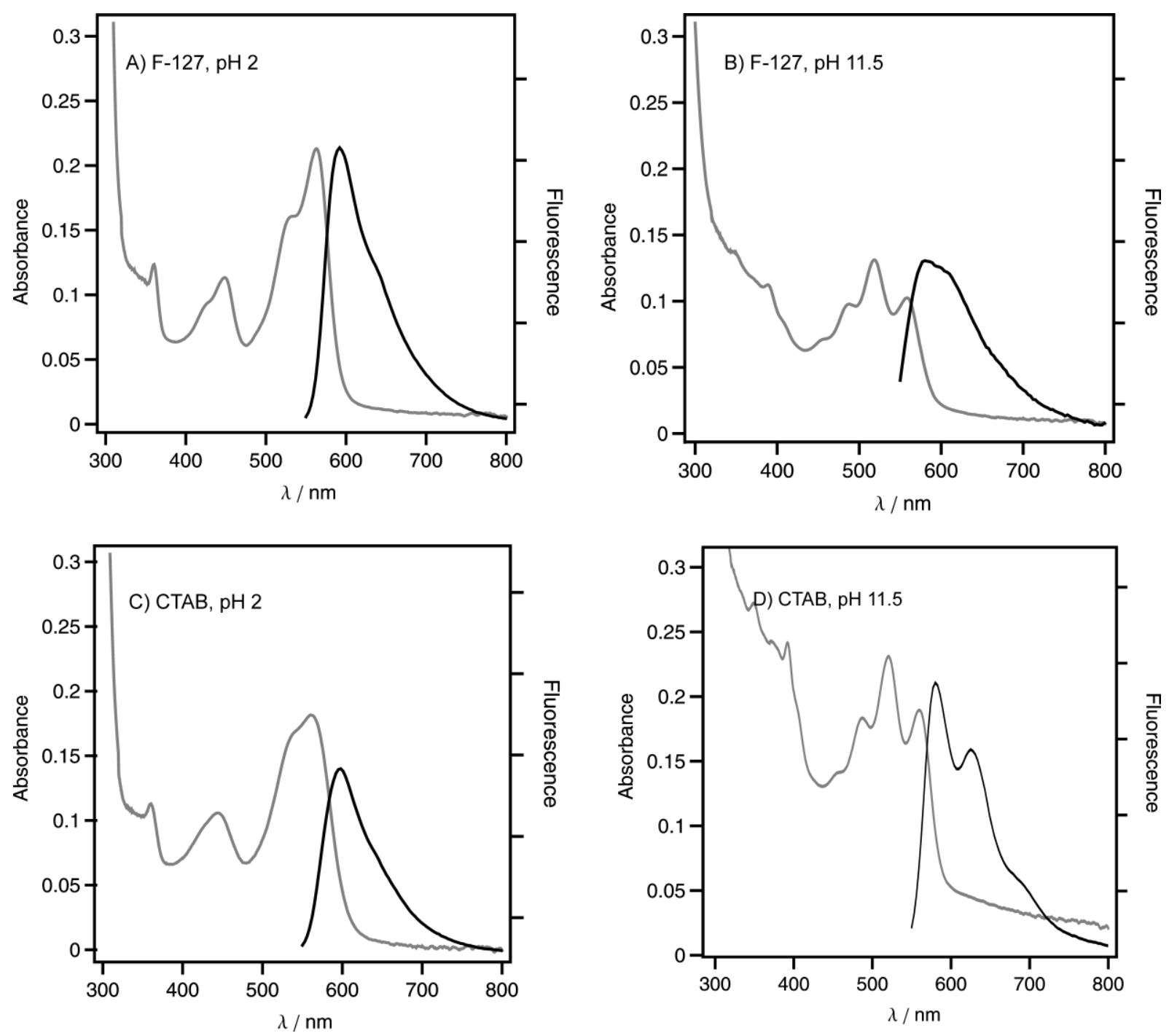

Figure S13. Absorption and emission spectra of 1c in F-127 (A, B) and CTAB (C, D) system recorded at different $\mathrm{pH}$. The concentration of the dye in the cuvette is $2.2 \times 10^{-5} \mathrm{M}$.

\subsection{Spectral and photophysical properties of triangulenes in organic solvents}

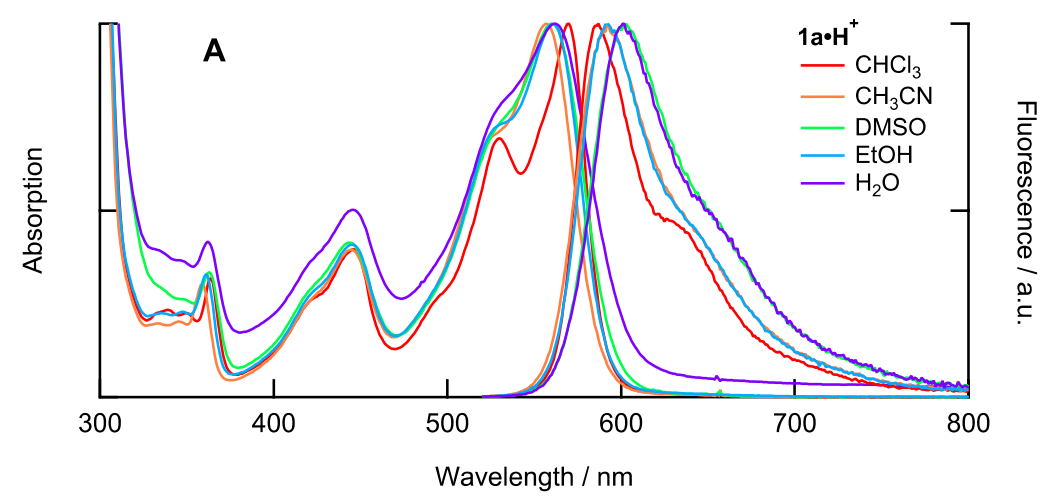



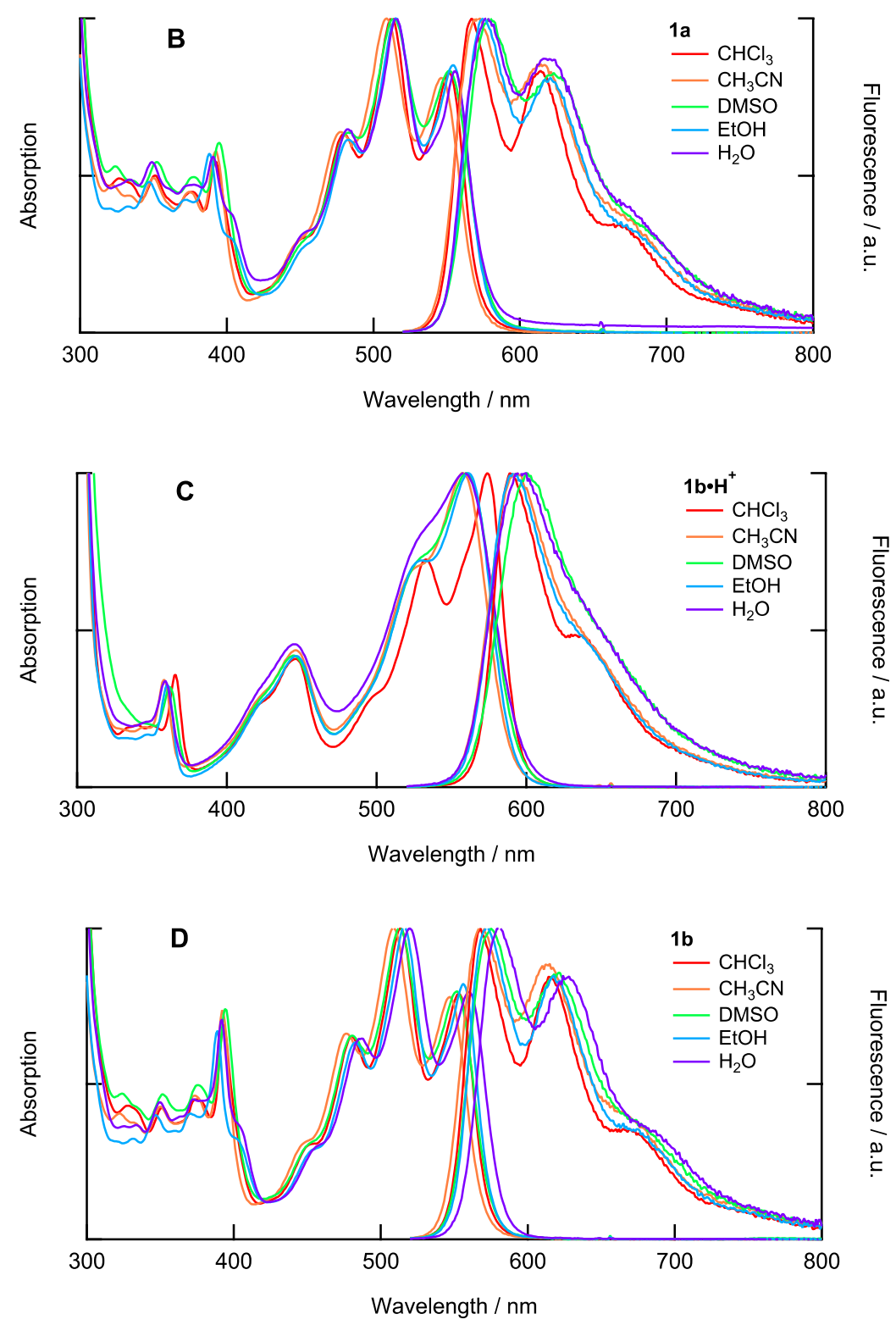

Figure S14. Absorption and emission spectra of $(A)\left[\mathbf{1} \mathbf{a} \cdot \mathrm{H}^{+}\right]\left[\mathrm{PF}_{6}\right],(B) \mathbf{1 a},(C)\left[\mathbf{1} \mathbf{b} \cdot \mathrm{H}^{+}\right]\left[\mathrm{PF}_{6}\right](D) \mathbf{1 b}$ in various solvents containing $0.03 \% \mathrm{DMSO}$ (by volume). $C=1.5 .10^{-5} \mathrm{M}$.

The neutral forms of $\mathbf{1 a}$ and $\mathbf{1 b}$ show a monotonic red shift of the absorption and fluorescence bands in the following order, $\mathrm{CH}_{3} \mathrm{CN}>\mathrm{DMSO}->\mathrm{CHCl}_{3}>\mathrm{EtOH}->\mathrm{H}_{2} \mathrm{O}$. The protonated forms $\mathbf{1 a} \cdot \mathrm{H}^{+}$and $\mathbf{1} \mathbf{b} \cdot \mathrm{H}^{+}$exhibit no shifts of the absorption band maximum (with the exception of chloroform) and a tiny displacements of the emission band depending of the solvent variation is noticed. These data show that both forms of triangulenes $\mathbf{1 a}$ and $\mathbf{1} \mathbf{b}$ possess spectral properties which are almost insensitive to the variation of solvent. 

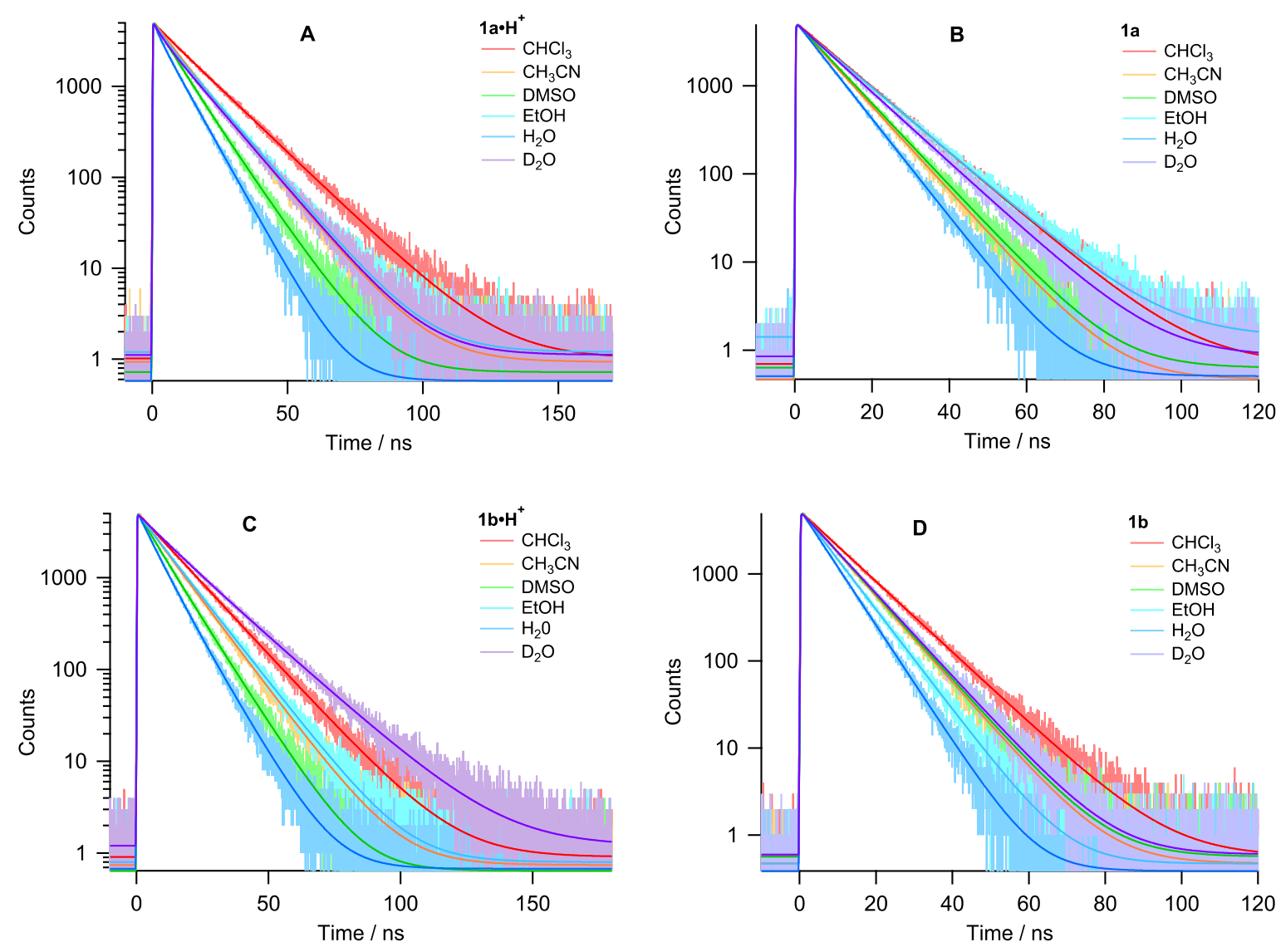

Figure S15. Fluorescence time profiles recorded with $(A)\left[\mathbf{1} \cdot \cdot \mathrm{H}^{+}\right]\left[\mathrm{PF} F_{6}\right],(B) \mathbf{1 a},(\mathrm{C})\left[\mathbf{1} \mathbf{b} \cdot \mathrm{H}^{+}\right]\left[\mathrm{PF}_{6}\right]$ (D) $\mathbf{1 b}$ in various solvents containing $0.03 \%$ DMSO (by volume). $C=1.5 .10^{-5} \mathrm{M}$. Smooth lines are the best fits.

The values of fluorescence quantum yield $\left(\Phi_{F}\right)$ of both forms of triangulenes $\mathbf{1 a}$ and $\mathbf{1} \mathbf{b}$ were determined relative to Rose Bengal in ethanol, $\Phi_{\mathrm{F}}=0.11,{ }^{5} \lambda_{\mathrm{ex}}=515 \mathrm{~nm}$. The obtained $\Phi_{\mathrm{F}}$ values are listed in Table S3. Fluorescence decays of protonated and neutral forms of $\mathbf{1 a}$ and $\mathbf{1 b}$ in various solvents were recorded at the maxima of the emission bands and with excitation at $375 \mathrm{~nm}$ (Figure S15). The time profiles are well reproduced by one exponential function numerically convolved with the experimental instrument response function. The best fits are shown as smooth lines; the resulting time constants are listed in Table S3. The obtained $\Phi_{F}$ and TF values were used to estimate the rate constants of radiative $\left(\mathrm{k}_{\mathrm{R}}\right)$ and nonradiative $\left(\mathrm{k}_{\mathrm{NR}}\right)$ decays; the resulting values are listed in Table S3.

The substitution of the triangulene core by an alkyl chain has a minor effect on the spectral and photophysical properties of the triangulene derivatives. $\mathbf{1 a}$ and $\mathbf{1 b}$ exhibit $\Phi_{\mathrm{F}}$ values of about 0.4 in low polar such as $\mathrm{CHCl}_{3}$ and somewhat smaller $\Phi_{\mathrm{F}}$ values $\approx 0.25$ in other polar and/or protic organic solvents. Aqueous environment results in visible decrease of the $\Phi_{F}$ and $T_{F}$ values. This acceleration of the non-radiative transition $S_{1->} S_{0}$ with increasing ability of hydrogen-bond-donating property of the solvent was observed for other helicenes derivatives. ${ }^{6}$ The interesting and unusual finding is a 
significant isotopic effect $T_{F}\left(D_{2} \mathrm{O}\right) / T_{F}\left(\mathrm{H}_{2} \mathrm{O}\right) \approx 2.1$ for $\mathbf{1 b} \cdot \mathrm{H}^{+}$in $\mathrm{D}_{2} \mathrm{O}$, while this ratio is on the level of 1.41.5 for other systems.

Table S3. Fluorescence quantum yield $\left(\Phi_{F}\right)$, fluorescence lifetime $\left(T_{F}\right)$ and rate constants of radiative $\left(k_{R}\right)$ and nonradiative $\left(k_{N R}\right)$ decay for protonated and neutral forms of $\mathbf{1 a}$ and $\mathbf{1 b}$ in various solvents. $\mathrm{C}($ dye $)=1 \cdot 5 \cdot 10^{-5} \mathrm{M} \cdot \mathrm{C}(\mathrm{CTAB})=4 \cdot 0 \cdot 10^{-3} \mathrm{M}$.

\begin{tabular}{|c|c|c|c|c|c|c|c|c|}
\hline Compounds & $\mathrm{pH}$ & Solvents & $\lambda_{\mathrm{abs},} \mathrm{nm}$ & $\lambda_{\mathrm{em}}, \mathrm{nm}$ & $\Phi_{\mathrm{F}}$ & $\mathbf{T}_{\mathbf{F}}(\mathrm{ns})$ & $\begin{array}{c}\mathbf{k}_{\mathbf{R}} / 10^{7} \\
\mathrm{~s}^{-1}\end{array}$ & $\begin{array}{c}\mathbf{k}_{\mathrm{NR}} / \\
10^{7} \mathrm{~s}^{-1}\end{array}$ \\
\hline \multirow{6}{*}[1\mathrm{a}\cdot\mathrm{H}^{+}]{$\left[\mathrm{PF}_{6}\right]$} & & $\mathrm{CHCl}_{3}$ & 570 & 587 & 0.42 & 15.1 & 2.8 & 3.9 \\
\hline & & $\mathrm{CH}_{3} \mathrm{CN}$ & 557 & 592 & 0.26 & 11.6 & 2.3 & 6.4 \\
\hline & & DMSO & 560 & 601 & 0.24 & 9.3 & 2.6 & 8.2 \\
\hline & & $\mathrm{EtOH}$ & 560 & 592 & 0.27 & 12.1 & 2.3 & 6.0 \\
\hline & & $\mathrm{D}_{2} \mathrm{O} / \mathrm{CTAB}$ & 562 & 601 & $0.21^{*}$ & 11.8 & 1.7 & 6.8 \\
\hline & 2.0 & $\mathrm{H}_{2} \mathrm{O} / \mathrm{CTAB}$ & 562 & 601 & $0.14^{*}$ & 7.7 & 1.7 & 11.4 \\
\hline \multirow{6}{*}{$1 a$} & & $\mathrm{CHCl}_{3}$ & 552 & 567 & 0.34 & 11.7 & 2.9 & 5.6 \\
\hline & & $\mathrm{CH}_{3} \mathrm{CN}$ & 546 & 571 & 0.22 & 9.1 & 2.4 & 8.6 \\
\hline & & DMSO & 552 & 579 & 0.27 & 9.3 & 2.9 & 7.8 \\
\hline & & $\mathrm{EtOH}$ & 554 & 575 & 0.20 & 11.8 & 1.7 & 6.8 \\
\hline & & $\mathrm{D}_{2} \mathrm{O} / \mathrm{CTAB}$ & 556 & 577 & $0.22^{*}$ & 10.9 & 2.0 & 7.1 \\
\hline & 11.1 & $\mathrm{H}_{2} \mathrm{O} / \mathrm{CTAB}$ & 556 & 578 & $0.16^{*}$ & 7.8 & 2.0 & 10.8 \\
\hline \multirow{8}{*}[1\mathrm{b}\cdot\mathrm{H}^{+}]{[} & & $\mathrm{CHCl}_{3}$ & 574 & 590 & 0.39 & 14.0 & 2.8 & 4.3 \\
\hline & & $\mathrm{CH}_{3} \mathrm{CN}$ & 558 & 593 & 0.26 & 11.2 & 2.3 & 6.6 \\
\hline & & DMSO & 560 & 601 & 0.25 & 9.3 & 2.7 & 8.1 \\
\hline & & $\mathrm{EtOH}$ & 561 & 593 & 0.28 & 11.7 & 2.4 & 6.1 \\
\hline & & $\mathrm{D}_{2} \mathrm{O}$ & 557 & 594 & 0.27 & 16.2 & 1.6 & 4.5 \\
\hline & & $\mathrm{D}_{2} \mathrm{O} / \mathrm{CTAB}$ & 557 & 594 & 0.26 & 15.9 & 1.6 & 4.7 \\
\hline & & $\mathrm{H}_{2} \mathrm{O}$ & 558 & 595 & 0.14 & 7.8 & 1.8 & 11.0 \\
\hline & 2.0 & $\mathrm{H}_{2} \mathrm{O} / \mathrm{CTAB}$ & 558 & 595 & 0.13 & 7.7 & 1.8 & 11.3 \\
\hline \multirow{6}{*}{$1 b$} & & $\mathrm{CHCl}_{3}$ & 553 & 568 & 0.32 & 10.7 & 3.0 & 6.4 \\
\hline & & $\mathrm{CH}_{3} \mathrm{CN}$ & 547 & 568 & 0.21 & 8.8 & 2.4 & 9.0 \\
\hline & & DMSO & 552 & 575 & 0.27 & 8.9 & 3.0 & 8.2 \\
\hline & & $\mathrm{EtOH}$ & 556 & 572 & 0.20 & 7.6 & 2.6 & 10.6 \\
\hline & & $\mathrm{D}_{2} \mathrm{O} / \mathrm{CTAB}$ & 558 & 580 & 0.18 & 9.1 & 1.9 & 9.0 \\
\hline & 11.2 & $\mathrm{H}_{2} \mathrm{O} / \mathrm{CTAB}$ & 559 & 580 & 0.14 & 6.5 & 2.1 & 13.3 \\
\hline
\end{tabular}

* Due to scattering of the aggregates present in sample, the direct measurements of $\Phi_{\mathrm{F}}$ values result in the underestimation of the quantum yield values. The correct $\Phi_{F}$ values were calculated according to equation $\Phi_{F}=$ $k_{R} \times T_{F}$, using the $k_{R}$ values for $\mathbf{1 b}$ in the corresponding solvents and the $T_{F}$ values obtained for $\mathbf{1 a}$. 


\subsection{Tests of photostability}

The samples of $\mathbf{1 a}$ in $\mathrm{CH}_{3} \mathrm{CN}$ were irradiated by a Quanta-Ray LAB-130-10 Nd:YAG laser operating at $355 \mathrm{~nm}$ in a $10 \times 8 \mathrm{~mm}^{2}$ quartz cell. The laser pulse energy was attenuated down to approximately $1 \mathrm{~mJ}$, the repetition rate was $10 \mathrm{~Hz}$, and the size of the laser beam on the surface of the quartz cell was approximately $0.5 \mathrm{~cm}^{2}$. The optical density of the samples was approximately 0.8 at $355 \mathrm{~nm}$ for $8 \mathrm{~mm}$ optical path. All solutions were bubbled with argon or oxygen for 15 minutes prior to and during irradiation.

The total photon flux for the used conditions is $2 \times 10^{18}$ photons $/\left(\min \times \mathrm{cm}^{2}\right)$. The values of the photodegradation yield $\Phi_{\text {deg }}$ were estimated in the assumption that the only channel of dye degradation is the formation of aggregates. The amount of the dye in the sample was calculated using the sample volume $\mathrm{V}=1.65 \mathrm{ml}$, the absorption values at the maxima of bands (Figure S16) and the extinction coefficients $14800 \mathrm{M}^{-1} \mathrm{~cm}^{-1}$ at $556 \mathrm{~nm}$ for $\mathbf{1 a} \cdot \mathrm{H}^{+7}$ and $12000 \mathrm{M}^{-1} \mathrm{~cm}^{-1}$ at $515 \mathrm{~nm}$ for $\mathbf{1 a} .^{8}$ The degree of $\mathbf{1 a} \cdot \mathrm{H}^{+}$degradation was estimated by an increase of absorption at $525 \mathrm{~nm}$, assuming the equal absorption of starting compound and formed $\mathrm{H}$-aggregates as it was observed for [4] helical quinacridines 7. Similar proposition was made for 1a; the degradation was estimated by change of absorption at $546 \mathrm{~nm}$. The estimations give the following values: $\Phi_{\text {deg }}<1 \times 10^{-3}$ for $1 \mathrm{a}$ under anaerobic conditions and as $\Phi_{\text {deg }}<5 \times 10^{-4}$ for other cases.

The presence of oxygen visibly reduces the degradation of the basic 1a form and has a minor influence on the photostability of $\mathbf{1 a} \cdot \mathrm{H}^{+}$. Rough estimations of the photodegradation yields $\left(\Phi_{\text {deg }}\right.$ ) give the following values: $\Phi_{\text {deg }}<1 \times 10^{-3}$ for $1 \mathbf{a}$ under anaerobic conditions and as $\Phi_{\text {deg }}<5 \times 10^{-4}$ for aerobic ones. 

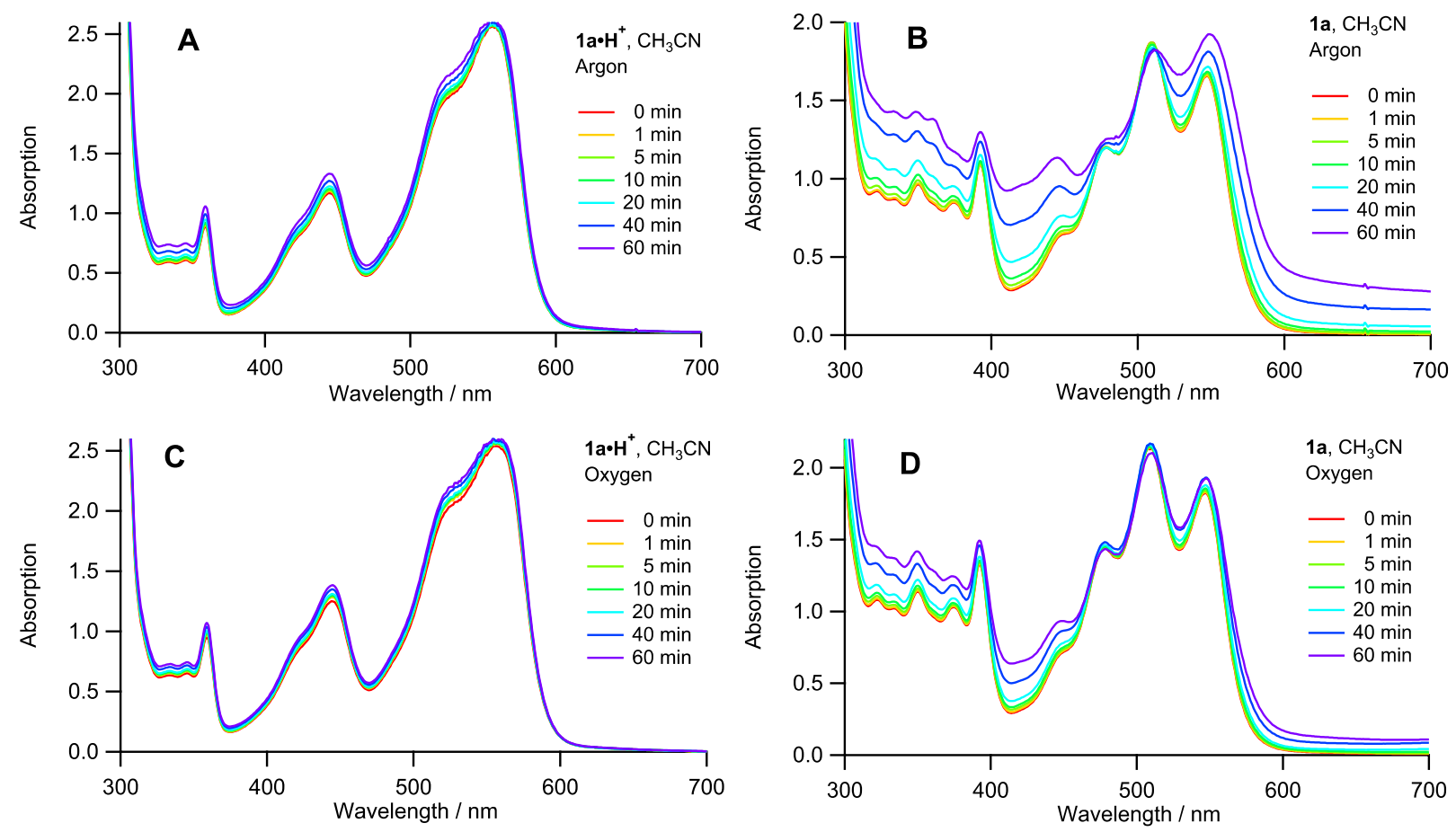

Figure S16. Absorption spectra of $(\mathrm{A}, \mathrm{C})\left[\mathbf{1} \cdot \mathrm{a}^{+}\right]\left[\mathrm{PF}_{6}\right]$ and $(\mathrm{B}, \mathrm{D}) \mathbf{1 a}$ in $\mathrm{CH}_{3} \mathrm{CN}$ recorded at different time intervals of $355 \mathrm{~nm}$ photolysis under $(A, B)$ anaerobic and $(C, D)$ aerobic conditions. 


\subsection{Stability of the solutions of $\left[1 \mathrm{a} \cdot \mathrm{H}^{+}\right][T F A]$ with respect to aggregation/precipitation}

Figure S17A shows the absorption spectra corresponding to different concentrations of $\left[1 \mathbf{a} \cdot \mathrm{H}^{+}\right][$TFA] at $\mathrm{pH}$ 1.8. Monotonic increase of signal at $\lambda>650 \mathrm{~nm}$ with the dye concentration indicates the formation of scattering particles, most probably large aggregates of triangulenes. The same spectra after normalization (Figure S17B) display an augmentation of relative contribution from scattering particles $(\lambda>650 \mathrm{~nm})$ and small deviations in the shape of spectra. A formation of a weak shoulder at the blue side of the absorption band (ca. $540 \mathrm{~nm}$ ) is similar to one observed for quinacridines ${ }^{9}$ that was assigned to the formation of weak dimers of $\mathrm{H}$-type. Thus, the protonated form of $\left[1 \mathrm{a} \cdot \mathrm{H}^{+}\right][$TFA] forms aggregates of different types in aqueous solutions.

The long-term stability of both protonated and neutral forms of $\left[\mathbf{1} \cdot \mathbf{H}^{+}\right][$TFA] for the aggregation and precipitation was studied by the incubation of dye solutions at $37^{\circ} \mathrm{C}$ (the temperature used for the cell staining). The freshly prepared stock solution of dye in DMSO was added in a sample to reach the final concentration of 50 or $300 \mu \mathrm{M}$. The total sample volume was $0.5 \mathrm{ml}$ and the presence of DMSO did not exceed $2 \%$ of the volume (with the exception of binary mixture PBS:DMSO 1:1 v/v). The acidity and basicity of $\mathrm{CH}_{3} \mathrm{CN}$ solution was adjusted by an addition of trifluoroacetic acid or trimethylamine (typically $0.5 \mu \mathrm{l}$ per $0.5 \mathrm{ml}$ of the sample volume). The concentration of $1 \mathrm{a}$ in the stock solution was determined by the absorption of $2 \mu \mathrm{l}$ of stock solution in $2 \mathrm{ml}$ of acidic $\mathrm{CH}_{3} \mathrm{CN}$ at $556 \mathrm{~nm}$ (extinction coef $\left.=14800 \mathrm{M}^{-1} \mathrm{~cm}^{-1}\right){ }^{7}$ Experiments were carried out in a quartz cell with the optical path $10 \mathrm{~mm}$ for the sample with the dye concentration of $50 \mu \mathrm{M}$ and $2 \mathrm{~mm}-$ for the dye concentration of $300 \mu \mathrm{M}$. The absorption spectra recorded at different time intervals are presented in Figure S17(C-E) and S18.

The incubation of protonated form of $\left[1 \mathrm{a} \cdot \mathrm{H}^{+}\right][$TFA] results in the formation of an intermediate structure between protonated and neutral ones. Subsequent incubation leads to a slow precipitation of dye with the formation of snowflake-like structures. This dynamics is faster for the sample with high dye concentration (300 $\mu \mathrm{M}$, Figure S17F). The neutral form aggregates and precipitates without changes in the absorption spectra (Figure S18A). The presence of DMSO slows down the precipitation (Figure $\mathrm{S} 18 \mathrm{~B}$ ), which is absent in the case of organic solvents like $\mathrm{CH}_{3} \mathrm{CN}$ (Figures S17E and S18C). A switch to acidic conditions after staining in aqueous environment does not restore the concentration of protonated form; a part of dye forms stable scattering particles.

In conclusion of this section, it should be emphasized that the neutral form is significantly less stable in aqueous solution than the protonated one (Figures S17F and S18D). Thus, in aqueous environment, neutral 1a displays poor solubility and precipitates by forming aggregates. 

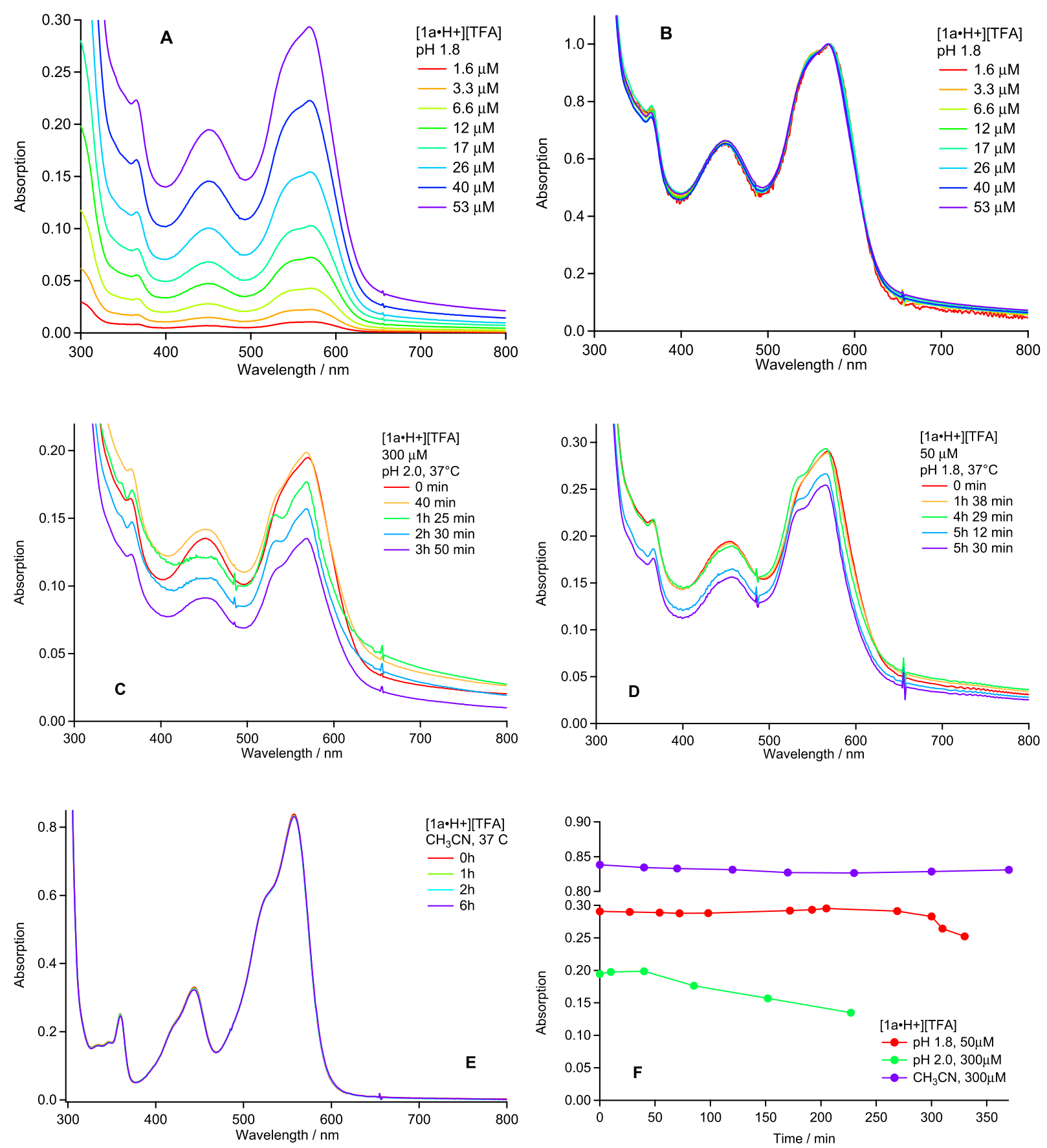

Figure S17. Absorption spectra of $\left[1 \mathbf{a} \cdot \mathrm{H}^{+}\right][T F A]$ in (A-D) acidic aqueous solutions and (E) acidic $\mathrm{CH}_{3} \mathrm{CN}$. (A) Absorption spectra recorded with different concentrations of $\left[1 \mathrm{a} \cdot \mathrm{H}^{+}\right][T F A]$; (B) the same spectra after normalization. (C-E) Absorption spectra at different time after the sample placing in the thermostated holder at $37^{\circ} \mathrm{C}$; (C) $300 \mu \mathrm{M}$ of dye, optical path $2 \mathrm{~mm}$; (D) $50 \mu \mathrm{M}$ of dye, optical path 10 $\mathrm{mm}$; (E) $300 \mu \mathrm{M}$ of dye, optical path $2 \mathrm{~mm}$. (F) Time profile of the absorption of [1a・H+][TFA] - in aqueous solution ( $\lambda_{\max }=568 \mathrm{~nm}$, red and green circles for $50 \mu \mathrm{M}$ and $300 \mu \mathrm{M}$, respectively) and in acidic ACN $\left(\lambda_{\max }=556 \mathrm{~nm}\right.$, violet points). 

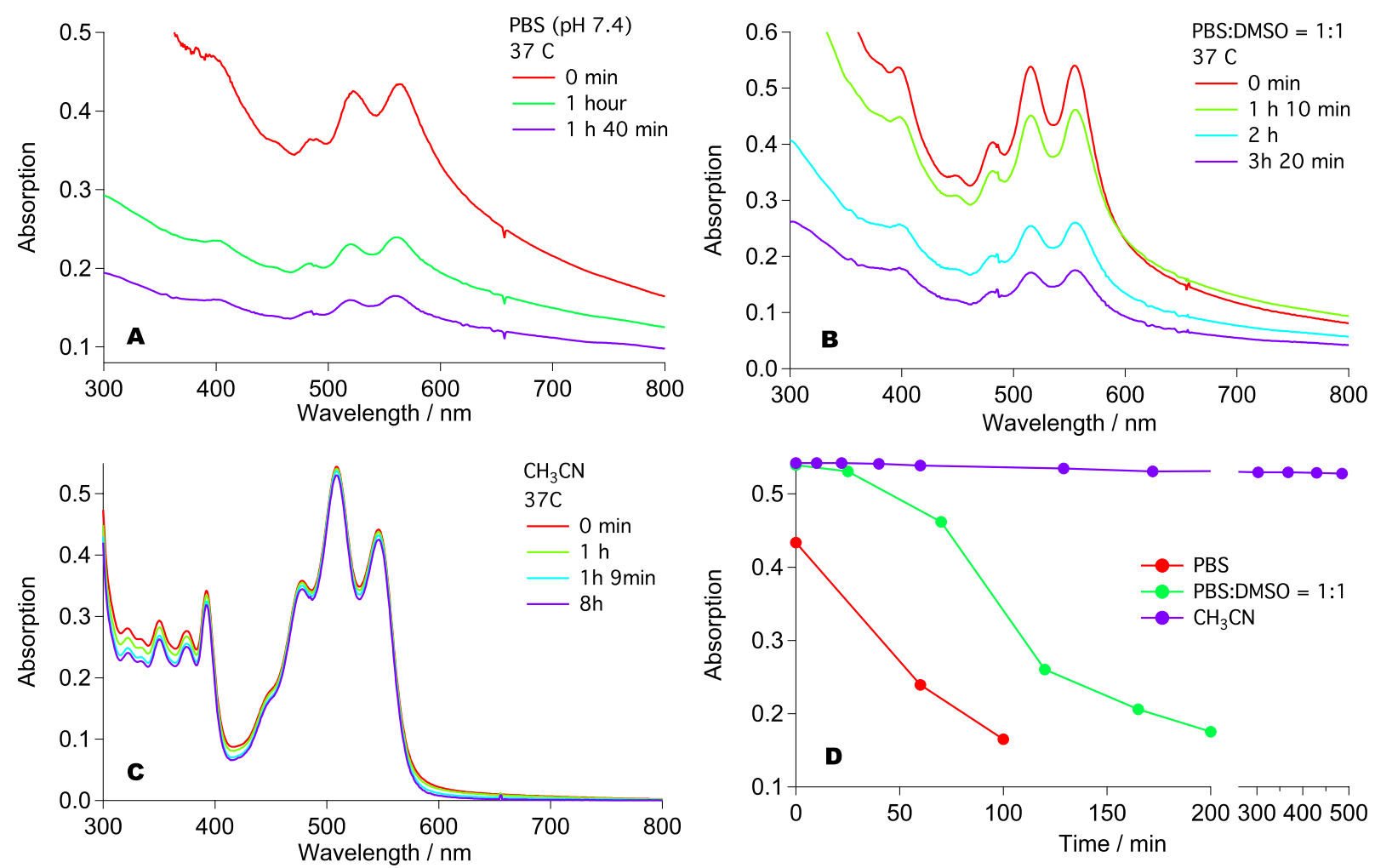

Figure S18. Absorption spectra of $0.3 \mathrm{mM}\left[\mathbf{1} \cdot \mathrm{H}^{+}\right][T F A]$ in (A) PBS, (B) PBS:DMSO 1:1 v/v and (C) basic $\mathrm{CH}_{3} \mathrm{CN}$ recorded at different time after the sample placing in the thermostated holder at $37^{\circ} \mathrm{C}$. (D) Time profile of the absorption of $0.3 \mathrm{mM}\left[\mathbf{1} \mathrm{a} \cdot \mathrm{H}^{+}\right][T F A]$ in PBS ( $\lambda_{\max }=562 \mathrm{~nm}$, red points), in PBS:DMSO 1:1 v/v ( $\lambda_{\max }=556 \mathrm{~nm}$, green points) and in basic ACN ( $\lambda_{\max }=509 \mathrm{~nm}$, violet points). 


\subsection{Excitation spectra}

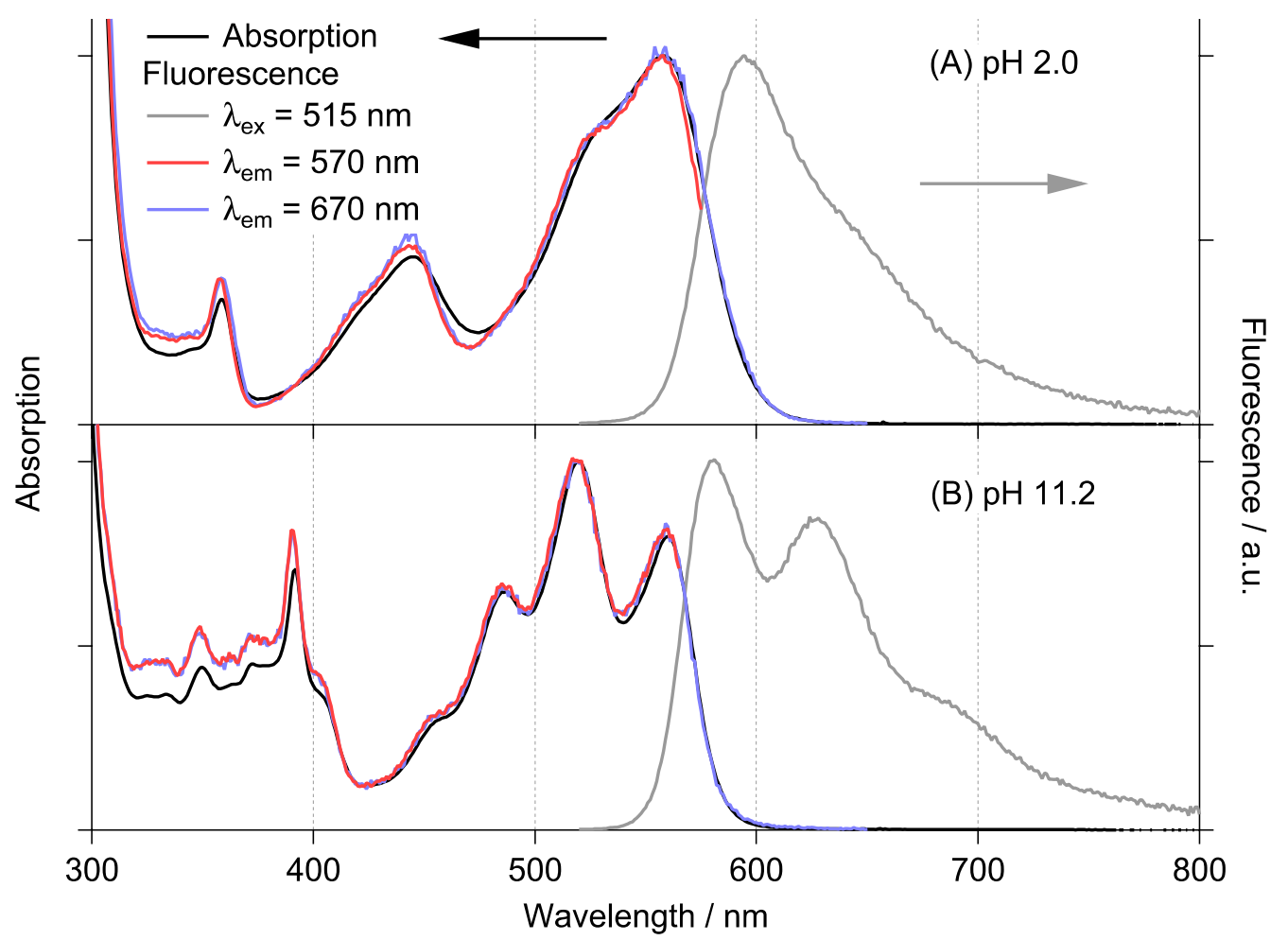

Figure S19. Electronic absorption, fluorescence emission $\left(\lambda_{\mathrm{ex}}=515 \mathrm{~nm}\right)$ and fluorescence excitation spectra $\left(\lambda_{\mathrm{em}}=570\right.$ and $\left.670 \mathrm{~nm}\right)$ recorded with aqueous solutions of $1.5 \times 10^{-5} \mathrm{M} \mathbf{1 b}$ at various $\mathrm{pH}(\mathrm{A}$ : 2.0, B: 11.2). The samples contain $0.03 \%$ DMSO (by volume); $\mathrm{PF}_{6}{ }^{-}$counter ion. 


\subsection{Effect of paraformaldehyde}

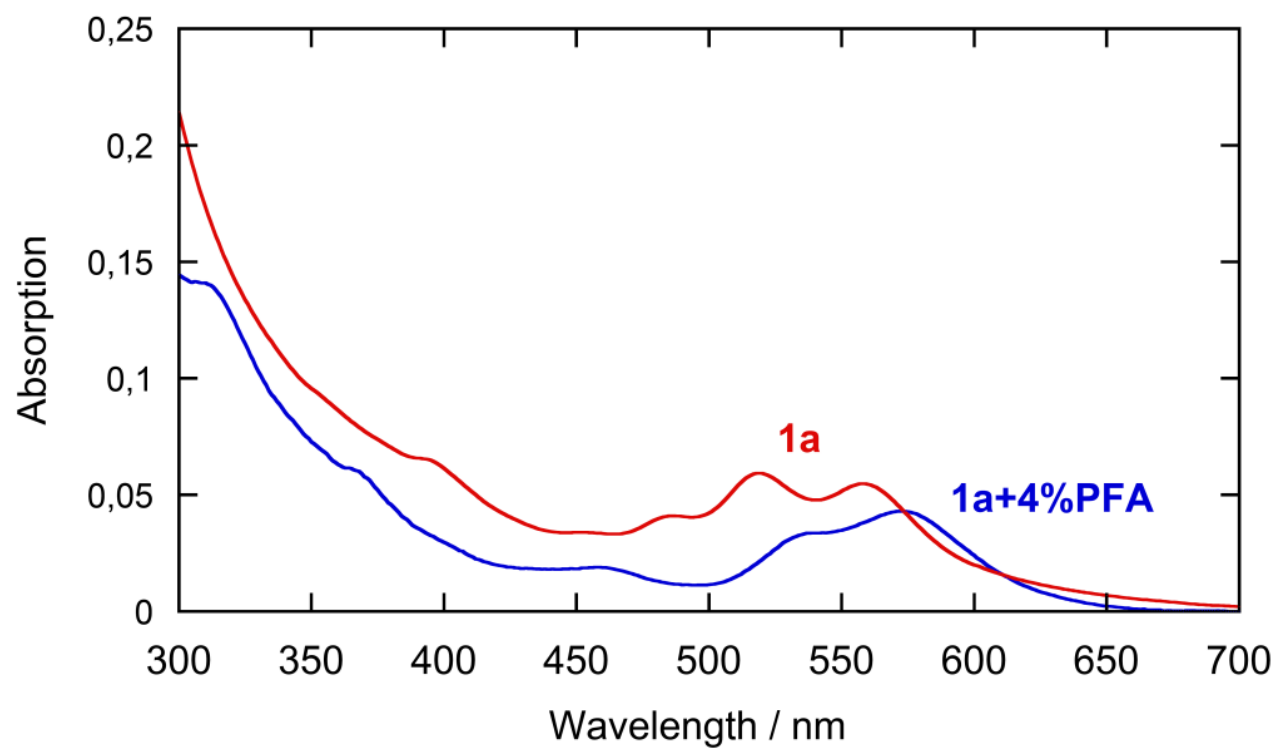

Figure S20. Absorption spectra of 1a in PBS buffer (red line) and 1a in PBS buffer containing $4 \%$ of paraformaldehyde (blue line). 


\section{Methods for biological assays}

All the triangulene derivatives $\left[\mathbf{1} \cdot \mathbf{H}^{+}\right][$TFA] were further purified on HPLC reverse phase before their use in biological assays. Using an Agilent 1100 Series instrument and a Waters XbridgePrepC8 5 micron $10 \times 150 \mathrm{~mm}$ column and under semi-preparative conditions, $50 \mathrm{mg}$ of product were separated $(\mathrm{CH} 3 \mathrm{CN}: \mathrm{H} 2 \mathrm{O} 8: 2+0.1 \%$ trifluoroacetic acid, $1.5 \mathrm{ml} / \mathrm{min}$ flow rate). Evaporation of the solvents afforded $\left[\mathbf{1} \cdot \mathbf{H}^{+}\right][$TFA] as orange-red solid. The retention time of derivatives $\mathbf{1} \cdot \mathrm{H}^{+}$varied between 9 and 15 min depending on the lateral chain. The polyclonal antibodies against Lamp1 were obtained from Thermo Fisher Scientific, Lafayette, $\mathrm{CO}$, and against EEA1 from Alexis Biochemicals, Lausanne Switzerland. The monoclonal antibody against LBPA was described. ${ }^{10}$

HeLa cells maintenance and analysis by immunofluorescence were as described. ${ }^{11}$ In live imaging, cells were analyzed using the automated microscope ImageXpress from Molecular Devices. To quantify the accumulation of 1a compound in lysosomes, we have used a wellestablished and reliable method commonly used in high content screening. ${ }^{12}$ Each fluorescent object, i.e. each endosomes in this case, is identified in the micrograph, and the object contour is identified (or segmented) by automated intensity and size thresholding, using the Custom Module Editor (CME) of the MetaXpress software (Figure S21, panel A). As a result, a precise mask is created for each individual endosome (Figure S21, panel B). The mask is then applied onto the second micrograph with the marker to be analyzed (Figure S21, panel C) so that both A and B can be overlapped (Figure S21, panel D) and the total amounts of each marker precisely quantified.

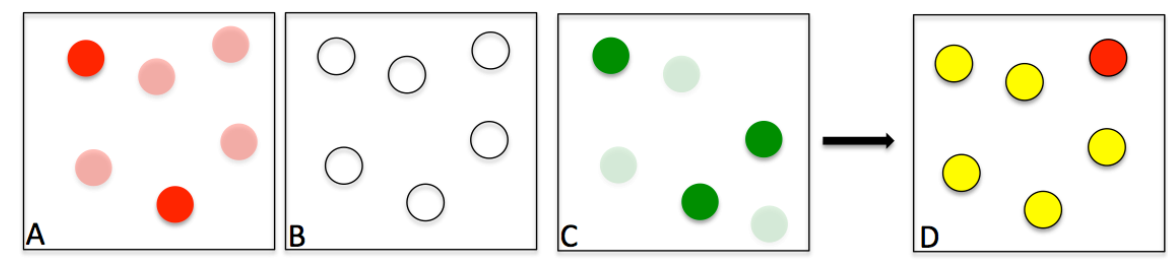

Figure S21. Diagram illustrating the segmentation process 
The segmentation of endosomes is illustrated with Lamp1 after staining with anti-Lamp1 antibodies (Figure S22 upper left panel, punctate red staining pattern), and the resulting mask is shown in the lower right panel (green color). The resulting mask will then be applied to the 1a micrograph, for quantification, as outlined in Figure S21. The segmentation of nuclei is illustrated after staining with DAPI (Figure S22, upper right panel nuclei staining in blue) with the corresponding mask in the lower left panel (yellow color), so that each endosome can be attributed to a single cell. We routinely quantified 20.000 to 90.000 endosomes in $>2000$ cells.
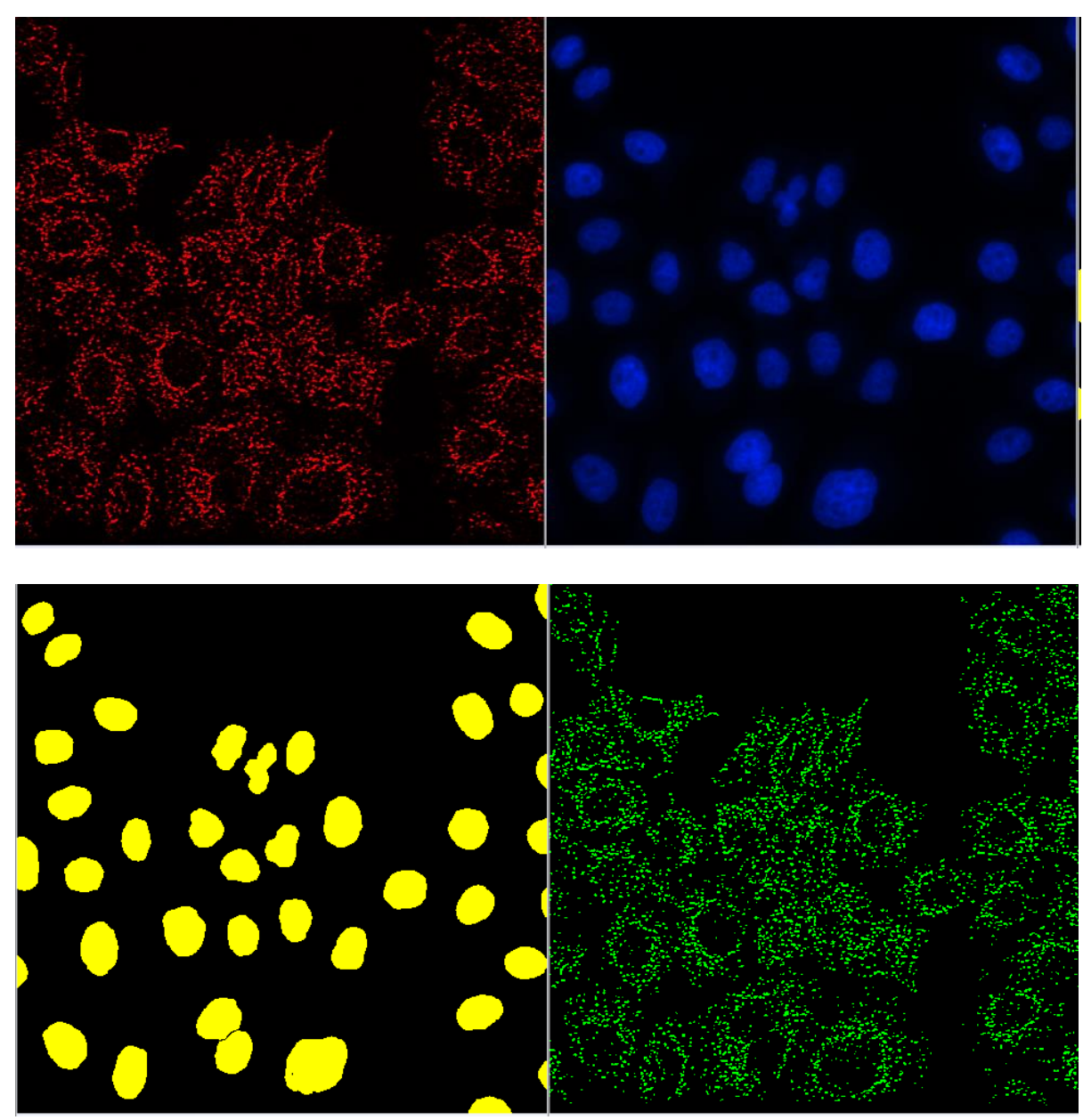

Figure S22. Segmentation of Lamp1 endosome. On top: original cell images, Lamp1 endosome in red, nucleus DAPI in Blue, on bottom: Segmentation performed with CME, nucleus mask in Yellow, Lysosome mask in green. 
EEA1 Marker intensity vs 1a compound

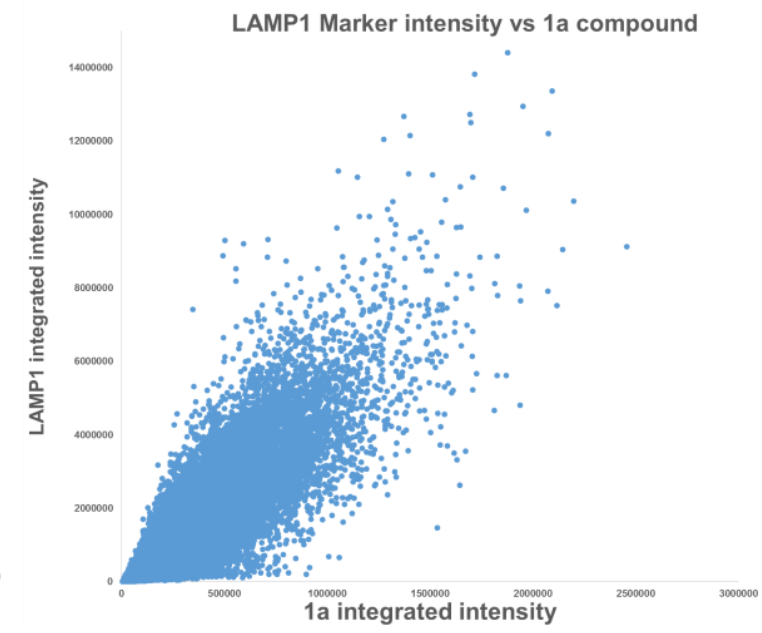

Figure S23. Pixels Intensity raw data. The intensity of endosomal markers (EEA1, left panel; LAMP1, right panel) is plotted vs. the intensity of $1 \mathrm{a}$ in each corresponding endosome. The plots show that $1 \mathrm{a}$ integrated intensity correlates with that of LAMP1, but not EEA1. 


\section{References}

1. Xie, X.; Mistlberger, G.; Bakker, E. Anal. Chem. 2013, 85, 9932-9938.

2. Bakker, E.; Buhlmann, P.; Pretsch, E. Chem. Rev. 1997, 97, 3083-3132.

3. Xie, X.; Zhai, J.; Jarolímová, Z.; Bakker, E. 2016, submitted.

4. Xie, X.; Bakker, E. Anal. Chem. 2015, 87, 11587-11591.

5. Seybold, P. G.; Gouterman, M.; Callis, J. Photochem. Photobiol. 1969, 9, 229-242.

6. Wallabregue, A.; Sherin, P.; Guin, J.; Besnard, C.; Vauthey, E.; Lacour, J. Eur. J. Org. Chem. 2014, 6431-6438.

7. Laursen, W.B.; Krebs, C.F. Chem. Eur. J. 2001, 7, 1773-1783.

8. This value was calculated from the absorption spectrum of $1 \mathbf{1 a}$ in $\mathrm{CH}_{3} \mathrm{CN}$, which concentration was determined under acidic conditions using the extinction coefficient value reported in [7]. The transformation from basic to acidic conditions was made by addition of $1 \mu$ l of trifluoroacetic acid in $1.65 \mathrm{ml}$ of $\mathrm{CH}_{3} \mathrm{CN}$.

9. Kel, O.; Sherin, P.; Mehanna, N.; Laleu, B.; Lacour, J.; Vauthey, E., Photochem. Photobiol. Sci. 2012, 11, 623-631.

10. Kobayashi, T.; Stang, E.; Fang, K. S.; De Moerloose, P.; Parton, R. G.; Gruenberg, J. Nature 1998, 392, 193-197.

11. Le Blanc, I.; Luyet, P. P.; Pons, V.; Ferguson, C.; Emans, N.; Petiot, A.; Mayran, N.; Demaurex, N.; Faure, J.; Sadoul, R.; Parton, R. G.; Gruenberg, J. Nat. Cell. Biol. 2005, 7, 653-664.

12. Chia, J.; Goh, G.; Racine, V.; Ng, S.; Kumar, P.; Bard, F., Molecular Systems Biology 2012, 8, doi:10.1038/msb.2012.59. 